\title{
Gastrointestinal targets to modulate satiety and food intake
}

Citation for published version (APA):

Geraedts, M. C. P. (2010). Gastrointestinal targets to modulate satiety and food intake. [Doctoral Thesis, Maastricht University]. Universiteit Maastricht. https://doi.org/10.26481/dis.20101203mg

Document status and date:

Published: 01/01/2010

DOI:

10.26481/dis.20101203mg

Document Version:

Publisher's PDF, also known as Version of record

\section{Please check the document version of this publication:}

- A submitted manuscript is the version of the article upon submission and before peer-review. There can be important differences between the submitted version and the official published version of record.

People interested in the research are advised to contact the author for the final version of the publication, or visit the DOI to the publisher's website.

- The final author version and the galley proof are versions of the publication after peer review.

- The final published version features the final layout of the paper including the volume, issue and page numbers.

Link to publication

\footnotetext{
General rights rights.

- You may freely distribute the URL identifying the publication in the public portal. please follow below link for the End User Agreement:

www.umlib.nl/taverne-license

Take down policy

If you believe that this document breaches copyright please contact us at:

repository@maastrichtuniversity.nl

providing details and we will investigate your claim.
}

Copyright and moral rights for the publications made accessible in the public portal are retained by the authors and/or other copyright owners and it is a condition of accessing publications that users recognise and abide by the legal requirements associated with these

- Users may download and print one copy of any publication from the public portal for the purpose of private study or research.

- You may not further distribute the material or use it for any profit-making activity or commercial gain

If the publication is distributed under the terms of Article $25 \mathrm{fa}$ of the Dutch Copyright Act, indicated by the "Taverne" license above, 


\section{GASTROINTESTINAL TARGETS TO MODULATE}

SATIETY AND FOOD INTAKE 


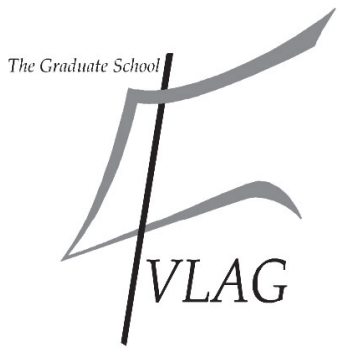

The study presented in this thesis was performed within the Nutrition and Toxicology Research Institute Maastricht (NUTRIM) which participates in the Graduate School VLAG (Food Technology, Agrobiotechnology, Nutrition and Health Sciences), accredited by the Royal Netherlands Academy of Arts and Sciences.

Cover design: Theo Hafmans and Maartje Geraedts Printed by: Ipskamp Drukkers, Enschede

(C) Maartje Geraedts, Maastricht 2010 


\title{
GASTROINTESTINAL TARGETS TO MODULATE
}

\section{SATIETY AND FOOD INTAKE}

\author{
PROEFSCHRIFT \\ ter verkrijging van de graad van doctor \\ aan de Universiteit Maastricht \\ op gezag van de Rector Magnificus, \\ Prof. mr. G.P.M.F. Mols \\ volgens het besluit van het College van Decanen, \\ in het openbaar te verdedigen \\ op vrijdag 3 December 2010 om 12:00 uur
}

door

Maria Christiana Peter Geraedts

geboren te Asselt op 4 maart 1982 


\section{Promotor}

Prof. dr. W.H.M. Saris

\section{Copromotor}

Dr. F.J. Troost

\section{Beoordelingscommissie}

Prof. Dr. M.A. van Baak (voorzitter)

Prof. Dr. F.J. van Schooten

Prof. Dr. R.F. Witkamp (Wageningen University)

Dr. H.P.F. Peters (Unilever R\&D, Vlaardingen, Belgie)

Dr. J. Plat

The research described in this thesis was funded by the Transnational University Limburg.

Financial support for the printing of this thesis by the Netherlands Society of Gastroenterology (NVGE), BioMedBooster, and FABPulous is gratefully acknowledged. 


\section{CONTENTS}

Chapter 1 General Introduction 7

Chapter 2 Review article: Gastrointestinal targets to modulate 21

satiety and food intake

Chapter $3 \quad$ Peptide-YY is released by the intestinal cell line STC-1

Chapter 4 Direct induction of CCK and GLP-1 release from murine endocrine cells by intact proteins

Chapter 5 The release of satiety hormones in response to specific dietary proteins is different between human and murine small intestinal mucosa

Chapter $6 \quad$ Intraduodenal administration of intact pea protein effectively reduces food intake in both lean and obese male subjects

Chapter $7 \quad$ Validation of Ussing chamber techology to study satiety hormone release from human duodenal specimens

Chapter 8 Different tastants and low-caloric sweeteners induce differential effects on the release of satiety hormones

Chapter 9 Addition of sucralose enhances the release of satiety hormones in combination with pea protein

Chapter 10 General discussion

Summary

Samenvatting

Acknowledgements - Dankwoord

Curriculum Vitae

List of Publications 



\section{CHAPTER 1}

GENERAL INTRODUCTION 


\section{INTRODUCTION}

In humans, body weight tends to remain within a relative narrow range, despite a large day-to-day fluctuation in the amount of food consumed. Overall, a stable body weight is maintained by keeping the balance between daily energy intake and energy expenditure. Obesity develops when the equilibrium between energy intake and energy expenditure shifts toward a positive balance, the excess energy being stored in the adipose tissue. To understand the problem of human obesity and to develop strategies to treat or prevent this condition it is necessary to understand the mechanisms of body weight regulation, i.e. energy balance regulation and as a part of it energy intake regulation, i.e. food intake regulation and appetite control. The concept of appetite includes at least two separate components: satiation and satiety. Satiation refers to the processes that promote meal termination, thereby limiting meal size. Satiation results from a coordinated series of neural and humoral signals that are produced in the gut in response to food-induced mechanical and chemical stimuli [1, 2]. Satiation might evoke a feeling of pleasure or it might lead to postprandial distress, and it is associated with other symptoms such as fullness, nausea, or bloating [3]. Satiety refers to postprandial events that affect the interval to the next meal, thereby regulating meal frequency. Although the relevant signals that emanate from the gut are commonly named 'satiety signals', this term is generally not appropriate, because most of them promote meal termination, and do not delay subsequent meal initiation or affect intake if delivered between meals $[1,3]$.

\section{THE ROLE OF THE GASTROINTESTINAL TRACT ON FOOD INTAKE}

The human gastrointestinal (GI) tract is the organ that takes in food, digests it to extract energy and nutrients, and expels the remaining matter. The structures forming the wall of the gastrointestinal tract from the posterior pharynx to the anus are shown in figure 1. There is some local variation, but in general there are four layers from the lumen outward: the mucosa, the submucosa, the muscularis, and the serosa. There are smooth muscle fibers in the submucosa (muscularis mucosae) and two layers of smooth muscle in the muscularis. The wall is lined by mucosa throughout and, except in the case of the oesophagus and distal rectum, is covered by serosa. The serosa continues onto the mesentery, which contains the nerves, lymphatic vessels, and blood vessels supplying the GI tract.

Within the mucosa of the stomach, small intestine, and colon, more than 15 different types of hormone-secreting enteroendocrine cells have been identified. Many of these cells secrete hormones that are most important in controlling digestive 
functions like gastrointestinal, pancreatic and gall bladder motility and gastric emptying, but also in appetite regulation [1].

\section{Figure 1. Representation of the layers of the} wall of the intestine.

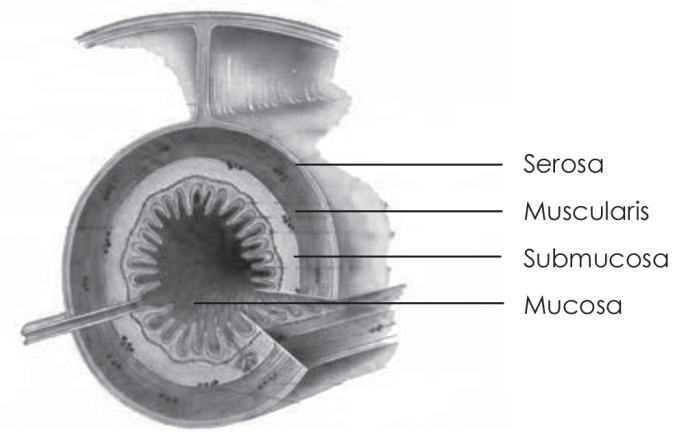

Hormones originating from the gastrointestinal tract appear in the blood. Receptors for these hormones have been shown in the brain, especially in the feeding centre, named the arcuate nucleus (ARC), which is located in the hypothalamus [4].

How and why the hormones are produced and secreted is not clearly established, however, the regulation of each hormone is different. Most hormones are secreted upon food intake, or more specifically linked to the presence of protein, carbohydrate and fat in the gastrointestinal tract.

\section{Cholecystokinin (CCK)}

CCK can be found both within the brain and in the gastrointestinal tract. In the brain, CCK functions as a neurotransmitter. It is present in the neurons, and released in response to depolarization. Within the gastrointestinal tract, CCK is located in the enteroendocrine cells within the duodenum and the jejunal mucosa [4]. CCK has a large variety of physiological functions in the human body, such as the stimulation of gallbladder contraction, pancreatic enzyme secretion, intestinal motor activity, and inhibition of gastric emptying. The release of CCK from the intestine is measured in vivo by increases in plasma CCK levels. Basal plasma levels of CCK are $\sim 1 \mathrm{pM}$ and rise up to $\sim 5$ to $8 \mathrm{pM}$ following meal ingestion $[4,5]$.

It is overall accepted that the release of CCK is mainly induced by the presence of fat in the small intestine. However, it is not clear how the release is mediated. Beglinger et al. showed that binding of free fatty acids to the apical side of the endocrine type I cell stimulates the secretion of CCK into the circulation [6]. Others showed that the secretion of CCK by type I cells is mediated by the CCK-releasing factor (CCK-RF) [4, 5, 7]. Trypsin sensitive CCK-RF is continuously secreted by the small intestine [7]. In the presence of trypsin, the CCK-RF is degraded and becomes inactivated. However, in the presence of intraluminal proteins, which are substrates for trypsin, competition for binding to trypsin occurs. This competition allows CCKRF to remain active for a prolonged period of time, allowing it to interact with CCK 
secreting cells. When CCK is secreted, the gallbladder and pancreas are stimulated to excrete its juices containing digestion enzymes and bile. CCK also sends signals to the brain, which results in satiety sensations and, hence, termination of food intake. Over time, dietary protein signals disappear from the intestinal lumen due to digestion and absorption processes, and by normal intestinal transit. Trypsin will then digest and inactivate the CCK-RF until new dietary proteins enter the small intestine. The phenomenon that intact proteins stimulate the release of CCK by inhibiting the trypsin digestion of the CCK releasing peptides from the pancreatic juice and intestinal lumen [8] is called the trypsin negative feedback loop (figure 2).

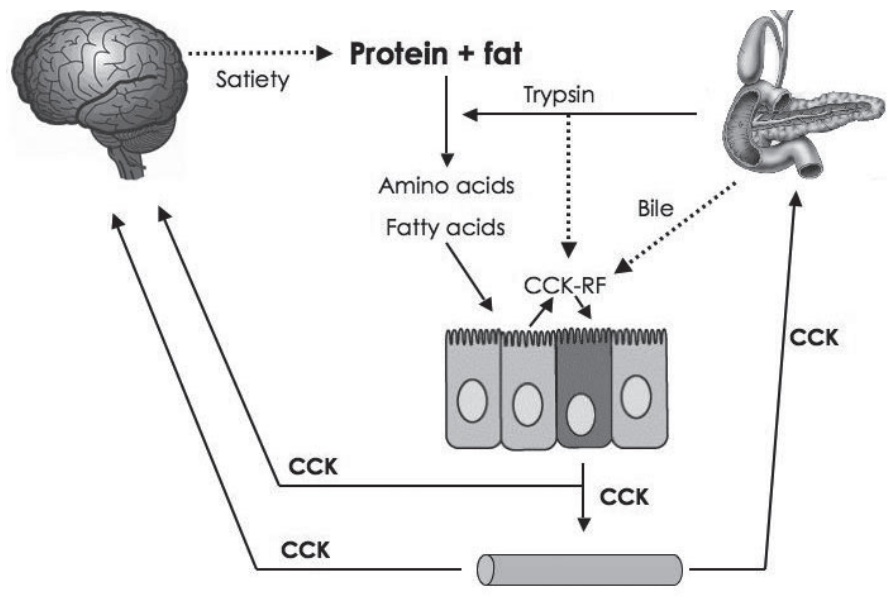

Figure 2. CCK regulation by the trypsin negative feedback loop. Trypsin, secreted by the pancreas, inactivates CCK-RF, which leads to low circulating levels of CCK. Upon food intake, competition for trypsin occurs. The food in the duodenum must be digested, resulting in higher levels of CCK-RF, and therefore higher levels of CCK in the circulation. The CCK gives satiety signals to the brain to stop eating, and also stimulates the pancreas to secrete more trypsin.

\section{Glucagon-like peptide 1 (GLP-1)}

GLP-1 is derived from posttranslational modification of the larger precursor molecule proglucagon. Proglucagon is synthesized within the endocrine L cells in the intestine, primarily the ileum and colon. Biological functions of GLP-1 are stimulating insulin secretion, reducing glucagon secretion, regulating gastric emptying, motility of the gut, and acid secretion, and regulating food intake. The release of GLP1 is elicited by both nutrient and neurohumoral stimulation from the distal part of the small intestine, but also, to a lesser extent, from the proximal region. Hence, macronutrients, primarily fat and carbohydrates, are likely to stimulate the L-cells to secrete GLP-1. Once present in the circulation, most plasma GLP-1 is degraded rapidly (within 2 min.) by the enzyme dipeptidyl-peptidase IV (DPP-IV).

Because GLP-1 inhibits gastrointestinal motility, reduces gastrointestinal secretions, and attenuates gastric emptying, it has been implicated as a major component 
of the 'ileal brake mechanism' (figure 3). This mechanism is an important regulator of gastrointestinal function. Unabsorbed nutrients in the ileum, especially fat, inhibit gastric emptying, decrease intestinal motility, transit and pancreatic secretions.

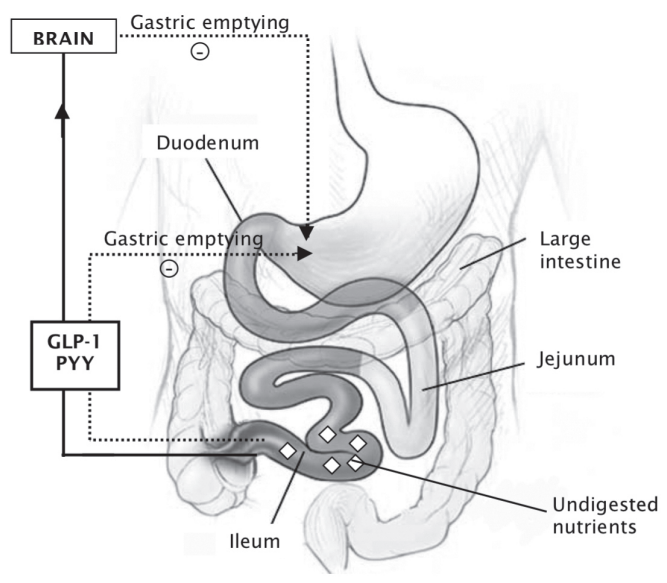

Figure 3. The 'ileal brake mechanism'. Unabsorbed nutrients present in the ileum, especially fat, stimulate the endocrine cells to secrete gastrointestinal hormones such as GLP-1 and PYY. These hormones affect gastric emptying, intestinal motility, transit, and pancreatic secretions, and by doing so, inhibit food intake.

\section{Peptide YY (PYY)}

PYY was first isolated by Tatemoto et al. in 1980 [9]. PYY is present both in the brain and in the gastrointestinal tract. In the brain, PYY is only found in a specific part of the ARC. The hormone was also found throughout the gastrointestinal tract. Biological functions of PYY are vasoconstriction, inhibition of gastric acid secretion, reduction of pancreatic and intestinal secretion, inhibition of gastrointestinal motility, and food intake inhibition [10].

PYY is synthesized in the endocrine $L$ cells which are found at their highest concentrations in the mucosa of the distal gut increasing from the ileum to the rectum [11]. It is a 36-amino acid gastrointestinal hormone, and named PYY because of the presence of an amino acid terminal (Y) tyrosine and a carboxyl terminal tyrosine amide (Y) [10]. The hormone is co-secreted with GLP-1 [12].

PYY can be found in two different forms, namely PYY ${ }_{1-36}$ and PYY ${ }_{3-36}$. The later product is produced by the action of the enzyme DPP-IV, which hydrolyses PYY at the Pro ${ }^{2}-11 e^{3}$ bond [13]. This is the active form of PYY. Synthesis of PYY starts when small chain fatty acids bind to the receptor GPR43 on the endocrine L cells [14]. Elevated plasma levels of PYY can be measured up to th after food intake. PYY is also a mediator of the ileal brake [10]. 


\section{TECHNIQUES TO STUDY THE EFFECTS OF NUTRIENTS ON GASTROINTESTINAL RELEASE OF SATIET HORMONES}

In vivo human studies are the preferred way to study the effects of food on secretion of satiety hormones and food intake. However, the major restriction of using subjects is that you can only test one product per experiment, resulting in many time-consuming studies. By developing high-throughput systems to test the effects of dietary compounds on their effects on secretion of satiety hormones, it is possible to reduce the amount of tests with humans.

As a first high-throughput system, in vitro assays can be used. Using cell cultures, many different nutritional compounds can be tested under the same conditions, at the same time. The major restriction of these assays is that it is very difficult to extrapolate the results to humans. The Ussing chamber provides another mediumthroughput system with great potential. This system consists of several chambers, in which intestinal tissue sample can be mounted. In each chamber, another compound can be tested. This allows the simultaneous investigation of different compounds, or different concentrations of a compound based on gut biopsies from one subject, under the same conditions.

\section{In vitro assays}

Using isolated intestinal cells for a high-throughput model to test effects of nutrients on hormone secretions would provide the best screening model. However, the isolation of native intestinal cells remains a tedious process and produces fairly low yields [15]. Hence, the intestinal hormone producing cell line STC-1 seems to be a good alternative, as these cells harbor many features of native intestinal hormone secreting cells. This cell line is derived from an intestinal endocrine tumor in a doubletransgenic mouse $[16,17]$. These cells are widely used as CCK and GLP-1 secreting cells, and are known to secrete these hormones in a manner that resembles that of humans [8, 18-21].

Cells are grown and maintained at an appropriate temperature and gas mixture (typically, $37^{\circ} \mathrm{C}, 5 \% \mathrm{CO}_{2}$ for mammalian cells) in a cell incubator. Culture conditions vary widely for each cell type, and variation of conditions for a particular cell type can result in different phenotypes being expressed. Aside from temperature and gas mixture, the most commonly varied factor in culture systems is the growth medium. The composition of different growth media varies in $\mathrm{pH}$, glucose concentration, growth factors, and the presence of other nutrients.

By growing the STC-1 cells in a 24 wells plate it is possible to test many substances at a time. After the cells have grown to approximately $85 \%$ confluency, the cells are washed. This is to wash away already secreted peptides. Subsequently, secretion medium, which contains the test substance, is added. After incubation the supernatant of the cells is collected to measure the secreted hormones of interest. 


\section{The Ussing Chamber}

The Ussing Chamber was invented by the Danish physiologists Ussing, H.H. and Zerahn, K. In their first publication in 1951 they showed that active transport of sodium was the source of electric current in the short-circuited isolated frog skin [22]. However, the original method described by Ussing was complicated and subsequent modified in 1988 by Grass and Sweetana [23]. The modified Ussing chamber consists of two half chambers with the tissue sample mounted as a semipermeable membrane between the halves. The two reservoirs on each side of the tissue sample is filled with buffer and continuously oxygenated. Due to the gas flow the buffer is continuously stirred, which reduces the thickness of the unstirred water layer [24]. With a heater block system the tissue samples and solutions are kept at $37^{\circ} \mathrm{C}$. Marker solutions and modulator substances can be applied on the apical or baso-lateral side of the tissue. Samples for marker permeation or secretions from the tissue may be drawn from either side of the chamber reservoirs.
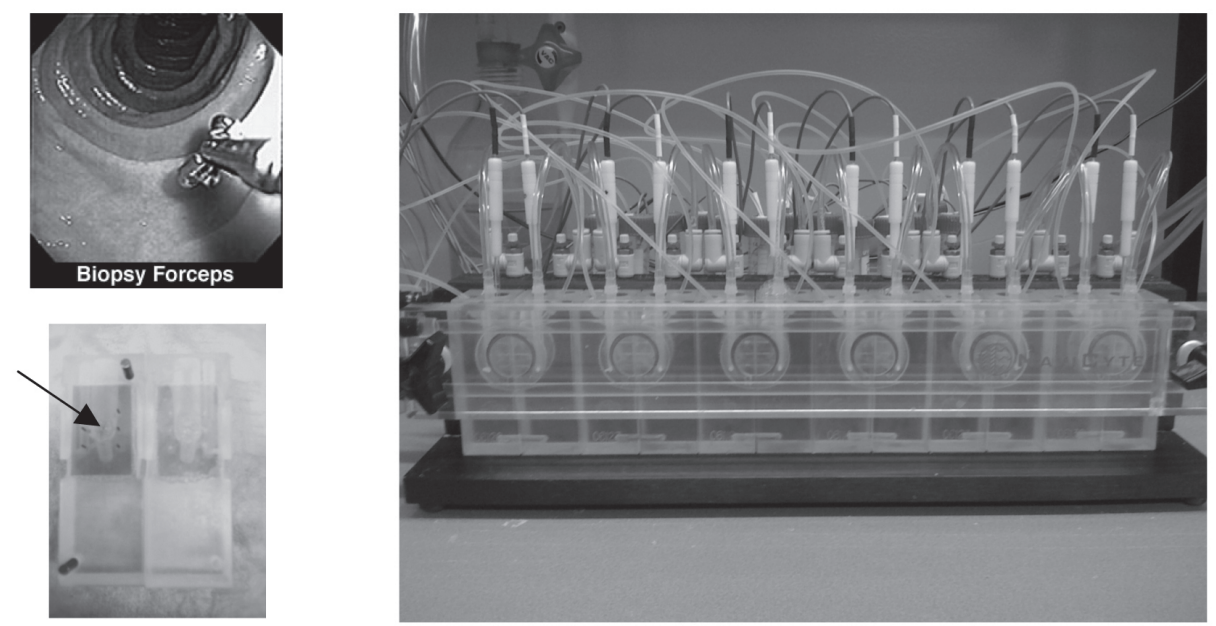

Figure 4. Upper left: Biopsy forceps during gastroendoscopy. Lower left: The biopsy is mounted on the plastic slide in an Ussing half chamber. Right: Assembled Ussing chamber coupled to gas flow and electronic equipment.

The preparation techniques of intestinal tissue for the use in Ussing chambers depend on the species and bowel segment being studied. Generally, the intestinal specimens are dissected, placed in oxygenated buffer without circulation and immediately transported to the laboratory. Tissues are either unstripped, or stripped, which means dissection of the muscle layers. In unstripped bowel, the whole bowel wall is intact, and it is possible to evaluate effects of the enteric nerves on intestinal tissue. In stripped tissue, the external muscle layers and myenteric plexus are removed and the mucosa mounted thus consists of the epithelium, the underlying lamina propria and the muscularis mucosae. After mounting in the chambers, tissues are equilibrated for 20-40 minutes to achieve steady state conditions in transepithelial 
potential difference (PD). During the entire experiment, electrophysiological parameters are monitored to measure electronic pump activities in the epithelial membrane. These consist mainly of $\mathrm{Na}^{+} / \mathrm{K}^{+}$-ATP-ases and the passive permeation of ions through channels apically and baso-laterally and ion flux over the tight junctions (TJ).

\section{Specimens}

In vitro studies of barrier functions in human intestine have mainly been limited to intestinal specimens from patients undergoing Gl-surgery. The use of surgical specimens does, however, have some obvious drawbacks. The patients have possible alterations in physiology due to medication, surgical stress, malnutrition, and other factors before and during surgery that are known to influence the mucosal barrier. Furthermore, it is difficult to find adequate control groups, as by definition, patients in need of bowel surgery are not healthy. In recent years, endoscopic biopsies of human intestine have been used to assess ion secretion as well as TJ permeability to ions and mono- and disaccharides [25-27]. It was shown by Wallon et al that the use of biopsies in Ussing chambers are a reliable tool for studying permeability of the human colon [27]. However, to our knowledge, there are no studies available on hormone secretions from the tissue after food ingredient stimulation using the Ussing Chamber system.

\section{PROOF OF PRINCIPLE: HUMAN STUDIES}

Even though the high-throughput systems allow testing of many substances in a relatively short time, the effectiveness of a compound always must be tested in humans, before it can be claimed that the product has an effect on satiety and body weight control. Effects on appetite in humans can be measured by using 100 $\mathrm{mm}$ Visual Analogue Scales (VAS), in which sensations of hunger, satiety, fullness, and desire to eat can be quantified. When used appropriately, these subjective ratings are reproducible and sensitive and can predict food intake to a certain extent $[28,29]$.

Besides using appetite ratings to assess appetite, food intake can be used to measure the effect of dietary manipulations. This is made possible by serving an ad libitum meal and asking the subjects to eat until they are full and then recoding the amount of food eaten in grams [30, 31] 


\section{AIMS AND OUTLINE OF THE THESIS}

Obesity is one of the major health problems in the world. By increasing the understanding of how food interacts with the gastrointestinal tract, leading to signals of satiety induced by $\mathrm{Gl}$ hormones, functional foods can be developed for a better weight control. The main goal of the project was to evaluate the effects of food compounds on the release of satiety hormones and food intake. Since dietary proteins are the most satiating, when compared to carbohydrates and fats, our focus was on dietary proteins, and their derivates. Also, more recently, it has been demonstrated that the gastrointestinal tract is able to sense 'taste'; however, little is known whether this also affects the release of satiety hormones.

First, in chapter 2 the recent knowledge regarding the receptors that are able to sense nutrients in the gastrointestinal tract has been reviewed. Chapter 3 describes that the STC-1 cell line is not only able to secrete CCK and GLP-1, but also PYY after exposure to different fatty acids. In chapter 4, different intact proteins, hydrolysates, and specific peptides were tested on their stimulatory effects on CCK and GLP-1 from the STC-1 cell line. The most potent proteins to release CCK and GLP-1 in this in vitro experiment were then tested on hormone release from human duodenal tissue. Chapter 5 describes the use of the Ussing chambers to measure the effects of dietary compounds on hormone release from human duodenal tissue. The protein that showed the strongest effects on hormone release was tested in an in vivo study. The protein was administered both orally and intraduodenally, in a randomised cross over design, using both lean and obese male subjects. The results from this in vivo study are described in chapter 6. The Ussing chambers are commonly used to measure tissue permeability, however, secretion of satiety hormones has never been measured before. In chapter 7, the Ussing chamber technology is validated whether the secretion levels measured in the Ussing chambers are comparable with results found in the in vivo study. Chapter 8 describes the use of STC-1 cells to measure the effects of tastants on satiety hormone release, and in chapter 9 , combinations of sweeteners with pea protein are tested both in vitro and ex vivo using the Ussing chambers on their stimulatory effect on CCK and GLP-1 release. Finally in chapter 10, the results and interpretations of the previous described studies are discussed en put into a broader perspective. 
1. Cummings, D.E. and J. Overduin, Gastrointestinal regulation of food intake. J Clin Invest, 2007. $117(1):$ p. 13-23.

2. Capasso, R. and A.A. Izzo, Gastrointestinal regulation of food intake: general aspects and focus on anandamide and oleoylethanolamide. J Neuroendocrinol, 2008. 20 Suppl 1: p. 39-46.

3. Camilleri, M. and A.B. Grudell, Appetite and obesity: a gastroenterologist's perspective. Neurogastroenterol Motil, 2007. 19(5): p. 333-41.

4. Moran, T.H. and K.P. Kinzig, Gastrointestinal satiety signals II. Cholecystokinin. Am J Physiol Gastrointest Liver Physiol, 2004. 286(2): p. G183-8.

5. Ganong, W.F., Review of Medical Physiology. Book. Vol. twenty-first edition. 2003.

6. Beglinger, C. and L. Degen, Fat in the intestine as a regulator of appetite--role of CCK. Physiol Behav, 2004. 83(4): p. 617-21.

7. Otsuki, M., Pathophysiological role of cholecystokinin in humans. J Gastroenterol Hepatol, 2000. 15 Suppl: p. D71-83.

8. Choi, S., et al., GPR93 Activation by Protein Hydrolysate Induces CCK Transcription and Secretion in STC-1 Cells. Am J Physiol Gastrointest Liver Physiol, 2007.

9. Tatemoto, K. and V. Mutt, Isolation of two novel candidate hormones using a chemical method for finding naturally occurring polypeptides. Nature, 1980. 285(5764): p. 417-8.

10. Batterham, R.L. and S.R. Bloom, The gut hormone peptide YY regulates appetite. Ann N Y Acad Sci, 2003. 994: p. 162-8.

11. Symersky, T., et al., Effect of peptide YY on pancreatico-biliary secretion in humans. Scand J Gastroenterol, 2005. 40(8): p. 944-9.

12. Young, A.A., Obesity: a peptide YY-deficient, but not peptide YY- resistant, state. Endocrinology, 2006. 147(1): p. 1-2.

13. Degen, L., et al., Effect of peptide YY3-36 on food intake in humans. Gastroenterology, 2005. 129(5): p. 1430-6.

14. Karaki, S.I., et al., Short-chain fatty acid receptor, GPR43, is expressed by enteroendocrine cells and mucosal mast cells in rat intestine. Cell Tissue Res, 2006: p. 1-8.

15. Evans, G.S., N. Flint, and C.S. Potten, Primary cultures for studies of cell regulation and physiology in intestinal epithelium. Annu Rev Physiol, 1994. 56: p. 399-417.

16. Chang, C.H., W. Y. Chey, and T.-M. Chang, Secretory mechanisms of cholecystokinin-like immunoreactivity from a murine endocrine tumor cell line (Abstract). Gastroenterology, 1991. 100: p. A634.

17. Rindi, G., et al., Development of neuroendocrine tumors in the gastrointestinal tract of transgenic mice. Heterogeneity of hormone expression. Am J Pathol, 1990. 136(6): p. 1349-63.

18. Wang, Y., et al., Luminal CCK-releasing factor stimulates CCK release from human intestinal endocrine and STC-1 cells. Am J Physiol Gastrointest Liver Physiol, 2002. 282(1): p. G16-22.

19. Cordier-Bussat, M., et al., Peptones stimulate cholecystokinin secretion and gene transcription in the intestinal cell line STC-1. Endocrinology, 1997. 138(3): p. 1137-44.

20. Foltz, M., et al., Protein hydrolysates induce CCK release from enteroendocrine cells and act as partial agonists of the CCK1 receptor. J Agric Food Chem, 2008. 56(3): p. 837-43.

21. Sidhu, S.S., et al., Fatty acid-induced cholecystokinin secretion and changes in intracellular Ca2+ in two enteroendocrine cell lines, STC-1 and GLUTag. J Physiol, 2000. 528 P† 1: p. 165-76.

22. Ussing, H.H. and K. Zerahn, Active transport of sodium as the source of electric current in the short-circuited isolated frog skin. Reprinted from Acta. Physiol. Scand. 23: 110-127, 1951. J Am Soc Nephrol, 1999. 10(9): p. 2056-65.

23. Grass, G.M. and S.A. Sweetana, In vitro measurement of gastrointestinal tissue permeability using a new diffusion cell. Pharm Res, 1988. 5(6): p. 372-6.

24. Karlsson, J. and P. Artursson, A new diffusion chamber system for the determination of drug permeability coefficients across the human intestinal epithelium that are independent of the 
unstirred water layer. Biochim Biophys Acta, 1992. 1111 (2): p. 204-10.

25. Soderholm, J.D., et al., Integrity and metabolism of human ileal mucosa in vitro in the Ussing chamber. Acta Physiol Scand, 1998. 162(1): p. 47-56.

26. Soderholm, J.D., et al., Epithelial permeability to proteins in the noninflamed ileum of Crohn's disease? Gastroenterology, 1999. 117(1): p. 65-72.

27. Wallon, C., et al., Endoscopic biopsies in Ussing chambers evaluated for studies of macromolecular permeability in the human colon. Scand J Gastroenterol, 2005. 40(5): p. 586-95.

28. Flint, A., et al., Reproducibility, power and validity of visual analogue scales in assessment of appetite sensations in single test meal studies. Int J Obes Relat Metab Disord, 2000. 24(1): p. 38-48.

29. Stubbs, R.J., et al., The use of visual analogue scales to assess motivation to eat in human subjects: a review of their reliability and validity with an evaluation of new hand-held computerized systems for temporal tracking of appetite ratings. Br J Nutr, 2000. 84(4): p. 405-15.

30. Yeomans, M.R. and T. Symes, Individual differences in the use of pleasantness and palatability ratings. Appetite, 1999. 32(3): p. 383-94.

31. Bellisle, F., et al., Deprivation, palatability and the micro-structure of meals in human subjects. Appetite, 1984. 5(2): p. 85-94. 


\section{CHAPTER 2}

\section{GASTROINTESTINAL TARGETS TO MODULATE FOOD INTAKE AND SATIETY}

MAARTJE C.P. GERAEDTS, FREDDY J. TROOST, WIM H.M. SARIS

OBESITY REVIEWS, IN PRESS 


\section{ABSTRACT}

This review discusses the role of enteroendocrine cells in the gastrointestinal tract as chemoreceptors that sense intraluminal contents and induce changes in food intake through the release of signaling substances, such as satiety hormones. Recent evidence supports the concept that chemosensing in the gut involves $G$ protein-coupled receptors (GPCRs) that are known to mediate gustatory signals in the oral cavity. GPCRs can be grouped into several families, depending on the stimuli to which they respond, e.g. proteins, amino acids, carbohydrates, fatty acids, or tastants. Sensing of these stimuli by GPCRs results in hormone secretions of enteroendocrine cells, which participate in the control of food intake. A better understanding of the stimuli that induce the strongest binding with these receptors, and thus induce a strong release of hormones, can be a very useful strategy for the development of novel foods in the treatment of obesity. 


\section{INTRODUCTION}

The dramatic increase in overweight and obesity over the past decades has become one of the major nutrition related health problems worldwide. Obesity accounts for $2-6 \%$ of total health costs in several developed countries [1]. A combination of excessive energy intake and a sedentary lifestyle are regarded as the primary causes of obesity.

Appetite is an important factor in the regulation of energy intake. The concept of appetite comprises at least two components: satiation and satiety. Satiation refers to the processes that induce meal termination, thereby limiting energy intake. It results from a coordinated series of neural and humoral signals mostly produced in the gastro-intestinal (Gl) tract in response to food-induced mechanical and chemical stimuli $[2,3]$. Satiety refers to the postprandial status that determines the intervals between meals, thereby regulating meal intake frequency.

Ingested food evokes satiety in the Gl tract primarily by two distinct ways, i.e. by mechanical stimulation and therefore stimulation of the nerve endings and by humoral stimulation, e.g. the release of peptide hormones [4]. Post-gastric factors seem to play a key role in satiety through secretion of various peptides by the wall of the small and large intestine in response to ingested food. The hormones that have the most robust effects on appetite are ghrelin, cholecystokinin (CCK), glucagon-like peptide 1 (GLP-1), and peptide YY (PPY) [5-9]. Short-term reduction of body weight can be achieved by several types of energy-restricted diets. However, long-term weight management is often unsuccessful [10]. In long-term weight loss and maintenance programs, decreased compliance and habituation to an energy-restricted diet accompanied by increased appetite [1 1] usually result in diminished weight loss, or even weight gain. Even though weight maintenance can be maintained for 12 weeks $[12,13]$ after weight loss, it has frequently been observed that weight loss is not maintained on the long-term (up to 48 months) $[14,15]$. Therefore, new strategies to improve the prevention of weight regain after body-weight loss are needed in the treatment of obesity.

One concept for successful weight-loss and weight-maintenance is to achieve sustained satiety. In this respect, high-protein diets seem to be the most potent in reducing hunger and sustain satiety [16, 17], and may improve long-term weight loss and prevent weight-regain. High intake of proteins result in a quantitatively and qualitatively different response compared to high-carbohydrate diets and in particular to a high-fat diet. The question remains whether this differential response is driven by the ability of enteroendocrine cells to directly sense the contents of the lumen, resulting in postprandial responses such as hormone release, or that other sensing routes are involved. 
This review provides an overview of the mechanisms of the Gl tract to sense and respond to the presence of nutrients, and describes the effects of specific dietary components on peptide hormone secretion by the human Gl tract. An increased understanding of this topic will help to guide the development of novel, effective anti-obesity therapies.

\section{LUMINAL SENSING IN THE GUT}

Over the past years, several receptors that respond to nutrients or their immediate breakdown products, i.e. fatty acids, sugars, amino acids, and proteolytic products, have been identified within the GI tract and serve as chemosensors for food intake [18-20] (figure 1). The current consensus is that these luminal contents activate $G$ protein-coupled receptors (GPCRs) in the enteroendocrine cell membranes, ultimately leading to increased intracellular $\mathrm{Ca}^{2+}$ levels and subsequently to peptide hormone release [21]. GPCRs constitute a large and diverse family of proteins whose primary function is to transduce extracellular stimuli into intracellular signals [22]. This diversity is dictated both by the multiplicity of stimuli to which they respond, as well as by the variety of intracellular signaling pathways they activate. GPCRs can be classified in 6 families based on sequence homology and functional similarity [2325], namely: Family A (Rhodopsin-like), Family B (Secretin receptor family), Family C (Metabotropic glutamate/pheromone), Family D (Fungal mating pheromone receptors), Family E (Cyclic AMP receptors), and Family F (Frizzled/Smoothened). Family $A$ and $C$ have been shown to play a role in nutrient sensing $[26,27]$, and hence, these receptor families will be discussed in more detail below.

\section{FAMILY C NUTRIENT-SENSING RECEPTORS}

The family $C$ receptors consists of several members, such as the metabotropic glutamate (mGlu) receptors, the $\gamma$-aminobutyric acid type $B\left(G A B A_{B}\right.$ ) receptors, calcium-sensing receptors (CaR), taste receptors, and $\mathrm{G}$ protein-coupled receptor family C, group 6, subtype A (GPRC6A). These receptors serve diverse functions, ranging from neurotransmission by the $m$ Glu and $G_{A B A}$ receptors and regulation of calcium homeostasis by CaR [26]. Because all endogenous agonists for Family $C$ receptors are in fact nutrient-like, such as amino acids and sugars, the receptors can be divided into L-amino acid sensing receptors, carbohydrate receptors, and taste receptors respectively. All groups will be discussed in more detail below. 


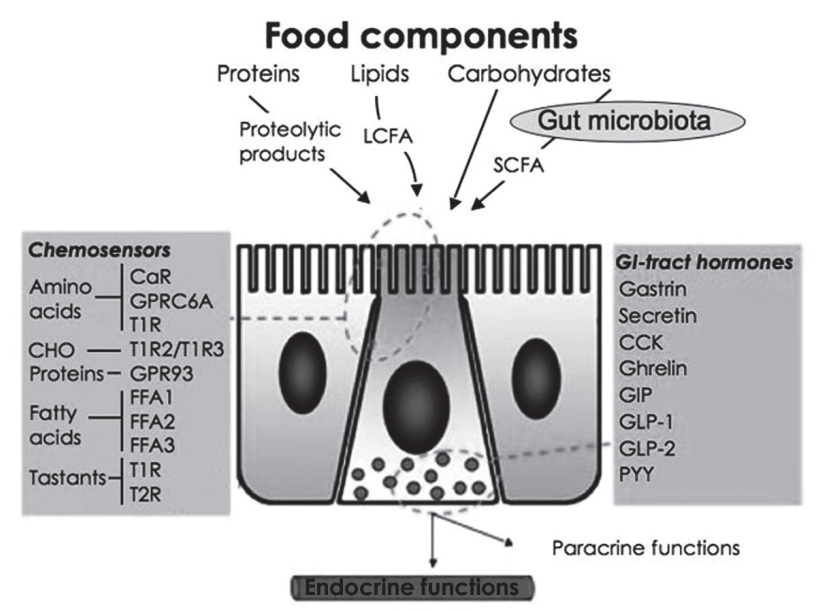

Figure 1. A schematic overview of sensory and secretory functions of enteroendocrine cells of the gut.

Between two enterocytes, a prototypical, conical enteroendocrine cell is shown with its microvillus decorated apical pole reaching the gut lumen and with peptide hormone-filled secretory granules at the base. The box at the right side of the figure lists a selection of classical gut hormones. The box at the left side of the figure lists a number of protein-coupled receptors that are assumed to function as chemosensors in the enteroendocrine cells. Adapted from Engelstoft et al [20].

\section{L-amino acid-sensing receptors}

Although the non-mGluR amino acid sensing-receptors are rather nonselective in their ligand profiles, in vitro studies have shown that they all have a preference for a specific subset of classes of amino acids, potentially providing a means for covering responses to all of the 20 proteinogenic L-amino acids [28, 29]. L-amino acid-sensing occurs mainly through the CaR, and GPRC6A, which will be described in this paragraph.

In the past few years, several reports have emerged that demonstrated a role for CaR in protein/amino acid sensing, including CaR-mediated L-amino acidstimulated gastric acid release from stomach parietal cells [30], and cholecystokinin (CCK) and glucagon-like peptide 1 (GLP-1) release from enteroendocrine cells [3133]. The most potent amino acids that target CaR in vitro are the aromatic amino acids such as L-phenylalanine and L-tryptophan, followed by aliphatic and polar amino acids, such as serine, threonine, glycine, and alanine, whereas acidic, basic, and branched-chain amino acids, such as valine, (iso-) leucine, aspartic acid, and glutamic acid, are weak activators or are not able to stimulate these receptors [34]. The GPRC6A receptor is an L-amino acid receptor cloned just five years ago. Its physiological role is still poorly understood. Given the broad sensitivity to L-amino acids and the expression of GPRC6A in organs and tissues such as tongue, 
pancreatic islets, liver, skeletal muscle, bone, and fat [29], GPRC6A represents a plausible nutrient-sensing receptor. Presently, the role of GPRC6A in the cells of the Gl tract has not been investigated.

\section{Carbohydrate sensing receptors}

As already outlined for L-amino acid sensing receptors, the molecular machinery for mediating taste sensation is also present in the Gl tract and, more specifically, in enteroendocrine cells. Thus far, the only known sweet sensing receptor is the heterodimeric receptor T1R2/T1R3 which displays an intriguingly broad sensitivity for naturally occurring sweet substances such as glucose, fructose, sucrose, and sweet-tasting D-amino acids, but also for synthetic sweeteners like aspartame (NutraSweet®), sucralose (Splenda®), cyclamate, saccharin, and acesulfame $K[35,36] . T 1 R 2 / T 1 R 3$ is expressed both in taste buds of the oral cavity [36], and throughout the Gl tract [37-39]. Thus, the gut is able to sense sweet stimuli, and in the last years exciting links between dietary sugars and chemosensing have surfaced, notably the regulation of glucose absorption [37, 39-41] and enteroendocrine GLP1 hormone secretion [42]. The T1R2/T1R3 receptor can also be classified as a taste receptor.

\section{Taste receptors}

In general, taste refers to five basic oral perceptions: sweet, salty, sour, bitter, and the taste of starch and umami (or savoury). Taste contributes to the selection of foods to be eaten and to palatability [43], but also to satiation, thermogenic effects [44] and the 'reward value' of food [45]. Another important role of the taste system is to determine whether a food is nutritious and should be ingested or is potentially toxic and should be rejected [46].

The idea that the Gl tract may have 'taste' cells that detect nutrients has been around for at least 25 years [47]. In 1996, Höfer et al. showed that $\alpha$-gustducin, a taste signaling protein, is located in gut epithelial cells [48]. More recently, several investigators reported the expression of bitter, sweet, and umami taste receptors in the gut $[37,38,49]$. Bezençon et al. showed that TIR1, T1R2, T1R3, $\alpha$-gustducin, and Trpm5 are expressed in the stomach, small intestine, and colon of mice and humans, with the exception of T1R2, which was not detected in the mouse and human stomach or mouse colon [37]. It has also been demonstrated that the expression of the taste receptors is decreased in obese diabetic subjects with elevated blood glucose concentrations [50]. However, the precise role of these receptors in the gut is still unknown, and limited literature is available on the release of satiety hormones after exposure to different tastants.

Activation of the taste receptor signaling molecules, which are expressed in enteroendocrine cells, by luminal content induces increases in intracellular $\mathrm{Ca}^{2+}$, 
which triggers the release of peptides like PYY, GLP-1, or CCK. This links tastants to satiety. Chen et al. showed that addition of unrelated structurally bitter stimuli of denatonium benzoate or phenylthiocarbamide increased the intracellular $\mathrm{Ca}^{2+}$ in STC-1 cells, leading to CCK release from the cells [32]. We confirmed these findings using the same cell line, but we also demonstrated that other tastants, such as quinine (bitter), $\mathrm{HCl}$ and $\mathrm{HAc}$ (sour), sucrose, sucralose, and erythritol (sweet), $\mathrm{NaCl}$ (salty), and monosodium glutamate (umami) were able to induce CCK release even stronger, in both a concentration and time dependent fashion [51].

GLP-1 is secreted in a taste receptor-dependent manner by gut enteroendocrine L cells in response to stimulation with natural and artificial sweeteners [42]. In in vitro experiments using murine enteroendocrine cells (GLUTag cells), Margolskee et al. demonstrated that these cells increase the secretion of GLP-1 after exposure to sucralose [52]. However, Fuijta et al. demonstrated that GLP-1 release from the gut is not enhanced by artificial sweeteners, but only by glucose [53]. Kokrashvili et al. showed that isolated small intestine and intestinal villi from gustducin null mice displayed markedly defective GLP-1 secretion in response to glucose [54], whereas in GLP-1 knock out mice the taste responses to sweeteners were dramatically decreased [55], suggesting the existence of a local circuit of sugar detection by intestinal cells followed by hormone secretion from the same cells.

We demonstrated that tastants representing the five basic tastants induce GLP-1 release, in both a concentration- and time dependent fashion. However, different tastants used for the same taste affected the release differently. For example, GLP1 release was affected by both sucrose and sucralose, but sucralose induced the hormone release to a higher extent than sucrose [51].

\section{FAMILY A NUTRIENT-SENSING RECEPTORS}

In addition to the family $\mathrm{C}$ receptors, several family $\mathrm{A}$ receptors are diverse in their ligand preferences, and several respond to nutrients derived from food, notably protein degradation products and free fatty acids (FFAs). Therefore, the Family A receptors can be divided in several subgroups, namely the protein receptors and fatty acid receptors, which will be discussed below.

\section{Protein/proteolysis-sensing receptors}

The family A receptor GPR93 was recently described as a nutrient-sensing receptor responsive to peptone, a peptide mixture resembling proteolytic degradation products. GPR93 is highly expressed in the small intestine and it has been shown that peptone stimulation of GPR93 in enterocytes and enteroendocrine cells leads to $G$ protein-signaling cascades ultimately promoting CCK gene transcription and 
CCK release [56]. However, the release of CCK depends on the kind of peptones. Several studies showed that exposing enteroendocrine cells in vitro to peptones or protein hydrolysates results in different CCK levels. Porcine peptones stimulate CCK release in vitro, and when orally given to rats, it suppresses appetite, compared to chicken, beef liver, and egg white peptones [9]. However, some studies found no differences between protein sources. In the study of Foltz et al., enteroendocrine cells were exposed to different protein hydrolysates in an in vitro situation. All hydrolysates induced release of satiety hormones, however, they did not find significant differences between the different protein hydrolysates [57]. CordierBussat et al showed that addition of protein hydrolysates from meat, casein and soybean to STC-1 cells increased CCK and GLP-1 release, whereas a mixture of free amino acids or undigested proteins were weak stimulants of CCK and GLP-1 release [58-60].

\section{Free fatty acid-sensing receptors}

FFAs are known to exert a wide range of physiological effects, typically on cellular metabolism and stimulate the release of satiety hormones. A variety of mediumand long-chain FFA's have been identified as ligands for the FFA 1 (previously termed GPR40), GRP84, and GRP120 receptors [61-64], whereas short-chain FFA's activate FFA2 and FFA3 (previously termed GPR43 and GPR41, respectively) [65-67].

$A$ wide range of medium- and long-chain FFA's have been identified as agonists of the FFA 1 receptor, with eicosatriynoic acid (C20:3) being the most potent example $[61,63,68]$. Intriguingly, the carbon chain lengths of saturated fatty acids correlate with the potency to activate the receptor, with pentadecanoic acid (C15) and palmitic acid ( $\mathrm{C} 16)$ being the most potent. The FFA1 receptor could be a nutrient sensor for FFA's generated by hydrolysis of ingested fat and oil, which is consistent with the expression of the receptor in the islets of Langerhans from the pancreas and the gut $[61,63,69,70]$. This hypothesis has been substantiated by several studies using FFA 1 knockout mice and selective FFA 1 small molecule agonists, showing that FFA 1 regulates the FFA-mediated release of gastric inhibitory peptide (GIP) and GLP-1 from the gut and the FFA-mediated enhancement of insulin release from $\beta$-cells of the pancreas $[68,69,71-74]$.

Three additional receptors, GPR84, GPR 1 19, and GPR 120, have recently been shown to be activated by FFAs but have so far not been studied in as great detail as FFA 1 3. The GPR84 receptor responds to medium-chain FFA (C9-C14) and is expressed in leukocytes and monocytes [64]. GPR120 is a receptor for both saturated (C14-C 18) and unsaturated (C16-C22) fatty acids $[62,75]$. Interestingly, the FFA $\alpha$-linolenic acid has been shown to stimulate release of GLP-1 in vitro in STC-1 intestinal endocrine cells and in vivo in mice and rats $[62,76]$. However, $\alpha$-linolenic acid is an agonist of both GPR120 and FFA1, which are both expressed in the intestine, and the latter 
has also been shown to mediate GLP-1 release, but the physiological effects in vivo remain to be established.

GPR 119 was initially identified as a novel member of the general class of G-protein coupled receptors which had no close homologues, although it was subsequently proposed to possess certain structural similarity with cannabinoid receptors [77], and can bind certain fatty acid ethanolamides [78]. Identification of these molecules as potential ligands for GPR 119 is important since such compounds can negatively influence food intake, reduce visceral fat mass and lower body weight, as was shown in various animal models of obesity [79-81].

In order to stimulate CCK secretion, triglycerides must be hydrolyzed to fatty acids. The length of the fatty acid carbon chain determines the impact of the fatty acid on CCK release [82]. Studies have shown that in humans, long chain fatty acids are the most potent stimulants for CCK release [82-84]. It was recently demonstrated that postprandial infusions of a small amount of fat into the ileum in healthy volunteers reduced feelings of hunger and increased satiety. This effect was similar for both 3 and $9 \mathrm{~g}$ fat, respectively. These findings correlated significantly with increased CCK levels in the blood [85]. Different fats also induce different effects on PYY release, with especially fatty acids chain length playing a crucial role in this process. 10-carbon fatty acids (decanoic acid) had no effect on PYY release [83], whereas ileal infusion of long-chain triglycerides (C18; oleic acid) and middle-chain fatty acids (C12; lauric acid) increased the plasma PYY concentration [86].

\section{DISCUSSION AND CONCLUSION}

This review summarizes the current knowledge on the sensing of nutrients in the $\mathrm{Gl}$ tract, and on the effects of nutrients on the gastrointestinal satiety-related peptide release. It is clearly demonstrated that diet composition affects different satiety signals and that different macronutrients exert diverse effects. The body of existing literature is, however, still limited and the study designs used vary considerably with respect to the amount and composition of tested foods as well as the characteristics of the subjects and animals that were studied.

The distribution of the receptors throughout the Gl tract is not consistent. Figure 1 shows that some receptors are only located in the small intestine, whereas other receptors can be found throughout the entire $\mathrm{Gl}$ tract. We also have to take into consideration that the expression levels of the receptors may not directly reflect hormone secretion rates. It could be that some receptors are not highly expressed, but affect the release of satiety hormones stronger, compared to receptors that are more commonly found within the Gl tract.

Proteins seem to be the most potent macronutrient for modulating food intake. 
In most cases, high-protein meals increase feelings of satiety and decrease subsequent energy intake compared to high-carbohydrate or high-fat meals [87]. There are suggestions that different types of proteins exert differential effects on satiety [88-92]. Post-ingestion and post-absorptive responses may be different and may contribute to differences in satiating capacities. Upon food ingestion, a variety of receptors will be triggered, since a meal does not consist of only proteins, but also of carbohydrates, fat, tastants and many others ingredients. It may be possible that the receptors function in a synergistic manner, and that an optimal combination of macronutrients and tastants affects gastrointestinal hormone release to a greater extent. Scientific data on this issue is currently lacking.

Overall we conclude that modulation of peptide hormone secretion in gastrointestinal cells through specific combinations of nutrients has a strong potency for developing novel therapeutic agents for the treatment of conditions associated with food intake, ranging from feeding disorders, obesity, and impairment of glucose homeostasis to intoxication and inflammation, which might be triggered by luminal contents. However, more research has to be done to understand the mechanisms by which macronutrients and tastants affect gastrointestinal peptide secretion, and how this secretion profile may affect satiety and satiation. The underlying mechaisms must be elucidated to get a better understanding of the role of the gastrointestinal tract in weight management.

\section{Therapeutic perspectives}

The field of nutrient-sensing receptors is evolving quickly and it is thus an exciting time as we have just begun to understand the molecular pharmacology and kinetics, physiological function, and therapeutic potential of the receptors. It is tempting to hypothesize that the metabolic syndrome and diabetes could be treated by activating the nutrient sensors, thereby 'tricking' the body to believe it has eaten, which would initiate physiological effects such as release of satiety signals from the gut, pancreas, and fatty tissue. It might not be that simple, but many of the different receptors discussed in this review are expressed in relevant organs and now receive increased focus as potential drug targets. 
1. Obesity: preventing and managing the global epidemic. Report of a WHO consultant. World Health Organ Tech Rep Ser, 2000. 894(i-xii): p. 1-253.

2. Cummings, D.E. and J. Overduin, Gastrointestinal regulation of food intake. J Clin Invest, 2007. 117(1): p. 13-23.

3. Capasso, R. and A.A. Izzo, Gastrointestinal regulation of food intake: general aspects and focus on anandamide and oleoylethanolamide. J Neuroendocrinol, 2008. 20 Suppl 1: p. 39-46.

4. Karhunen, L.J., et al., Effect of protein, fat, carbohydrate and fibre on gastrointestinal peptide release in humans. Regul Pept, 2008. 149(1-3): p. 70-8.

5. Degen, L., et al., Effect of peptide YY3-36 on food intake in humans. Gastroenterology, 2005. 129(5): p. 1430-6.

6. Feinle-Bisset, C., et al., Fat digestion is required for suppression of ghrelin and stimulation of peptide YY and pancreatic polypeptide secretion by intraduodenal lipid. Am J Physiol Endocrinol Metab, 2005. 289(6): p. E948-53.

7. Adam, T.C., M.P. Lejeune, and M.S. Westerterp-Plantenga, Nutrient-stimulated glucagon-like peptide 1 release after body-weight loss and weight maintenance in human subjects. Br J Nutr, 2006. 95(1): p. 160-7.

8. Bowen, J., et al., Energy intake, ghrelin, and cholecystokinin after different carbohydrate and protein preloads in overweight men. J Clin Endocrinol Metab, 2006. 91 (4): p. 1477-83.

9. Sufian, M.K., et al., Pork peptone stimulates cholecystokinin secretion from enteroendocrine cells and suppresses appetite in rats. Biosci Biotechnol Biochem, 2006. 70(8): p. 1869-74.

10. Jeffery, R.W., et al., Long-term maintenance of weight loss: current status. Health Psychol, 2000. 19(1 Suppl): p. 5-16.

11. Doucet, E., et al., Appetite after weight loss by energy restriction and a low-fat diet-exercise follow-up. Int J Obes Relat Metab Disord, 2000. 24(7): p. 906-14.

12. Claessens, M., et al., The effect of a low-fat, high-protein or high-carbohydrate ad libitum diet on weight loss maintenance and metabolic risk factors. Int J Obes (Lond), 2009.

13. Hursel, R. and M.S. Westerterp-Plantenga, Green tea catechin plus caffeine supplementation to a high-protein diet has no additional effect on body weight maintenance after weight loss. Am J Clin Nutr, 2009.

14. van Dale, D., W.H. Saris, and F. ten Hoor, Weight maintenance and resting metabolic rate 18-40 months after a diet/exercise treatment. Int J Obes, 1990. 14(4): p. 347-59.

15. Fogelholm, M., K. Kukkonen-Harjula, and P. Oja, Eating control and physical activity as determinants of short-term weight maintenance after a very-low-calorie diet among obese women. Int J Obes Relat Metab Disord, 1999. 23(2): p. 203-10.

16. Due, A., et al., Effect of normal-fat diets, either medium or high in protein, on body weight in overweight subjects: a randomised 1-year trial. Int J Obes Relat Metab Disord, 2004. 28(10): p. 1283-90.

17. Skov, A.R., et al., Effect of protein intake on bone mineralization during weight loss: a 6-month trial. Obes Res, 2002. 10(6): p. 432-8.

18. Conigrave, A.D. and E.M. Brown, Taste receptors in the gastrointestinal tract. II. L-amino acid sensing by calcium-sensing receptors: implications for Gl physiology. Am J Physiol Gastrointest Liver Physiol, 2006. 291 (5): p. G753-61.

19. Egan, J.M. and R.F. Margolskee, Taste cells of the gut and gastrointestinal chemosensation. Mol Interv, 2008. 8(2): p. 78-81.

20. Engelstoft, M.S., et al., A gut feeling for obesity: 7TM sensors on enteroendocrine cells. Cell Metab, 2008. 8(6): p. 447-9.

21. Sternini, C., L. Anselmi, and E. Rozengurt, Enteroendocrine cells: a site of 'taste' in gastrointestinal chemosensing. Curr Opin Endocrinol Diabetes Obes, 2008. 15(1): p. 73-8.

22. Kroeze, W.K., D.J. Sheffler, and B.L. Roth, G-protein-coupled receptors at a glance. J Cell Sci, 
2003. $116(P+24):$ P. 4867-9.

23. Attwood, T.K. and J.B. Findlay, Fingerprinting G-protein-coupled receptors. Protein Eng, 1994 7(2): p. 195-203

24. Kolakowski, L.F., Jr., GCRDb: a G-protein-coupled receptor database. Receptors Channels, 1994. 2(1): p. 1-7.

25. Foord, S.M., et al., International Union of Pharmacology. XLVI. G protein-coupled receptor list. Pharmacol Rev, 2005. 57(2): p. 279-88.

26. Brauner-Osborne, H., P. Wellendorph, and A.A. Jensen, Structure, pharmacology and therapeutic prospects of family C G-protein coupled receptors. Curr Drug Targets, 2007. 8(1): p. 169-84.

27. Choi, S., et al., Identification of a protein hydrolysate responsive $G$ protein-coupled receptor in enterocytes. Am J Physiol Gastrointest Liver Physiol, 2007. 292(1): p. G98-G112.

28. Conigrave, A.D. and D.R. Hampson, Broad-spectrum L-amino acid sensing by class 3 G-proteincoupled receptors. Trends Endocrinol Metab, 2006. 17(10): p. 398-407.

29. Wellendorph, P. and H. Brauner-Osborne, Molecular basis for amino acid sensing by family C G-protein-coupled receptors. Br J Pharmacol, 2009. 156(6): p. 869-84.

30. Busque, S.M., et al., L-type amino acids stimulate gastric acid secretion by activation of the calcium-sensing receptor in parietal cells. Am J Physiol Gastrointest Liver Physiol, 2005. 289(4): p. G664-9.

31. Hira, T., et al., Calcium-sensing receptor mediates phenylalanine-induced cholecystokinin secretion in enteroendocrine STC-1 cells. Febs J, 2008. 275(18): p. 4620-6.

32. Chen, M.C., et al., Bitter stimuli induce Ca2+ signaling and CCK release in enteroendocrine STC1 cells: role of L-type voltage-sensitive Ca2+ channels. Am J Physiol Cell Physiol, 2006. 291 (4): p. C726-39.

33. Leech, C.A. and J.F. Habener, Regulation of glucagon-like peptide-1 receptor and calciumsensing receptor signaling by L-histidine. Endocrinology, 2003. 144(11): p. 4851-8.

34. Conigrave, A.D., S.J. Quinn, and E.M. Brown, L-amino acid sensing by the extracellular Ca2+sensing receptor. Proc Natl Acad Sci U S A, 2000. 97(9): p. 4814-9.

35. Li, X., et al., Human receptors for sweet and umami taste. Proc Natl Acad Sci U S A, 2002. 99(7): p. 4692-6.

36. Nelson, G., et al., Mammalian sweet taste receptors. Cell, 2001. 106(3): p. 381-90.

37. Bezencon, C., J. le Coutre, and S. Damak, Taste-signaling proteins are coexpressed in solitary intestinal epithelial cells. Chem Senses, 2007. 32(1): p. 41-9.

38. Dyer, J., et al., Expression of sweet taste receptors of the TIR family in the intestinal tract and enteroendocrine cells. Biochem Soc Trans, 2005. 33(Pt 1): p. 302-5.

39. Mace, O.J., et al., An energy supply network of nutrient absorption coordinated by calcium and TIR taste receptors in rat small intestine. J Physiol, 2009. 587(Pt 1): p. 195-210.

40. Mace, O.J., et al., Sweet taste receptors in rat small intestine stimulate glucose absorption through apical GLUT2. J Physiol, 2007. 582(Pt 1): p. 379-92.

41. Le Gall, M., et al., Sugar sensing by enterocytes combines polarity, membrane bound detectors and sugar metabolism. J Cell Physiol, 2007. 213(3): p. 834-43.

42. Jang, H.J., et al., Gut-expressed gustducin and taste receptors regulate secretion of glucagonlike peptide-1. Proc Natl Acad Sci U S A, 2007. 104(38): p. 15069-74.

43. Yeomans, M.R., Taste, palatability and the control of appetite. Proc Nutr Soc, 1998. 57(4): p. 60915.

44. Brondel, L., J. Fricker, and M. Fantino, Postprandial thermogenesis and alimentary sensory stimulation in human subjects. Int J Obes Relat Metab Disord, 1999. 23(1): p. 34-40.

45. Berridge, K.C., 'Liking' and 'wanting' food rewards: brain substrates and roles in eating disorders. Physiol Behav, 2009. 97(5): p. 537-50.

46. Breslin, P.A. and L. Huang, Human taste: peripheral anatomy, taste transduction, and coding. Adv Otorhinolaryngol, 2006. 63: p. 152-90.

47. Newson, B., et al., Ultrastructural observations in the rat ileal mucosa of possible epithelial "taste 
cells" and submucosal sensory neurons. Acta Physiol Scand, 1982. 114(2): p. 161-4.

48. Hofer, D., B. Puschel, and D. Drenckhahn, Taste receptor-like cells in the rat gut identified by expression of alpha-gustducin. Proc Natl Acad Sci U S A, 1996. 93(13): p. 6631-4.

49. WU, S.V., et al., Expression of bitter taste receptors of the $T 2 R$ family in the gastrointestinal tract and enteroendocrine STC-1 cells. Proc Natl Acad Sci U S A, 2002. 99(4): p. 2392-7.

50. Young, R.L., et al., Expression of taste receptor molecules in the upper gastrointestinal tract in humans with and without type 2 diabetes. Gut, 2008.

51. Geraedts, M.C.P., Release of satiety hormones induced by the five basic tastants is controlled by the influx of calcium. Gut Supplement, 2009.

52. Margolskee, R.F., et al., TIR3 and gustducin in gut sense sugars to regulate expression of Na+glucose cotransporter 1. Proc Natl Acad Sci U S A, 2007. 104(38): p. 15075-80.

53. Fujita, Y., et al., Incretin release from gut is acutely enhanced by sugar but not by sweeteners in vivo. Am J Physiol Endocrinol Metab, 2009. 296(3): p. E473-9.

54. Kokrashvili, Z., B. Mosinger, and R.F. Margolskee, Taste signaling elements expressed in gut enteroendocrine cells regulate nutrient-responsive secretion of gut hormones. Am J Clin Nutr, 2009.

55. Shin, Y.K., et al., Modulation of taste sensitivity by GLP-1 signaling. J Neurochem, 2008. 106(1): p. 455-63.

56. Choi, S., et al., GPR93 Activation by Protein Hydrolysate Induces CCK Transcription and Secretion in STC-1 Cells. Am J Physiol Gastrointest Liver Physiol, 2007.

57. Foltz, M., et al., Protein hydrolysates induce CCK release from enteroendocrine cells and act as partial agonists of the CCK1 receptor. J Agric Food Chem, 2008. 56(3): p. 837-43.

58. Bernard, C., et al., Peptones stimulate intestinal cholecystokinin gene transcription via cyclic adenosine monophosphate response element-binding factors. Endocrinology, 2001. 142(2): p. 721-9.

59. Cordier-Bussat, M., et al., Peptones stimulate both the secretion of the incretin hormone glucagon-like peptide 1 and the transcription of the proglucagon gene. Diabetes, 1998. 47(7): p. 1038-45.

60. Cordier-Bussat, M., et al., Peptones stimulate cholecystokinin secretion and gene transcription in the intestinal cell line STC-1. Endocrinology, 1997. 138(3): p. 1137-44.

61. Briscoe, C.P., et al., The orphan G protein-coupled receptor GPR40 is activated by medium and long chain fatty acids. J Biol Chem, 2003. 278(13): p. 11303-11.

62. Hirasawa, A., et al., Free fatty acids regulate gut incretin glucagon-like peptide-1 secretion through GPR120. Nat Med, 2005. 11 (1): p. 90-4.

63. Kotarsky, K., et al., A human cell surface receptor activated by free fatty acids and thiazolidinedione drugs. Biochem Biophys Res Commun, 2003. 301 (2): p. 406-10.

64. Wang, J., et al., Medium-chain fatty acids as ligands for orphan $G$ protein-coupled receptor GPR84. J Biol Chem, 2006. 281 (45): p. 34457-64.

65. Nilsson, N.E., et al., Identification of a free fatty acid receptor, FFA2R, expressed on leukocytes and activated by short-chain fatty acids. Biochem Biophys Res Commun, 2003. 303(4): p. 104752.

66. Le Poul, E., et al., Functional characterization of human receptors for short chain fatty acids and their role in polymorphonuclear cell activation. J Biol Chem, 2003. 278(28): p. 25481-9.

67. Brown, A.J., et al., The Orphan G protein-coupled receptors GPR4 1 and GPR43 are activated by propionate and other short chain carboxylic acids. J Biol Chem, 2003. 278(13): p. 11312-9.

68. Itoh, Y., et al., Free fatty acids regulate insulin secretion from pancreatic beta cells through GPR40. Nature, 2003. 422(6928): p. 173-6.

69. Edfalk, S., P. Steneberg, and H. Edlund, Gpr40 is expressed in enteroendocrine cells and mediates free fatty acid stimulation of incretin secretion. Diabetes, 2008. 57(9): p. 2280-7.

70. Ma, D., et al., Expression of free fatty acid receptor GPR40 in the neurogenic niche of adult monkey hippocampus. Hippocampus, 2008. 18(3): p. 326-33. 
71. Briscoe, C.P., et al., Pharmacological regulation of insulin secretion in MIN6 cells through the fatty acid receptor GPR40: identification of agonist and antagonist small molecules. Br J Pharmacol, 2006. 148(5): p. 619-28.

72. Christiansen, E., et al., Discovery of potent and selective agonists for the free fatty acid receptor 1 (FFA(1)/GPR40), a potential target for the treatment of type II diabetes. J Med Chem, 2008. 51 (22): p. 7061-4.

73. Steneberg, P., et al., The FFA receptor GPR40 links hyperinsulinemia, hepatic steatosis, and impaired glucose homeostasis in mouse. Cell Metab, 2005. 1 (4): p. 245-58.

74. Tan, C.P., et al., Selective small-molecule agonists of $G$ protein-coupled receptor 40 promote glucose-dependent insulin secretion and reduce blood glucose in mice. Diabetes, 2008. 57(8): p. 2211-9.

75. Tanaka, T., et al., Free fatty acids induce cholecystokinin secretion through GPR 120. Naunyn Schmiedebergs Arch Pharmacol, 2008. 377(4-6): p. 523-7.

76. Miyauchi, S., et al., Distribution and regulation of protein expression of the free fatty acid receptor GPR120. Naunyn Schmiedebergs Arch Pharmacol, 2009. 379(4): p. 427-34.

77. Brown, A.J., Novel cannabinoid receptors. Br J Pharmacol, 2007. 152(5): p. 567-75.

78. Overton, H.A., et al., Deorphanization of a $G$ protein-coupled receptor for oleoylethanolamide and its use in the discovery of small-molecule hypophagic agents. Cell Metab, 2006. 3(3): p. 16775.

79. Matias, I., et al., Role and regulation of acylethanolamides in energy balance: focus on adipocytes and beta-cells. Br J Pharmacol, 2007. 152(5): p. 676-90.

80. Lambert, D.M. and G.G. Muccioli, Endocannabinoids and related N-acylethanolamines in the control of appetite and energy metabolism: emergence of new molecular players. Curr Opin Clin Nutr Metab Care, 2007. 10(6): p. 735-44.

81. Hansen, H.S. and T.A. Diep, N-acylethanolamines, anandamide and food intake. Biochem Pharmacol, 2009. 78(6): p. 553-60.

82. Hopman, W.P., et al., Effect of equimolar amounts of long-chain triglycerides and medium-chain triglycerides on plasma cholecystokinin and allbladder contraction. Am J Clin Nutr, 1984. 39: p. 356-9.

83. Feltrin, K.L., et al., Effect of fatty acid chain length on suppression of ghrelin and stimulation of PYY, GLP-2 and PP secretion in healthy men. Peptides, 2006. 27(7): p. 1638-43.

84. Jonkers, I.J., et al., Effects of very long chain versus long chain triglycerides on gastrointestinal motility and hormone release in humans. Dig Dis Sci, 2000. 45(9): p. 1719-26.

85. Maljaars, J., et al., Effect of ileal fat perfusion on satiety and hormone release in healthy volunteers. Int J Obes, 2008. 32: p. 1633-1639.

86. Maljaars, P.W., et al., Effect of ileal fat perfusion on satiety and hormone release in healthy volunteers. Int J Obes (Lond), 2008. 32(11): p. 1633-9.

87. Anderson, G.H. and S.E. Moore, Dietary proteins in the regulation of food intake and body weight in humans. J Nutr, 2004. 134(4): p. 974S-9S.

88. Anderson, G.H., et al., Protein source, quantity, and time of consumption determine the effect of proteins on short-term food intake in young men. J Nutr, 2004. 134(11): p. 3011-5.

89. Bowen, J., M. Noakes, and P.M. Clifton, Appetite regulatory hormone responses to various dietary proteins differ by body mass index status despite similar reductions in ad libitum energy intake. J Clin Endocrinol Metab, 2006. 91 (8): p. 2913-9.

90. Bowen, J., M. Noakes, and P.M. Clifton, Appetite hormones and energy intake in obese men after consumption of fructose, glucose and whey protein beverages. Int J Obes (Lond), 2007. 31 (11): p. 1696-703

91. Hall, W.L., et al., Casein and whey exert different effects on plasma amino acid profiles, gastrointestinal hormone secretion and appetite. Br J Nutr, 2003. 89(2): p. 239-48.

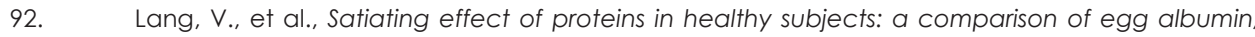
casein, gelatin, soy protein, pea protein, and wheat gluten. Am J Clin Nutr, 1998. 67(6): p. $1197-$ 204. 


\section{ChApter 3}

\section{PEPTIDE-YY Is RELEASEd BY THE INTESTINAL CELL LINE STC - 1}

MAARTJE C.P. GERAEDTS, FREDdy J. TROOST, WIM H.M. SARIS

JOURNAL OF FOOD SCIENCE 2009, 74(2):H79-82 


\section{ABSTRACT}

Dietary modulation of the response of gut satiety hormones, which partly regulate food intake, provides a promising treatment for overweight and obesity. Gut derived cell-lines such as STC-1 are widely used to investigate these hormonal responses to nutrients. At present, no peptide-YY (PYY) secreting cell-line has been identified. This study aimed to investigate whether STC-1 cells are able to secrete PYY and if so, whether dietary compounds can modulate PYY secretion.

Effects of fatty acid types C4:0, C12:0, C14:0, C16:0, and C18:0 on PYY release were investigated by measuring PYY in the supernatant after $30,60,90$, and 120 minutes of incubation, respectively, using RIA assays.

The STC-1 cells were able to secrete PYY in a time dependent manner. It was shown that after $30 \mathrm{~min}, \mathrm{C} 4: 0, \mathrm{C12}: 0, \mathrm{C16}: 0$, and C18:0 caused increased PYY levels compared to the control. At time points 60 and 90 minutes, $\mathrm{C} 4: 0$ and $\mathrm{C} 18: 0$ induced elevated PYY levels compared to the control. After $120 \mathrm{~min}, \mathrm{C4}: 0, \mathrm{C} 14: 0$, and C18:0 caused elevated levels compared to the control.

We are the first to show that the STC-1 cells are also able to secrete PYY next to cholecystokinin (CCK) and glucagon-like peptide 1 (GLP-1). Addition of fatty acids resulted in increased levels of PYY, which is consistent with literature describing human studies. We conclude that the STC-1 cell-line provides an appropriate cellline for screening the effects of ingredients on the release of the satiety related gut hormones CCK, GLP-1, and PYY. 


\section{INTRODUCTION}

The incidence of overweight and obesity has increased dramatically worldwide. Recent data indicate that there are more than 400 million obese people worldwide [1]. This so-called obesity epidemic has prompted an increased research effort in the food industry, with particular emphasis on the development of strategies to suppress appetite and thereby reducing energy intake.

Gastrointestinal hormones such as cholecystokinin (CCK), glucagon like peptide 1 (GLP-1), and peptide YY (PYY) are important regulators of food intake and energy homeostasis. Increasing the levels of satiety hormones could potentially be of benefit for body weight control. After food intake, satiety hormones are secreted from intestinal endocrine cells into the blood circulation. Although cells that secrete satiety hormones are present throughout the gut, each type of cell is sensitive to different nutrients (e.g., carbohydrates, fats, or proteins) [2]. CCK is primarily secreted by cells located in the duodenum, and has an acute, short-term effect on satiety, whereas GLP-1 and PYY, mainly secreted by L-cells located in the ileum, exert a late, long-term effect on satiety. However, the effect of many nutrients on the different satiety hormones remains to be elucidated.

Using isolated intestinal cells for a high-throughput model to test effects of nutrients on hormone secretions would provide the best screening model. However, the isolation of native intestinal cells remains a tedious process and produces fairly low yields. Hence, the intestinal hormone producing cell line STC-1 seems to be a good alternative, as these cells harbor many features of native intestinal hormone secreting cells. The STC-1 cell line is derived from an intestinal endocrine tumor in a double-transgenic mouse [3,4]. These cells are widely used as CCK and GLP1 secreting cells, and are known to secrete these hormones in a manner that resembles that of humans. These cells can be used as a high-throughput system to identify food ingredients that stimulate hormone secretion [5-7].

Although CCK and GLP-1 are important regulators of satiety, other hormones also play an important role. One of these hormones is PYY. It is synthesized and secreted as PYY ${ }_{1-36}$ by L-cells in the distal ileum and colon, and has been implicated as a major component of the ileal brake [2]. Once present in the blood circulation, PYY is degraded by dipeptidyl peptidase IV (DPP-IV) to PYY ${ }_{3-36}$, which displays a highly selective agonistic activity for the $Y 2$ receptor. Stimulation of this receptor has been reported to reduce food intake [8]. The $Y 2$ receptor can be found in the hypothalamic arcuate nucleus, and is the most likely mediator of the food intakereducing properties of PYY [2]. The secretion of PYY from the gut is proportional to the caloric density of the ingested nutrients [2]. Peripheral administration of PYY to rodents, primates, and humans acutely decreases food intake [8-12]. This suggests that PYY is an important regulator of satiety, and therefore a mediator of body 
weight control.

Batterham et al. reported that high-protein intake stimulated PYY secretion in humans and mice [8, 12], whereas other studies described that fat appears to be the most potent stimulus of PYY and carbohydrate the least potent (13). However, no literature is available describing the effects of proteins compared to fatty acids. Ileal infusion of the fatty acid oleic acid in animals and humans significantly increased plasma PYY levels [13]. Literature on effects of nutrition on PYY release is limited because until present, no PYY secreting cell lines were available.

The objectives of this study were to investigate (1) whether the STC-1 cell line secretes PYY, and (2) if the cell line is sensitive to fatty acids, resulting in stimulation of PYY release, conform previous in vivo studies.

\section{MATERIAL AND METHODS}

\section{Cell culture}

The STC-1 cell line, a murine cell line of enteroendocrine origin, was kindly provided by Dr. Hanahan (University of California, San Francisco). The cells (passage 25 to 45) were maintained in Dulbecco's Modified Eagles Medium (DMEM) with 10\% fetal bovine serum, $2 \mathrm{mM}$ L-glutamine, $100 \mathrm{units} / \mathrm{ml}$ penicillin, and $100 \mu \mathrm{g} / \mathrm{ml}$ streptomycin as additional supplements; at $37^{\circ} \mathrm{C}$ in $5 \% \mathrm{CO}_{2}$ /air.

\section{Preparation of fatty acids}

The fatty acids butyric acid (C4:0), lauric acid (C12:0), myristic acid (C14:0), palmitic acid (C16:0), and stearic acid (C18:0) were purchased from Sigma Aldrich (Steinheim, Germany). All fatty acids were mixed with ethanol and sonicated prior to addition to the cell culture.

\section{PYY secretion studies}

For the measurement of PYY release, STC-1 cells were seeded in 24-well plates ( $1.0 \times 10^{5}$ cells/well). After 72 hours of incubation the cells were washed twice with PBS. Subsequently, cells were incubated with Hanks Balanced Salt Solution (HBSS) as control, or the free fatty acids C4:0, C12:0, C14:0, C16:0, and C18:0 (final concentration: $0,5 \mu \mathrm{M}$ in HBSS). All fatty acids remained in solution after mixing with HBSS buffer. After an incubation period at $37^{\circ} \mathrm{C}$ in a humified incubator at $5 \% \mathrm{CO}_{2}$ of $30,60,90$, and 120 minutes, respectively, the supernatant was collected and stored at $-20^{\circ} \mathrm{C}$.

\section{Analysis of samples}

Supernatants were thawed and equilibrated to room temperature. PYY concentrations were measured using a radioimmunoassay (RIA) kit for total PYY from Linco Research (cat. \#RMPYYT-68HK St. Charles, Mo., USA). The assays were performed in accordance with the manufacturer's instructions. This assay measures 
the sum of PYY (1-36) and PYY (3-36). The lower detection limit was $15.6 \mathrm{pg} / \mathrm{ml}$, and the within-assay coefficient of variation between $3 \%$ and $9 \%$. Quality controls were within expected limits.

\section{Statistical analysis}

Differences in the potency of the different fatty acids to increase PYY release from the STC-1 cells were analyzed using one-way ANOVA followed by the bonferroni post-hoc test (performed with SPSS, version 11.0). Differences were considered to be significant at $P<0.05$. Data are presented as the mean \pm SEM. All experiments were performed in triplicate.

\section{RESULTS}

\section{PYY release by STC-1 cells}

Incubation of STC-1 cells without addition of nutrients resulted in release of PYY in a time dependent manner. After 30 minutes of incubation, PYY levels were $16.3 \mathrm{pg} / \mathrm{ml}$ \pm 1.9 , and reached a steady state after 60 minutes with PYY levels of approximately $21.1 \mathrm{pg} / \mathrm{ml} \pm 1.6$ (figure 1).

\section{PYY release after fatty acid stimulation}

Exposure to the fatty acids increased PYY release compared to the control solution (figure 2). Incubation with the short chain fatty acid C4:0 caused a significantly larger PYY release than the negative control at all time points, ranging from 33.4 $\mathrm{pg} / \mathrm{ml} \pm 0.4$ at 30 minutes to $37.9 \mathrm{pg} / \mathrm{ml} \pm 0.9$ at 120 minutes. Incubation with the long chain fatty acid C18:0 also caused a significantly larger PYY release at all time points compared to the negative control. PYY levels ranged from $31.4 \mathrm{pg} / \mathrm{ml} \pm 3.0$ at 30 minutes to $34.3 \mathrm{pg} / \mathrm{ml} \pm 1.6$ at 120 minutes.

Addition of C12:0 and C16:0 caused a significantly larger PYY release only after 30 minutes of incubation $(29.5 \mathrm{pg} / \mathrm{ml} \pm 1.8,29.2 \mathrm{pg} / \mathrm{ml} \pm 1.1$, respectively), compared to the negative control. C14:0 only caused a significant increase after an incubation period of 120 minutes $(33.6 \mathrm{pg} / \mathrm{ml} \pm 2.1)$, compared to the negative control.

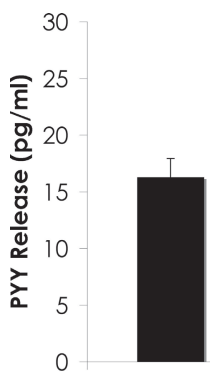

30

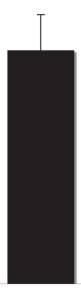

60

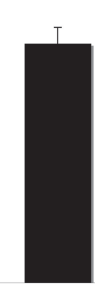

90

Time (min)

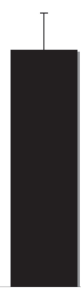

120
Figure 1. PYY release by STC-1 cells PYY release into STC-1 supernatant was investigated after an incubation period of 30, 60, 90, and 120 minutes, respectively with HBSS. The cells secreted PYY without stimulation by specific nutrients. The results are reported as the mean $\pm \operatorname{SEM}(n=3)$. 


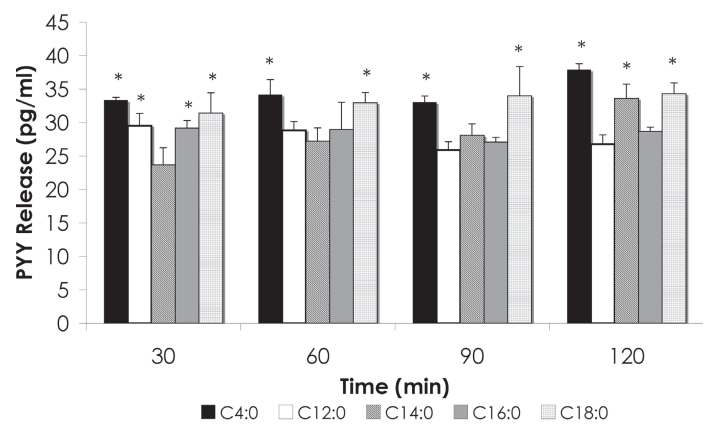

FIGURE 2. PYY release after addition of several fatty acids. Effects of the fatty acids C4:0, C 12:0, C14:0, C16:0, and C18:0 on PYY release by the STC-1 cells were investigated. Samples of the supernatant were taken after 30,60,90, and 120 minutes, respectively. Incubation of STC-1 cells with either C4:0, C12:0, C16:0, or C18:0 for a 120-min period induced a significant increase in secretion of PYY in all cases, compared to the control. The results are expressed as mean \pm SEM $(n=3) . * P<0.05$ compared to negative control.

\section{DISCUSSION}

Food intake induces the release of a variety of satiety hormones by intestinal mucosa. Using the STC-1 cell line as a high throughput system to evaluate the effects of macronutrients on satiety hormone release by enteroendocrine cells provide a useful technology to study the satiating properties of these macronutrients. We were the first to show that STC-1 cells are able to secrete the satiety hormone PYY under basal and nutrient-stimulated conditions. We demonstrated that addition of several fatty acids resulted in elevated levels of PYY in the same extent as previously described in human in vivo studies.

It was shown previously that ingestion of nutrients results in elevated levels of PYY release, with fatty acids as the most potent stimulators. Long-chain fatty acids in the form of sodium oleate infused to the small intestine are potent secretagogues for PYY release, whereas medium-chain fatty acids are ineffective [14]. Small chain fatty acids (SCFAs) are known to stimulate PYY release for at least 1 hour when infused in the duodenum [15]. In our study, we investigated the effects of fatty acids of different chain lengths, and we confirmed that the long chain fatty acid C18:0 and the short chain fatty acid C4:0 were the most potent stimulators of PYY release.

Long chain fatty acids are known to stimulate PYY release, but to our knowledge, no literature is available describing the effects of C14:0 and C16:0 on PYY release. Therefore, we hypothized that these fatty acids do not exert strong effects on PYY release, and our study confirmed this. Both C14:0 and C16:0 did not affect PYY release in the same extent as all other fatty acids did.

Most studies investigating the effects of long chain fatty acids used oleic acid (C 18:1). It was shown that C18:1 increased PYY release for 6 hours after infusion into the duodenum and ileum in vivo in humans $[13,16,17]$. In our study, we showed that C18:0 also induced PYY release by STC-1 cells. Even though long chain fatty acids were previously shown to be very good stimulators of PYY release, Feltrin et al. showed that intraduodenal infusion of C12 caused elevated PYY levels after 
15 - 30 minutes [18], and that C12 is a stronger inhibitor of food intake compared to C18:1, which was a more potent stimulator in PYY release [19]. This implicates that even though PYY is a strong mediator of satiety, other factors, such as other satiety hormones and chemical and sensory stimuli, also play an important role in the sensation of satiety.

The mechanism by which the SCFAs stimulate the enteroendocrine cells to release PYY is not completely understood, but activation of the SCFA G-receptor protein (GRP) GRP43 expressed in these cells may play a role in the release of PYY [20, 21]. Other studies showed that the STC-1 cell line contains many GRPs, which all play a role in the secretion of satiety hormones [6, 22, 23]. Zhou et al. showed that butyrate increased the expression of PYY and proglucagon in vitro in rat epithelial cells [24]. We also demonstrated the strong effect of butyrate on PYY release. This suggests that STC-1 cells are sensitive to stimuli leading to satiety hormone release by mechanisms resembling the human situation, and can therefore be used as a model system for studying the underlying mechanisms of the PYY release upon food intake.

It is suggested that after meal intake $60-70 \%$ of circulating PYY is in the form of PYY(336) and the rest is present as PYY(1-36). The different circulating forms of PYY have only been measured in very few studies; therefore there is only limited information available with respect to the different circulating molecular forms of PYY. It is not clear from literature whether total PYY concentrations are measured, or only PYY(336), which is the biologically active form of the peptide in satiation. To be able to compare our results with literature, we chose to measure only total PYY levels.

Taken together, this study showed that the STC-1 cell line is able to secrete PYY, and that fatty acids stimulated PYY release by these cells. Even though more research is necessary to understand the underlying mechanisms for the release of PYY by the STC-1 cells, the observations in this study were all in line with previously published data of human in vivo studies. Therefore, we conclude that the STC-1 cell line can be used as the first high-throughput in vitro system for synchronously investigating the effects of food ingredients on secretion levels of different satiety hormones, including PYY. 
1.

2.

3. Chang, C.H., W. Y. Chey, and T.-M. Chang, Secretory mechanisms of cholecystokinin-like immunoreactivity from a murine endocrine tumor cell line (Abstract). Gastroenterology, 1991. 100: p. A634.

4. Rindi, G., et al., Development of neuroendocrine tumors in the gastrointestinal tract of transgenic mice. Heterogeneity of hormone expression. Am J Pathol, 1990. 136(6): p. 1349-63.

5. Wang, Y., et al., Luminal CCK-releasing factor stimulates CCK release from human intestinal endocrine and STC-1 cells. Am J Physiol Gastrointest Liver Physiol, 2002. 282(1): p. G16-22.

6. Choi, S., et al., GPR93 Activation by Protein Hydrolysate Induces CCK Transcription and Secretion in STC-1 Cells. Am J Physiol Gastrointest Liver Physiol, 2007.

7. Cordier-Bussat, M., et al., Peptones stimulate both the secretion of the incretin hormone glucagon-like peptide 1 and the transcription of the proglucagon gene. Diabetes, 1998. 47(7): p. 1038-45.

8. Batterham, R.L. and S.R. Bloom, The gut hormone peptide YY regulates appetite. Ann N Y Acad Sci, 2003. 994: p. 162-8.

9. Conlon, J.M., The origin and evolution of peptide YY (PYY) and pancreatic polypeptide (PP). Peptides, 2002. 23(2): p. 269-78.

10. Hoentjen, F., W.P. Hopman, and J.B. Jansen, Effect of circulating peptide YY on gallbladder emptying in humans. Scand J Gastroenterol, 2001. 36(10): p. 1086-91.

11. Brubaker, P.L., et al., Regulation of peptide-YY synthesis and secretion in fetal rat intestinal cultures. Endocrinology, 1991. 129(6): p. 3351-8.

12. Batterham, R.L., et al., Critical role for peptide $Y Y$ in protein-mediated satiation and body-weight regulation. Cell Metab, 2006. 4(3): p. 223-33.

13. Feinle-Bisset, C., et al., Fat digestion is required for suppression of ghrelin and stimulation of peptide YY and pancreatic polypeptide secretion by intraduodenal lipid. Am J Physiol Endocrinol Metab, 2005. 289(6): p. E948-53.

14. Beglinger, C. and L. Degen, Gastrointestinal satiety signals in humans--physiologic roles for GLP-1 and PYY? Physiol Behav, 2006. 89(4): p. 460-4.

15. Cherbut, C., et al., Short-chain fatty acids modify colonic motility through nerves and polypeptide YY release in the rat. Am J Physiol, 1998. 275(6 Pt 1): p. G1415-22.

16. Feltrin, K.L., et al., Effect of fatty acid chain length on suppression of ghrelin and stimulation of PYY, GLP-2 and PP secretion in healthy men. Peptides, 2006. 27(7): p. 1638-43.

17. Jonkers, I.J., et al., Effects of very long chain versus long chain triglycerides on gastrointestinal motility and hormone release in humans. Dig Dis Sci, 2000. 45(9): p. 1719-26.

18. Feltrin, K.L., et al., Effects of lauric acid on upper gut motility, plasma cholecystokinin and peptide YY, and energy intake are load, but not concentration, dependent in humans. J Physiol, 2007. $581(\mathrm{P}+2)$ : p. 767-77.

19. Feltrin, K.L., et al., Comparative effects of intraduodenal infusions of lauric and oleic acids on antropyloroduodenal motility, plasma cholecystokinin and peptide $Y Y$, appetite, and energy intake in healthy men. Am J Clin Nutr, 2008. 87(5): p. 1181-7.

20. Hamer, H.M., et al., Review article: the role of butyrate on colonic function. Aliment Pharmacol Ther, 2007.

21. Karaki, S.I., et al., Short-chain fatty acid receptor, GPR43, is expressed by enteroendocrine cells and mucosal mast cells in rat intestine. Cell Tissue Res, 2006: p. 1-8.

22. Deavall, D.G., et al., Control of CCK gene transcription by PACAP in STC-1 cells. Am J Physiol Gastrointest Liver Physiol, 2000. 279(3): p. G605-12.

23. Tanaka, T., et al., Free fatty acids induce cholecystokinin secretion through GPR 120. Naunyn Schmiedebergs Arch Pharmacol, 2008. 377(4-6): p. 523-7.

24. Zhou, J., et al., Peptide YY and proglucagon mRNA expression patterns and regulation in the gut. Obesity (Silver Spring), 2006. 14(4): p. 683-9. 


\section{ChApter 4}

\section{DIRECT INDUCTION OF CCK AND GLP-1 RELEASE FROM MURINE ENDOCRINE CELLS BY INTACT PROTEINS}

MAARTJE C.P. GERAEDTS, FREdDY J. Troost, MARC A.J.G. Fisher, LUPPO EDENS, WIM H.M. SARIS

SubmitTEd to Molecular Nutrition AND FoOd SCIENCE 


\section{ABSTRACT}

Consumption of high-protein diets cause elevated levels of CCK and GLP-1. Although unknown, this might be due to protein breakdown by various proteases that originate from the gastrointestinal tract. This study investigated which dietary proteins, hydrolysates, or synthetic-peptides are most potent to affect secretion of CCK and GLP-1 in STC-1 cells known for satiety hormone release. Addition of intact proteins to STC-1 cells exerted strong effects on secretion of satiety hormones. Casein, whey, and pea showed strongest effects on CCK release, whereas casein, codfish, egg, and wheat showed most pronounced effects on GLP-1 release. Egg-hydrolysate stimulated release of CCK and GLP-1, whereas all other tested hydrolysates and synthetic-peptides showed no significant effects on hormone release. Addition of a combination of trypsin and casein-hydrolysate, codfish, egg, egg-hydrolysate, sodium-casein, wheat-hydrolysate, or wheat resulted in additional stimulation of CCK release, compared to only the protein. Addition of a combination of DPP-IV and egg-hydrolysate, ovomucoid, or sodium-casein decreased GLP-1 levels. This study showed that specific intact, or partially digested proteins, in contrast to protein-hydrolysates and synthetic-peptides, stimulated hormone release. We conclude that intact proteins exert strong effects on satiety hormone release, and may therefore provide potent dietary supplements for prevention or treatment of obesity. 


\section{INTRODUCTION}

Food ingestion exerts a transient suppressive effect on appetite and further food intake. Among all properties of food, total energy content and the macronutrient composition (e.g. fat, carbohydrate or protein) appear to be the major determinants of such satiety related subjective feelings [1]. A strong body of evidence indicates that the three macronutrients differ in extent to which they suppress hunger and energy intake. Proteins have been shown to be more satiating than carbohydrates, which in turn are more satiating than fats [1-3]. Findings that some specific peptide structures derived from parent food proteins are biologically active have stimulated the search for bioactive peptides that may lead to the development of functional foods, targeting to control food intake and thus, body weight [3-5].

Proteins and peptides have the capacity to affect food intake and appetite in several species, including humans $[2,4,6,7]$. Many factors are known to play a role in this satiating effect, e.g. luminal proteins or luminal hydrolysates have been found to increase the secretion of satiety inducing gut hormones such as glucagon-like peptide 1 (GLP-1) [8] and cholecystokinin (CCK) [9, 10]. In humans, it is believed that digestion of protein is required to stimulate CCK release in plasma [1 1, 12]. After ingestion, proteins are in part hydrolyzed by pepsin in the stomach, and luminal digestion is completed in the small intestine by a number of pancreatic proteases, of which trypsin is the most important. The resulting peptides are able to stimulate the release of CCK and GLP-1 by the intestinal enterocytes.

Secretion of CCK in the in vivo situation is under negative feedback regulation by proteases present in pancreatic secretion. Active proteases in the intestinal lumen inhibit CCK secretion. Release of CCK is stimulated by a luminal CCK releasing factor (LCRF), which is secreted from enteroendocrine cells within the Gl-tract, and binds to receptors on the secreting cells of the gut. In rats, it was shown that under basal conditions, the LCRF is broken down by trypsin and no CCK is secreted. Inactivation of intestinal proteases or binding of proteases by substrates such as proteins, results in stimulation of CCK secretion [13, 14]. GLP-1 stimulates glucosedependent insulin secretion and insulin biosynthesis, inhibits glucagon secretion and gastric emptying rates, and inhibits food intake [15]. GLP-1 is released by endocrine cells which are distributed throughout the small and large intestine [16]. After an initial nutrient-stimulated rise in circulating levels of GLP-1, the levels fall rapidly, largely due to renal clearance and the N-terminal degradation of the peptide by dipeptidyl peptidase IV (DPP IV). Mclntosh et al. observed with oral treatment of a DPP IV inhibitor over a 12-week period in DM2 rats a body weight decrease of 12.5\%. Inhibitor treated diabetic animals showed a marked improvement in glucose tolerance and increased insulin secretion [17]. However, the effects of DPP IV on protein digestion and the release of satiety hormones are still unknown. 
The nature of the protein provided as a factor affecting short-term food intake response has received relatively little investigation and the results obtained are diverse. For example, in STC-1 cells it was shown that soy, potato, and casein protein hydrolysates directly stimulated CCK release, whereas whey and pea protein hydrolysates were inactive in stimulating CCK release [18]. However, in rats food intake suppression in the hour after feeding is larger with whey compared to eggalbumin or soy protein [19], and in a human study it was shown that pea protein hydrolysates had the strongest effects on satiety [6]. This effect on food intake may be due to specific physiological activities in the gut based on specific peptides which comes available after appropriate digestion [20].

Overall, the data suggest that dietary compounds, in particular proteins, stimulate hormone release from enteroendocrine cells, that contribute to the termination of the meal. Therefore, identification of either specific proteins, protein hydrolysates or even specific peptides with optimized satiety hormone releasing properties is an interesting target for the development of functional food products for weight management purposes.

The aim of this study was to investigate the effects of various intact dietary proteins, protein hydrolysates, and specific synthetic peptides on the secretion of the satiety hormones CCK and GLP-1. To that end the STC-1 cell line was incubated with these components. Cell line STC-1, derived from an intestinal tumor arising in double transgenic mice [21], is known to secrete CCK and GLP-1, and was shown to be sensitive to protein exposure [18]. The proteins, protein hydrolysates, and synthetic peptides applied were selected based on their potential ability to stimulate the release of satiety hormones. In addition, experiments were executed where the intestinal serine proteases trypsin and DPP-IV were added in combination with proteins, to estimate the effect of these hydrolyzed proteins on the CCK and GLP-1 levels.

\section{MATERIALS AND METHODS}

\section{Proteins, hydrolysates, and synthetic peptides}

Ovomucoid and soybean were obtained from Worthington Biochemicals (Huissen, the Netherlands). Free tryptophane, egg-hydrolysate, egg protein, wheathydrolysate, wheat protein, whey protein, pea protein, casein-hydrolysate, sodiumcasein, and codfish protein were obtained from Dutch Protein Services (DPS, Tiel, The Netherlands), pea protein from Cosucura (Pisane, Cosucra, Warcoing, Belgium), pea protein from Nutralys (SM, Nutralys, France), and pea protein hydrolysate from Triballat (HP90, Triballat, France). All other pea hydrolysates, a selected number of specific peptides were provided by DSM Food Specialties (Delft, the Netherlands). 
The pea hydrolysates pea $\mathrm{B} 1$, pea $\mathrm{HB} 1$, pea $\mathrm{B} 2$, pea $\mathrm{HB} 2$, pea $\mathrm{B} 3$ and pea $\mathrm{HB} 3$ were obtained by enzymatic hydrolysis using subtilisin (EC 3.4.21.62; Protex $6 \mathrm{~L}$ from Danisco, Leiden, The Netherlands) at pH 8.0 in combination with a proline-specific endoprotease (EC 3.4.21.26; from DSM Food Specialities, Delft, The Netherlands) at $\mathrm{pH}$ 6.0. With the pea HB1, the pea HB2, and the pea HB3 samples, a heat treatment was applied to inactivate the proteases used. The hydrolysates pea B1, pea B2, and pea B3 were not heat-treated. The pea B1 and the pea HB1 samples represent the total hydrolysate, the pea B2 and pea HB2 samples represent supernatants obtained after centrifugation. The pea B3 and the pea HB3 samples represent 10 kDa permeates of the pea Bl and the pea HBI sample respectively.

The synthetic peptides used in this study (TAP, peptide VPI, opioid BCM-7 and peptide GRGRGRG) were selected for their possible potential to induce satiety. The peptide TAP (sequence: APFDDDK) is the octapeptide that is cleaved from trypsinogen in the duodenum, resulting in active trypsin. Tripeptide VPI is a known DPP IV inhibitor. Tryptophan could affect the release of satiety hormones [22]. Opioid BCM-7 (sequence: YPFPGPI) is a peptide present in casein. Although its function is unknown, literature suggests that it delays $\mathrm{Gl}$ transit times, and stimulates mucus production [23]. Peptide GRGRGRG has been shown to stimulate CCK and GLP-1 release [24].

\section{Cell culture conditions}

STC-1 cells were a gift from Dr. Douglas Hanahan (University of California, San Francisco), and were maintained in Dulbecco's Modified Eagles Medium (DMEM; Invitrogen) with 10\% fetal bovine serum (FBS; Invitrogen), 2 mM L-glutamine, 100 units $/ \mathrm{ml}$ penicillin, and $100 \mu \mathrm{g} / \mathrm{ml}$ streptomycin as additional supplements, at $37^{\circ} \mathrm{C}$ in $5 \% \mathrm{CO}_{2}$ /air humidity. All studies were performed on cells with passage number 31 .

\section{Cell secretion studies}

Two sets of secretion assays were performed. The first set was performed to study the effects of dietary proteins, hydrolysates, and peptides on the secretion of several satiety hormones. Briefly, three days before the experiment, STC-1 cells were seeded in 24 -well plates ( $1.0 \times 10^{5}$ cells/well). On the day of the experiment, cells were washed twice with PBS, followed by addition of protein, hydrolysates, and peptides $\left(1 \mathrm{mg} / \mathrm{ml}\right.$ ) to each well. After an incubation period of 2 hours at $37^{\circ} \mathrm{C}$ $(n=3)$, the supernatant was collected for the measurement of CCK, total GLP-1, and LDH.

In the second set, the effects of the dietary proteins, protein hydrolysates, and synthetic peptides combined with intestinal serine proteases were determined on secretion of satiety hormones. Briefly, on the day of experiment, cells were incubated with a mixture of protein $(1 \mathrm{mg} / \mathrm{ml}$ ) with human trypsin (human pancreas, EC: 3.4.21.4, Athens Research; Georgia, USA) or human DPP IV (Athens Research; Georgia, USA), for 30 min at $37^{\circ} \mathrm{C}(n=3)$. CCK and GLP-1 levels were determined in the supernatant. 


\section{Determination of CCK and GLP-1 levels in supernatant}

CCK levels were determined using the RIA from Euria-CCK (Euro-Diagnostica AB, Malmö, Sweden), with a detection limit of $0.3 \mathrm{pmol} / \mathrm{L}$. The intra-assay variation ranges from 2.0 to $5.5 \%$ and the inter-assay variation from 4,1 to $13,7 \%$. Crossreaction with gastrin is $0.5 \%$. GLP-1 levels were determined using the RIA from Linco Research, Missouri, USA. The detection limit of this kit was 3 to $333 \mathrm{pM}$. The intra-assay variation ranges from 10 to $23 \%$ and the inter-assay variation from 22 to $38 \%$. There is no cross-reaction with GLP-2 and glucagon $(0.01 \%$ and $0.2 \%$, respectively).

\section{Determination of lactate dehydrogenase (LDH) levels}

To check for lysis of the STC-1 cells due to presence of active proteases in the tested protein hydrolysates, LDH levels were determined. To measure LDH, the LDH detection kit from Clontech (Clontech laboratories, California, USA) was used. Briefly, the cell-free culture supernatant was collected and incubated with the reaction mixture from the kit. LDH activity was determined by a colorimetric assay: in the first step, $\mathrm{NAD}^{+}$was reduced to $\mathrm{NAHDH} / \mathrm{H}^{+}$by the $\mathrm{LDH}$-catalyzed conversion of lactate to pyruvate. In the second step, a catalyst included in the reaction mixture (diaphorase) transfers $\mathrm{H} / \mathrm{H}^{+}$from $\mathrm{NADH} / \mathrm{H}^{+}$to the tetrazolium salt INT, which is reduced to a formazan dye. The amount of dye produced is proportional to the number of lysed cells [25].

\section{Statistical analysis}

The descriptive and statistical analyses were performed with SPSS, version 11.0. The means of the variables are presented with their standard deviation (mean $\pm S D$ ). Comparison of means of the secretion studies was done using the one-way ANOVA, with the Bonferroni test as post-hoc test. A P-value of less than 0.05 was considered statistically significant.

\section{RESULTS}

Effects of intact proteins, protein hydrolysates, and specific synthetic peptides on CCK and GLP-1 release.

A negative control (only Hanks Buffered Salt Solution (HBSS) buffer) was tested with every assay. Addition of this negative control to STC-1 cells resulted in CCK levels of $25.6 \pm 1.2 \mathrm{pM}$ and GLP-1 levels of $849.3 \pm 64 \mathrm{pM}$. To correct for the small differences in the release of the satiety hormones, the negative control was subtracted from each assay. As shown in figure 1, the addition of various intact proteins to STC-1 cells resulted in increased CCK levels in the supernatant. Intact casein, pea and wheat protein were able to significantly elevate the release of CCK into the supernatant (45.9 pM 4.8, 46.1 pM 4.0, 53.8 pM \pm 7.3; respectively) compared to the negative control (only Hanks Buffered Salt Solution (HBSS) buffer). Also the addition of protein hydrolysates to STC-1 cells (figure 1B) resulted in significantly elevated CCK levels. 
Addition of egg hydrolysate and the pea hydrolysates pea B1, and pea B2 exerted the most pronounced effects $(45,9 \mathrm{pM} \pm 6.2,107,5 \mathrm{pM} \pm 7.5,108.8 \mathrm{pM} \pm 8.1,130.1$ $\mathrm{pM} \pm 3.2$, respectively). None of the selected synthetic peptide sequences or free tryptophane, all potentially of interest in relation to satiety, were able to elevate CCK levels compared to the negative control (figure 1C).
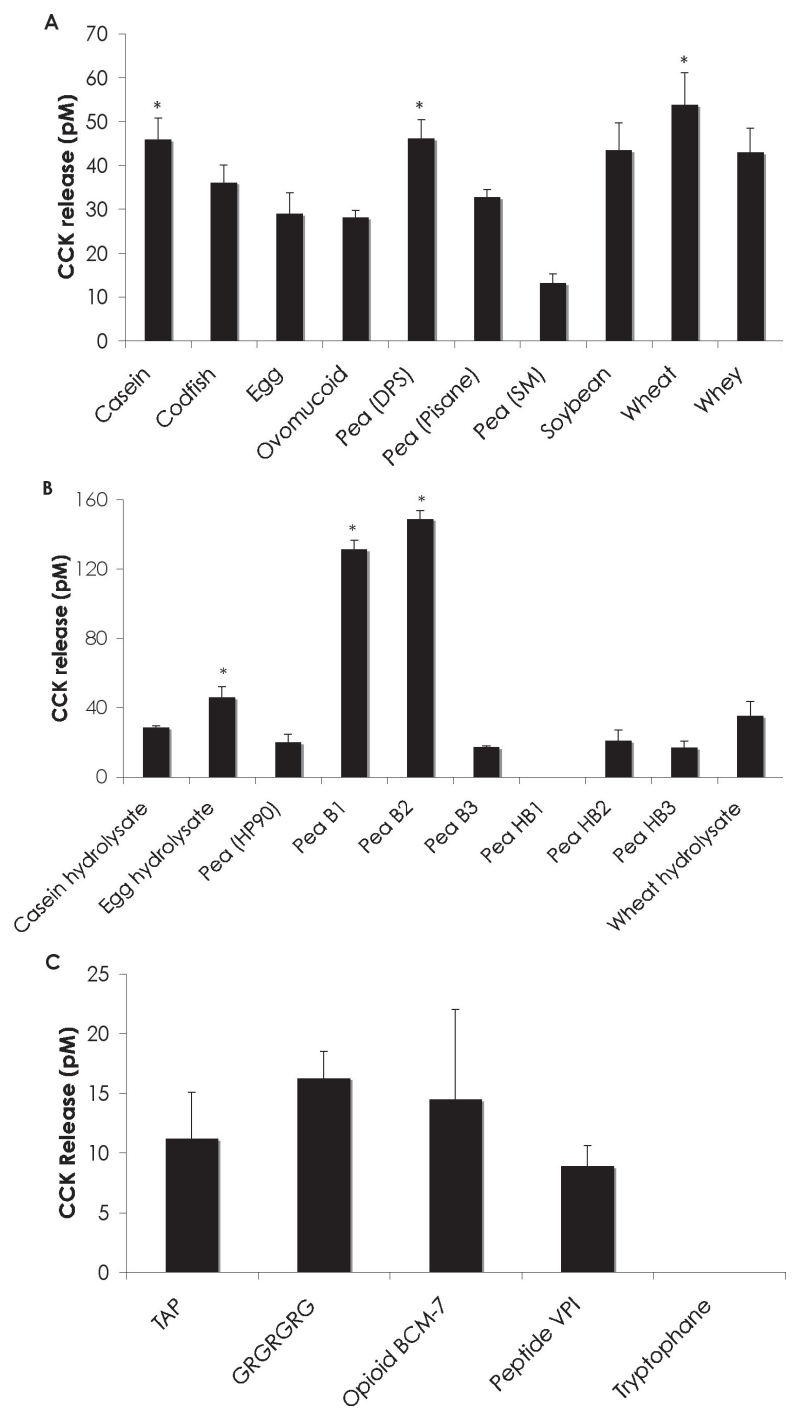

Figure 1. Effects of dietary proteins, hydrolysates, and peptides on CCK release. The levels of CCK were measured in the supernatant of STC-1 cells after being exposed to proteins for $2 \mathrm{~h}$. Results are expressed as mean $\pm S D$ of 4 individual experiments. Figure A shows that addition of intact proteins to the cells. Casein, pea (DPS), and wheat where able to increase the release of CCK from the STC-1 cells when compared to the negative control. Figure B shows that addition of egg hydrolysate, pea B1, and Pea B2 increase the release CCK, where as all tested peptides (figure $C$ ) are not able to elevate CCK release compared to the negative control. * $P<0.05$ when compared to negative control 
Figure 2 shows the effects on GLP-1 release by STC-1 cells. Addition of intact casein, codfish, egg, pea, whey and wheat protein significantly increased the release of GLP-1 into the supernatant (4255.9 pM $\pm 3587,4889.4 \mathrm{pM} \pm 4403,16662.3 \mathrm{pM} \pm 12239$, $7488.3 \mathrm{pM} \pm 5023,7847.3 \mathrm{pM} \pm 4856,7765.4 \mathrm{pM} \pm 2371$; respectively; see figure $2 \mathrm{~A}$ ). Addition of protein hydrolysates to STC-1 cells (figure 2B) resulted in significantly elevated GLP-1 levels with egg hydrolysate and pea B2 hydrolysates (15670.2 $\mathrm{pM} \pm 4965$ and $13891.8 \mathrm{pM} \pm 2106$, respectively). Neither the selected synthetic peptide sequences nor the free tryptophane were not able to elevate GLP-1 levels compared to the negative control (data not shown).

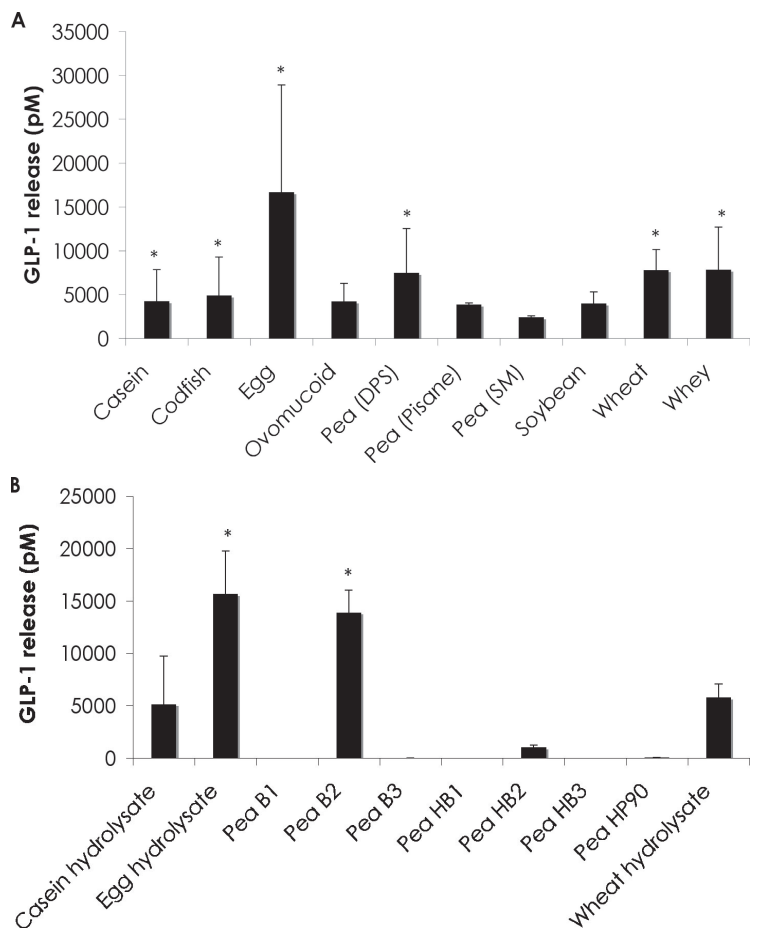

Figure 2. Effects of dietary proteins, hydrolysates, and peptides on GLP-1 release. The levels of GLP-1 were measured in the supernatant of STC- 1 cells after being exposed to proteins for $2 h$. Results are expressed as mean $\pm S D$ of 4 individual experiments. Figure A shows that addition of intact proteins to the cells. Casein, egg, pea, whey and wheat where able to increase the release of GLP-1 from the STC-1 cells when compared to the negative control. Figure B shows that addition of egg hydrolysate and Pea B2 increase the release GLP-1. * $P<0.05$ when compared to negative control

\section{LDH release from STC-1 cells}

To check for hormone release caused by lysis of the STC-1 cells, LDH release was measured. Pea hydrolysates provided by DSM Food Specialities were prepared using two different proteases (see Materials \& Methods). Among these, the pea "HB" samples were heated to inactivate these proteases but the pea "B" samples 
were not. By measuring lactate dehydrogenase (LDH), cell lysis can be determined. As is shown in figure 3 , addition of intact pea protein and pea HB2 cause increased levels of $\mathrm{LDH}(19.0 \mathrm{IU} / \mathrm{L} \pm 0.6$ and $27.2 \mathrm{IU} / \mathrm{L} \pm 3.2$, respectively) when compared to the negative control $(8.3 \mathrm{IU} / \mathrm{L} \pm 1.5)$, but the cell layer was still intact after the incubation period. After addition of pea B2 or a relevant concentration of the subtilisin protease used during pea hydrolysis, the cell layer was visibly broken down after the incubation period, and LDH levels $193.3 \mathrm{IU} / \mathrm{L} \pm 0.9$ and $140.7 \mathrm{IU} / \mathrm{L} \pm 2.2$, respectively) were significantly increased when compared to the negative control, but also when compared to intact pea and pea HB2.

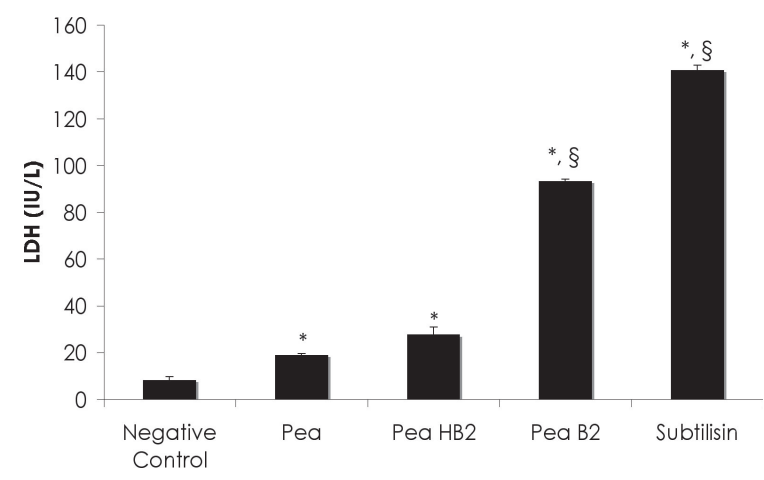

Figure 3. $L D H$ levels after 30 minutes of exposure to pea, pea B2, pea HB2, and subtilisin. The levels of $L D H$ were measured after an incubation period of 30 minutes with pea, pea B2, pea HB2, or subtilisin. The results are expressed as mean \pm SEM of three individual experiments. Addition of these substances to the STC-1 cells resulted in a significant increase in LDH levels when compared with the negative control. Addition of pea B2 and subtilisin where also significantly increased when compared to pea protein.

* $P<0.05$ when compared to negative control

$\S P<0.05$ when compared to pea protein

Effects of trypsin and DPP IV in combination with intact proteins, protein hydrolysates, and specific synthetic peptides on CCK secretion

The effects of the tested dietary proteins in combination with trypsin and DPP IV on CCK release by STC-1 cells are presented in table 1. Decreased levels of CCK were observed after addition of active trypsin combined with ovomucoid, all pea products (with the exception of pea HB1), the TAP peptide and peptide GRGRGRG, the opioid BCM-7 peptide, or tripeptide VPI. Increased levels of CCK release were observed after addition of active trypsin in combination with either casein, casein hydrolysate, codfish, egg, egg hydrolysate, wheat hydrolysate, or whey protein. All other proteins in combination with trypsin did not affect CCK release differently compared to exposure to only protein. Addition of DPP IV resulted in a decreased CCK release after addition of DPP IV and casein, ovomucoid, pea (DPS), egg hydrolysate, and tripeptide VPI. Increased levels of CCK were observed after 
combining DPP IV with codfish, egg, casein hydrolysate, wheat hydrolysate, TAP, and GRGRGRG. All other proteins in combination with DPP IV did not affect CCK release.

\section{Effects of trypsin and DPP IV in combination with intact proteins, protein hydrolysates, and specific synthetic peptides on GLP-1 secretion}

Both with the addition of trypsin and DPP IV there was no visible indication of lysis in the cell layer, so all hormone levels secreted into the supernatant were due to addition of the proteins. The effects of the tested dietary proteins in combination trypsin and DPP IV on GLP-1 release by STC-1 cells are presented in table 2. Decreased levels of GLP-1 were also observed after addition of trypsin with ovomucoid, intact pea (DPS), pea (Pisane), intact pea (SM), egg hydrolysate, pea hydrolysate HP-90), pea $\mathrm{HB} 2$, pea HB3, and wheat hydrolysate. All other proteins in combination with trypsin did not affect GLP-1 release. Addition of DPP IV resulted in a decreased release of GLP-1 after addition of DPP IV with ovomucoid, pea (DPS) egg hydrolysate, and peptide VPI. Increased levels of GLP-1 were observed after addition of DPP IV with TAP to the STC-1 cells. All other proteins in combination with DPP IV did not affect GLP-1 release.

\section{DISCUSSION}

The present study was designed to identify potent appetite suppressing dietary proteins or protein derivates by determining the modulating effects on intestinal CCK and GLP-1 release in a murine intestinal cell line. We are the first to demonstrate that not only protein hydrolysates [18], but also intact proteins are able to directly modulate the release of the satiety hormones CCK and GLP-1. We also showed that in some cases the hydrolysates do not affect hormone release, whereas the intact protein does stimulate hormone release. Furthermore, we showed for the first time to our knowledge, that proteases such as trypsin, DPP-IV, and subtilisine modulate the effects of proteins on satiety hormone release.

Some previous studies in rats have shown that intact proteins, but not amino acids or carbohydrates, stimulates CCK release [26]. The present study also demonstrated that intact proteins were able to stimulate the release of CCK and GLP-1. Under physiological circumstances, little intact protein will enter the small intestine. To use intact proteins as a possible therapeutic option for weight management, gastric degradation has to be prevented. There are some studies describing coatings for enteric delivery, such as $\mathrm{pH}$-triggered coatings, pressure-sensitive coatings, or timerelease coatings [27-31]. For duodenal delivery of relatively large amount of protein, a $\mathrm{pH}$-sensitive coating is suitable. 


\begin{tabular}{|c|c|c|c|}
\hline & \multicolumn{3}{|c|}{ CCK release $(\mathrm{pM})$} \\
\hline & Only protein & Protein with trypsin & Protein with DPP-IV \\
\hline Casein & $21.2 \pm 3.1$ & $25.1 \pm 2.4 *$ & $14.6 \pm 1.0^{*}$ \\
\hline Codfish & $24.9 \pm 1.2$ & $45.3 \pm 3.1^{*}$ & $32.0 \pm 1.8 *$ \\
\hline Egg & $16.3 \pm 3.2$ & $30.7 \pm 3.1 *$ & $22.5 \pm 7.2$ \\
\hline Ovomucoid & $34.2 \pm 2.1$ & $23.5 \pm 1.0 *$ & $16.7 \pm 1.3^{*}$ \\
\hline Pea (DPS) & $57.2 \pm 3.8$ & $30.6 \pm 6.6 *$ & $18.8 \pm 3.1^{*}$ \\
\hline Pea (Pisane) & $57.4 \pm 2.3$ & $16.7 \pm 1.8 *$ & $46.0 \pm 1.5$ \\
\hline Pea (SM) & $39.3 \pm 2.6$ & $21.5 \pm 3.1 *$ & $41.2 \pm 1.1$ \\
\hline Soybean & $13.1 \pm 4.9$ & $18.4 \pm 5.0$ & $16.7 \pm 3.1$ \\
\hline Wheat & $27.5 \pm 3.1$ & $30.6 \pm 2.3$ & $27.4 \pm 8.6$ \\
\hline Whey & $11.9 \pm 1.9$ & $27.5 \pm 6.2 *$ & $13.3 \pm 1.5$ \\
\hline Casein hydrolysate & $15.7 \pm 2.7$ & $32.1 \pm 5.4^{*}$ & $24.7 \pm 3.9 *$ \\
\hline Egg hydrolysate & $26.1 \pm 6.9$ & $40.4 \pm 3.1 *$ & $15.2 \pm 4.3^{*}$ \\
\hline Pea (HP90) & $42.3 \pm 3.4$ & $25.9 \pm 1.6 *$ & $47.8 \pm 5.2$ \\
\hline Pea Bl & $131.4 \pm 4.1$ & $122.5 \pm 3.8^{*}$ & $127.8 \pm 4.8$ \\
\hline Pea B2 & $148.7 \pm 7.2$ & $135.4 \pm 6.8^{*}$ & $132.1 \pm 8.0 *$ \\
\hline Pea B3 & $30.8 \pm 3.6$ & $20.5 \pm 1.9 *$ & $26.9 \pm 5.7$ \\
\hline Pea HBl & $16.8 \pm 1.1$ & $13.8 \pm 1.0$ & $16.2 \pm 1.2$ \\
\hline Pea HB2 & $32.6 \pm 2.0$ & $24.5 \pm 1.6 *$ & $30.9 \pm 2.1$ \\
\hline Pea HB3 & $32.9 \pm 3.3$ & $23.5 \pm 3.8 *$ & $30.1 \pm 4.0$ \\
\hline Wheat hydrolysate & $18.0 \pm 2.5$ & $31.8 \pm 3.1 *$ & $26.0 \pm 1.7^{*}$ \\
\hline TAP & $35.7 \pm 1.9$ & $18.7 \pm 1.6^{*}$ & $74.3 \pm 2.6^{*}$ \\
\hline GRGRGRG & $35.0 \pm 2.3$ & $24.8 \pm 2.6^{*}$ & $53.5 \pm 2.2 *$ \\
\hline Opioid BCM-7 & $40.8 \pm 5.3$ & $25.3 \pm 4.2 *$ & $49.3 \pm 7.8$ \\
\hline Peptide VPI & $34.0 \pm 3.4$ & $17.7 \pm 2.0 *$ & $75.2 \pm 2.2 *$ \\
\hline Tryptophan & $24.9 \pm 4.1$ & $18.9 \pm 1.0$ & $25.1 \pm 4.3$ \\
\hline
\end{tabular}

Table 1. CCK release after a 30-minute incubation period with proteins, hydrolysates, and peptides in combination with trypsin or DPP-IV. Egg hydrolysate, ovomucoid, pea protein or sodium casein, a decrease of CCK was also observed. Addition of DPP IV with casein hydrolysate, codfish, wheat hydrolysate, TAP, GRGRGRG, or peptide VPI resulted in an increase of CCK release was observed. Addition of DPP IV with other tested proteins showed no effect.

* : Significantly different compared to addition of only protein 


\begin{tabular}{|c|c|c|c|}
\hline & \multicolumn{3}{|c|}{ GLP-1 release (pM) } \\
\hline & Only protein & Protein with trypsin & Protein with DPP-IV \\
\hline Casein & $1664.7 \pm 745$ & $576.1 \pm 249$ & $1157.9 \pm 372$ \\
\hline Codfish & $1820.7 \pm 694$ & $548.6 \pm 322$ & $1924.6 \pm 347$ \\
\hline Egg & $1152.0 \pm 972$ & $461.3 \pm 251$ & $1201.2 \pm 487$ \\
\hline Ovomucoid & $929.5 \pm 112$ & $381.1 \pm 39 *$ & $567.0 \pm 56 *$ \\
\hline Pea (DPS) & $3149.2 \pm 572$ & $607.9 \pm 261 *$ & $1002.0 \pm 286^{*}$ \\
\hline Pea (Pisane) & $1955.8 \pm 0.9$ & $33.5 \pm 1 *$ & $1680.8 \pm 241$ \\
\hline Pea (SM) & $1572.8 \pm 0.7$ & $77.5 \pm 14^{*}$ & $1258.2 \pm 236$ \\
\hline Soybean & $839.7 \pm 343$ & $1427.0 \pm 160$ & $1253.2 \pm 171$ \\
\hline Wheat & $2250.5 \pm 742$ & $1105.4 \pm 457$ & $1869.3 \pm 371$ \\
\hline Whey & $1722.9 \pm 651$ & $694.7 \pm 304$ & $843.7 \pm 326$ \\
\hline Casein hydrolysate & $957.5 \pm 487$ & $610.7 \pm 333$ & $695.4 \pm 243$ \\
\hline Egg hydrolysate & $1837.7 \pm 414$ & $642.2 \pm 251 *$ & $583.8 \pm 207 *$ \\
\hline Pea (HP90) & $115.6 \pm 8$ & $377.8 \pm 89 *$ & $72.2 \pm 9$ \\
\hline Pea B1 & $89.5 \pm 20$ & $113.0 \pm 10$ & $79.6 \pm 4$ \\
\hline Pea B2 & $11392.8 \pm 1971$ & $14631.8 \pm 1671$ & $17118.4 \pm 1019$ \\
\hline Pea B3 & $72.2 \pm 6$ & $143.4 \pm 61$ & $116.1 \pm 31$ \\
\hline Pea HBl & N.D. & N.D. & N.D. \\
\hline Pea HB2 & $555.1 \pm 26$ & $264.0 \pm 7 *$ & $561.2 \pm 23$ \\
\hline Pea HB3 & $157.1 \pm 61$ & $72.2 \pm 6 *$ & $221.0 \pm 7$ \\
\hline Wheat hydrolysate & $1129.7 \pm 556$ & $332.7 \pm 172 *$ & $924.7 \pm 278$ \\
\hline TAP & $30.6 \pm 12$ & $35.1 \pm 16$ & $90.5 \pm 12 *$ \\
\hline GRGRGRG & $54.4 \pm 3$ & $48.2 \pm 9$ & $74.0 \pm 16$ \\
\hline Opioid BCM-7 & $35.7 \pm 5$ & $74.6 \pm 32$ & $47.5 \pm 5$ \\
\hline Peptide VPI & $68.7 \pm 21$ & $21.2 \pm 5$ & $116.4 \pm 5^{*}$ \\
\hline Tryptophan & $58.2 \pm 4$ & $39.5 \pm 11$ & $70.4 \pm 24$ \\
\hline
\end{tabular}

Table 2. GLP-1 release after a 30-minute incubation period with proteins, hydrolysates, and peptides in combination with trypsin or DPP-IV. The levels of GLP-1 were measured in the supernatant of STC-1 cells after being exposed to protein with trypsin or protein with DPP IV for 30 minutes. Results are expressed as $\mathrm{pmol} / \mathrm{L}$ and represent mean \pm SD of 4 individual experiments. Addition of trypsin to ovomucoid, intact pea protein, pea hydrolysates, egg hydrolysate, or wheat hydrolysates resulted in decreased levels of GLP-1. All other proteins, hydrolysates and peptides where not affected Addition of only DPP IV decreased GLP1 release. Combining DPP IV with ovomucoid, pea protein from DPS, or egg hydrolysate, a decrease of GLP-1 was also observed. Addition of DPP IV with pea 11B, TAP, or peptide VPI resulted in an increase of GLP-1 release was observed. Addition of DPP IV with other tested proteins showed no effect. N.D.: Not Detectable

*: Significantly different compared to addition of only protein 
Human studies have shown that plasma levels of CCK and GLP-1 differ after intake of proteins from different origins $[3,6,26,32,33]$. These data suggest that amino acids and/or specific amino acid sequences are of importance in stimulating the release of CCK and GLP-1. It was previously shown that protein hydrolysates are able to stimulate CCK and GLP-1 release by the STC-1 cells [18, 34]. Cordier-Bussat et al showed that addition of protein hydrolysates from meat, casein and soybean to STC-1 cells increased CCK and GLP-1 release, whereas a mixture of free amino acids or undigested proteins were weak stimulants of CCK and GLP-1 release $[4,34$, 35].

After ingestion, the proteins are hydrolyzed by pepsin in the stomach, and by, among others, trypsin in the small intestine. Some of the hydrolysates used in this study were prepared using the serine proteases subtilisin and a proline-specific endoprotease. However, after ingestion, these hydrolysates will still be cleaved by other serine proteases such as trypsin and DPP IV. We found that the addition of intact casein, intact codfish, intact egg, intact pea (DPS), intact wheat, egg hydrolysate, pea B1, and pea B2 showed strongest effects on the release of CCK and GLP-1. However, after addition of trypsin or DPP IV, most products are less potent to stimulate the release of CCK and GLP-1. The breakdown of the proteins by trypsin and DPPIV seems to influence the ability of the proteins to stimulate hormone release. This might be due to the enzymatic effects of the proteases on the proteins and hydrolysates, which might cleave the protein in its "inducing" site, thereby loosing its effects to induce an increase in hormone release. Another possibility is that the cells used in this study were not able to detect the small peptides created upon the second enzymatic digestion. Addition of the synthetic peptides that were potentially of interest in relation to satiety also did not show any effects on release of CCK and GLP-1 by the STC-1 cells.

The STC-1 cell line provides a good screening model to study the effects of food compounds on hormone release. Many samples can be tested in a very short amount of time, and the responses of the cells seem to differentiate between specific compounds. However, there are also some drawbacks using this cell line. It originates from mice, so the effects on hormone release may not be translatable to the effects in human duodenal tissue. Also, the concentrations used for the products may be different when testing the same product in an in vivo situation. Human intervention studies must always be performed before conclusions can be drawn whether the product affects food intake and weight regulation. We also demonstrated in this study that it important to include a marker for cell lysis, in order to exclude a possible artificial increase of CCK and GLP-1 in the supernatant. In summary, we showed that most proteins were able to directly affect hormone release in the STC-1 cell line, and that in most cases, intact proteins and egg hydrolysate were more potent than the other protein hydrolysates or synthetic 
peptides. We also demonstrated that most proteins lost the ability to increase the release of CCK and GLP-1 after the addition of trypsin or DPP IV. Overall, we conclude that intact proteins, or proteins that were partially hydrolyzed by trypsin or DPP IV, such as codfish, egg, pea, and wheat exert stronger effects on satiety hormone release than the completely hydrolyzed proteins tested in this study. Hence, dietary protein supplements in which gastric degradation is prevented, i.e. by the application on an enteric coating of the proteins, may provide a novel strategy for the control of food intake and body weight. 


\section{REFERENCES}

1. Westerterp-Plantenga, M.S., et al., Dietary protein, metabolism, and body-weight regulation: dose-response effects. Int J Obes (Lond), 2006. 30 Suppl 3: p. S16-23.

2. Westerterp-Plantenga, M.S., The significance of protein in food intake and body weight regulation. Curr Opin Clin Nutr Metab Care, 2003. 6(6): p. 635-8.

3. Hall, W.L., et al., Casein and whey exert different effects on plasma amino acid profiles, gastrointestinal hormone secretion and appetite. Br J Nutr, 2003. 89(2): p. 239-48.

4. Cordier-Bussat, M., et al., Peptones stimulate both the secretion of the incretin hormone glucagon-like peptide 1 and the transcription of the proglucagon gene. Diabetes, 1998. 47(7): p. 1038-45.

5. Yoshikawa, M., et al., Bioactive peptides derived from food proteins preventing lifestyle-related diseases. Biofactors, 2000. 12(1-4): p. 143-6.

6. Diepvens, K., D. Haberer, and M. Westerterp-Plantenga, Different proteins and biopeptides differently affect satiety and anorexigenic/orexigenic hormones in healthy humans. Int J Obes (Lond), 2008. 32(3): p. 510-8.

7. Anderson, G.H., et al., Dissociation between plasma and brain amino acid profiles and short-term food intake in the rat. Am J Physiol, 1994. 266(5 Pt 2): p. R1675-86.

8. Gevrey, J.C., et al., Protein hydrolysates stimulate proglucagon gene transcription in intestinal endocrine cells via two elements related to cyclic AMP response element. Diabetologia, 2004. 47(5): p. 926-36.

9. Liddle, R.A., Cholecystokinin cells. Annu Rev Physiol, 1997. 59: p. 221-42.

10. Nemoz-Gaillard, E., et al., Regulation of cholecystokinin secretion by peptones and peptidomimetic antibiotics in STC-1 cells. Endocrinology, 1998. 139(3): p. 932-8.

11. Liddle, R.A., Regulation of cholecystokinin secretion in humans. J Gastroenterol, 2000. 35(3): p. $181-7$.

12. Thimister, P.W., et al., Role of intraduodenal proteases in plasma cholecystokinin and pancreaticobiliary responses to protein and amino acids. Gastroenterology, 1996. 110(2): p. 567 75.

13. Wang, Y., et al., Luminal CCK-releasing factor stimulates CCK release from human intestinal endocrine and STC-1 cells. Am J Physiol Gastrointest Liver Physiol, 2002. 282(1): p. G16-22.

14. Green, G.M. and R.L. Lyman, Feedback regulation of pancreatic enzyme secretion as a mechanism for trypsin inhibitor-induced hypersecretion in rats. Proc Soc Exp Biol Med, 1972. 140(1): p. 6-12.

15. Drucker, D.J., Minireview: the glucagon-like peptides. Endocrinology, 2001. 142(2): p. 521-7.

16. Meier, J.J. and M.A. Nauck, Glucagon-like peptide 1(GLP-1) in biology and pathology. Diabetes Metab Res Rev, 2005. 21 (2): p. 91-117.

17. Mclntosh, C.H., et al., Dipeptidyl peptidase IV inhibitors: how do they work as new antidiabetic agents? Regul Pept, 2005. 128(2): p. 159-65.

18. Foltz, M., et al., Protein hydrolysates induce CCK release from enteroendocrine cells and act as partial agonists of the CCK1 receptor. J Agric Food Chem, 2008. 56(3): p. 837-43.

19. Morgan, G., The role of CholecystokininA-receptors in protein hydrolysate-induced suppression of food intake in rats. Department of Nutritional Sciences. University of Toronto, Toronto, 1998: p. 143.

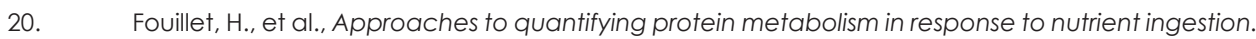
J Nutr, 2002. 132(10): p. 3208S-18S.

21. Rindi, G., et al., Development of neuroendocrine tumors in the gastrointestinal tract of transgenic mice. Heterogeneity of hormone expression. Am J Pathol, 1990. 136(6): p. 1349-63.

22. Nieuwenhuizen, A.G., et al., Acute effects of breakfasts containing alpha-lactalbumin, or gelatin with or without added tryptophan, on hunger, 'satiety' hormones and amino acid profiles. $\mathrm{Br} \mathrm{J}$ Nutr, 2008: p. 1-8. 
23. Wood, J.D. and J.J. Galligan, Function of opioids in the enteric nervous system. Neurogastroenterol Motil, 2004. 16 Suppl 2: p. 17-28.

24. Nishi, T., et al., The soybean beta-conglycinin beta 51-63 fragment suppresses appetite by stimulating cholecystokinin release in rats. J Nutr, 2003. 133(8): p. 2537-42.

25. Borra, R.C., et al., A simple method to measure cell viability in proliferation and cytotoxicity assays. Braz Oral Res, 2009. 23(3): p. 255-62.

26. Liddle, R.A., et al., Proteins but not amino acids, carbohydrates, or fats stimulate cholecystokinin secretion in the rat. Am J Physiol, 1986. 251 (2 Pt 1): p. G243-8.

27. Bodmeier, R., H.G. Chen, and O. Paeratakul, A novel approach to the oral delivery of micro- or nanoparticles. Pharm Res, 1989. 6(5): p. 413-7.

28. Dhaliwal, S., et al., Mucoadhesive microspheres for gastroretentive delivery of acyclovir: in vitro and in vivo evaluation. Aaps J, 2008. 10(2): p. 322-30.

29. Ichikawa, H. and Y. Fukumori, [Design of nanohydrogel-incorporated microcapsules for appropriate controlled-release of peptide drugs]. Yakugaku Zasshi, 2007. 127(5): p. 813-23.

30. Malik, D.K., et al., Recent advances in protein and peptide drug delivery systems. Curr Drug Deliv, 2007. 4(2): p. 141-51.

31. Mustata, G. and S.M. Dinh, Approaches to oral drug delivery for challenging molecules. Crit Rev Ther Drug Carrier Syst, 2006. 23(2): p. $111-35$

32. Bowen, J., M. Noakes, and P.M. Clifton, Appetite regulatory hormone responses to various dietary proteins differ by body mass index status despite similar reductions in ad libitum energy intake. $J$ Clin Endocrinol Metab, 2006. 91 (8): p. 2913-9.

33. Bowen, J., M. Noakes, and P.M. Clifton, Appetite hormones and energy intake in obese men after consumption of fructose, glucose and whey protein beverages. Int J Obes (Lond), 2007. 31 (11): p. 1696-703.

34. Cordier-Bussat, M., et al., Peptones stimulate cholecystokinin secretion and gene transcription in the intestinal cell line STC-1. Endocrinology, 1997. 138(3): p. 1137-44.

35. Bernard, C., et al., Peptones stimulate intestinal cholecystokinin gene transcription via cyclic adenosine monophosphate response element-binding factors. Endocrinology, 2001. 142(2): p. $721-9$ 


\section{ChAPTER 5}

THE RELEASE OF SATIETY HORMONES IN RESPONSE TO SPECIFIC DIETARY PROTEINS IS DIFFERENT BETWEEN HUMAN AND MURINE SMALL INTESTINAL MUCOSA

MAARTJE C.P. GERAEDTS, FREDDY J. TROOST, RIK TINNEMANS, JOHAN D. SÖDERHOLM, ROBERT-JAN BRUMMER, WIM H.M. SARIS

ANNALS OF NUTRITION AND METABOLISM 2010;56(4):308-13 


\section{ABSTRACT}

High protein diets are the most effective to stimulate CCK and GLP-1 release, however, which proteins are the most potent is not known. Here, the effects of specific dietary proteins on intestinal CCK and GLP-1 release were examined.

Duodenal biopsies of ten healthy male subjects and ten male rats were taken and placed in an Ussing Chamber system. The biopsies were exposed on the luminal side to buffer, egg-protein, codfish-protein, ovomucoid, pea-protein, and wheatprotein, respectively. After an exposure time of 2 hours, samples were taken from the serosal side.

Pea-protein and wheat-protein increased CCK and GLP-1 release in human duodenal tissue, while codfish-protein only increased CCK release. No elevated levels of CCK and GLP-1 were found after exposure of rat tissue to different proteins. Pea and wheat-protein are the most potent stimulators of CCK and GLP-1 release in human duodenal tissue, and may therefore be good dietary additives in weight management. 


\section{INTRODUCTION}

The macronutrient composition of the diet plays an important role in the release of satiety hormones. Recent literature describes the positive role of dietary protein in reducing food intake by improving satiety sensations [1, 2]. It seems that protein has the highest satiating effect when compared to other macronutrients in humans and rats [3,4], although the nature of the protein can influence its satiating effects. However, the differences in satiating properties of individual proteins are currently unknown.

Food ingestion triggers a number of stimuli, such as the release of the gastrointestinal hormones cholecystokinin (CCK) and glucagon-like peptide 1 (GLP-1) within the gastrointestinal tract that modulate appetite-sensations. CCK is produced by l-cells in the duodenal and jejunal mucosa, and secreted in response to luminal concentrations of nutrients, especially lipids and proteins [5]. GLP-1 is produced primarily by the L-cells in the distal small intestine and colon. Ingested nutrients stimulate CCK and GLP-1 secretion by indirect, duodenally activated, neurohumoral mechanisms, as well as by direct luminal exposure within the distal intestine [6, 7]. We recently showed in an in vitro model, applying murine STC-1 cells that intact dietary proteins are able to induce a stronger increase in CCK and GLP-1 release compared to their hydrolysates (unpublished data), and also that the source of the protein is an important determinant of the impact on satiety hormone release. Consequently, the present study focused on the effects of intact proteins on hormone release from human small intestinal tissue, using Ussing chamber technology. Because intact proteins will quickly be degraded into di- and tri peptides in the gut, only the duodenum is exposed to intact dietary proteins. Therefore, in the present study, human duodenal tissue samples were studied.

The Ussing Chamber technique is used widely for the characterization of gastrointestinal permeability, ion transport, and drug delivery in animal models [810] and human studies [1 1, 12]. However, to our knowledge, release of intestinal hormones has not been investigated before using this technology.

The aim of this study was to identify the effects of selected dietary proteins on secretion of the hormones CCK and GLP-1 by human small intestinal mucosa. We also tested the effects of these proteins on rat duodenal tissue to determine whether rat tissue provides an alternative for human duodenal tissue in the future for determining the effects of proteins on release of satiety hormones. 


\section{SUBJECTS AND METHODS}

\section{Human duodenal biopsy specimens and ethics}

Ten healthy lean men (mean age $35 \pm 16$ years), with an average body mass index (BMI) of $23,8 \pm 3 \mathrm{~kg} / \mathrm{m}^{2}$ ) were recruited for this study. Subjects did not suffer from gastrointestinal disease or current Gl-symptoms. Other exclusion criteria were smoking, intake of medication, or alcohol abuse. This study was conducted according to the guidelines laid down in the Declaration of Helsinki and the Medical Ethical Committee of the University Hospital Maastricht approved all procedures involving human subjects. Written informed consent was obtained from all subjects. All subjects received a standardized evening meal (9 g protein, 39,5 g carbohydrates, $16 \mathrm{~g}$ fat per meal) for two days prior to the test day to standardize macronutrient intake. After an overnight fast, eight mucosal tissue samples from the horizontal part of the duodenum were obtained by flexible gastroduodenoscopy using standard biopsy forceps. The diameter of the biopsies taken varied from $2.0 \mathrm{~mm}$ to $2.2 \mathrm{~mm}$. During this procedure, no sedatives were given to the subjects. After sampling, the biopsies were placed in ice-cold Krebs-Ringer bicarbonate buffer (KRB) and transferred to the laboratory within $15 \mathrm{~min}$.

\section{Preparation of animal duodenal tissue}

Ten male Lewis rats, at least 100 days of age, were used in this study. The rats had free access to food and water prior to sacrifice. After sacrifice, the duodenum was placed in ice-cold Krebs-Ringer bicarbonate buffer (KRB) and transferred to the laboratory within 15 min. The muscle layer was removed, and mucosal tissue samples were obtained with a standard biopsy forceps, equal to the forceps used in the human experiments. The experiment was approved by the Animal Studies Ethics Committee of Maastricht University, The Netherlands.

\section{Ussing Chamber experiments}

\section{Experimental procedure}

The tissue samples were mounted in modified $1.5 \mathrm{ml}$ Ussing Chambers (Harvard Apparatus Inc., Holliston, Mass., USA) with a 9-mm opening and reduced to an exposed tissue area of $1.76 \mathrm{~mm}^{2}$, using a technique previously described by Wallon et al $[13,14]$. The tissue segments were mounted between two $0.4 \mathrm{~mm}$ polyester films with a $1.5 \mathrm{~mm}$ opening with round edges. The flexibility of the films reduced squeezing of the tissues at the border of the openings to minimize edge damage. The surface of the polyester was roughened with a fine abrasive paper to keep the tissue segments in position. After mounting, each half chamber was filled with $1.5 \mathrm{ml}$ KRB, bathing both the mucosal and serosal side of the specimen. The KRB solution was continuously oxygenated and stirred by gas flow in the chambers. $\mathrm{pH}$ was kept at 7.4 at a temperature of $37^{\circ} \mathrm{C}$ with a heater block system. After a 40 min equilibration 
period to achieve steady state conditions regarding potential difference (PD), the $\mathrm{KRB}$ in the mucosal compartment was replaced with $\mathrm{KRB}$ containing $0.1 \mathrm{mg} / \mathrm{ml}$ protein (codfish, egg, ovomucoid, pea, or wheat protein), and that in the serosal compartment was replaced with fresh KRB. PD, transmucosal electrical resistance (TER) and short-circuit current (ISC) were followed for $120 \mathrm{~min}$. Experiments were done in open-circuit conditions with assessment of electrophysical parameters at 2 min intervals. In this experiment, samples of the serosal side of the tissue segments were taken at the end of the experiment (after 2h) for CCK- and GLP-1 analysis.

\section{Electrical measurements}

A four-electrode system was used, as described previously [15]. One pair of Ag/ $\mathrm{Cl}$ electrodes with $3 \mathrm{M} \mathrm{NaCl} / 2 \%$ agar bridges was used for measurement of transepithelial PD and another pair of $\mathrm{Ag} / \mathrm{Cl}$ electrodes was used to monitor current. The electrodes were coupled to an external 6-channel electronic unit with a voltage controlled current source. Data sampling was computer controlled via an A/D D/A board (iworx IX/1 18, Iworx, Dover, USA), using the Labscribe program. Every other minute, direct pulses of $-3,3$, and $0 \mu \mathrm{A}$, with a duration of 2 seconds each, were sent across the tissue segments and the voltage response was measured. In each measurement, the mean voltage response of 2 seconds was calculated. A linear-squares fit was performed on the current (I) - voltage (U) pair relationship: $U=$ PD + TER x I. The TER was obtained from the slope of the I-U line and the PD from the intersection of the voltage.

\section{Measurement of CCK and GLP-1}

CCK levels were determined using the RIA from Euria-CCK, Euro-Diagnostica AB, Malmö, Sweden. According to the manufacturers instructions, the detection limit of this kit was $0.3 \mathrm{pmol} / \mathrm{L}$. The intra-assay variation ranged from 2.0 to $5.5 \%$ and the inter-assay variation from 4,1 to $13,7 \%$. Cross-reaction with gastrin was $0.5 \%$. Total GLP-1 levels were determined using the RIA from Linco Research, Missouri, USA. The detection limit of this kit was 3 to $333 \mathrm{pM}$. The intra-assay variation ranged from 10 to $23 \%$ and the inter-assay variation from 22 to $38 \%$. There was no cross-reaction with GLP-2 and glucagon $(0.01 \%$ and $0.2 \%$, respectively). GLP-1 samples were spiked with 100 pM of GLP-1 to be within range of the detection limit. Both RIAs can be used for the analysis of both rat and human samples.

\section{Statistical Analyses}

The descriptive and statistical analyses were performed with SPSS, version 11.0. Comparison of the electrophysiological parameters was done using the Wilcoxon signed rank test. Comparison of means of the secreted hormones was done using an unpaired Student t-test. The means of the variables are presented with their standard error (mean \pm SEM). A P-value of less than 0.05 was considered statistically significant. 


\section{RESULTS}

\section{Hormone release}

In rat duodenal tissue we observed basal CCK secretion levels of $1.9 \mathrm{pM} \pm 0.2$ (Figure 1), and basal GLP-1 secretions levels of $11.3 \mathrm{pM} \pm 2.2$ (figure 2). Addition of the different proteins to the luminal side of the tissue did not significantly influence the release of CCK and GLP-1.

In human duodenal tissue we observed basal CCK secretion levels of $5.3 \mathrm{pM} \pm 0.6$ (Figure 1). Addition of codfish, pea protein, or wheat protein to human duodenal tissue significantly increased CCK levels in the supernatant (12.2 pM \pm 1 ; $16.9 \mathrm{pM} \pm$ $2.3 ; 10.7 \mathrm{pM} \pm 1$; respectively, $\mathrm{p}<0.05)$. Egg protein and ovomucoid did not affect CCK release in human duodenum. Human mucosa was not able to secrete GLP1 under basal conditions. However, addition of pea protein or wheat increased the GLP-1 release into the supernatant significantly $(3.2 \mathrm{pM} \pm 0.5 ; 0.9 \mathrm{pM} \pm 0.2$; respectively, $\mathrm{p}<0.05)$ compared to the negative control in human biopsies.

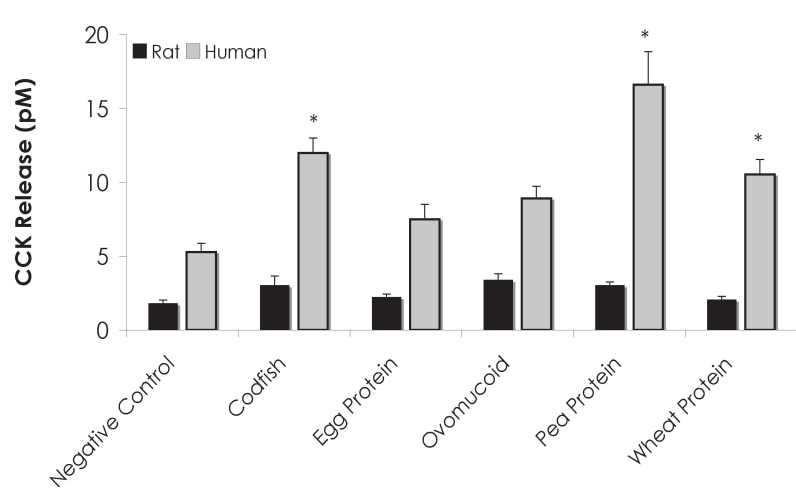

Figure 1. CCK release from rat and human duodenal biopsies in Ussing Chambers. The levels of CCK were measured in the basolateral supernatant of the biopsies in the Ussing Chambers after being exposed to proteins for $2 \mathrm{~h}$ on the apical side. Addition of codfish, pea protein, or wheat protein to human duodenal biopsies increased the release of CCK compared to the negative control. All other proteins did not show effects on CCK release. Exposure of rat duodenum to proteins did not affect CCK release. Results are expressed as mean \pm SEM. $(* p<0.05)$

Figure 2. GLP-1 release from rat and

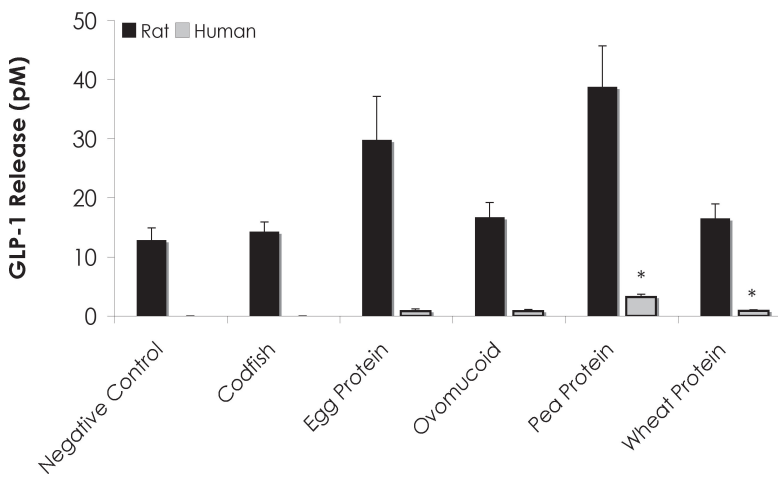
human duodenal biopsies in Ussing Chambers. The levels of GLP-1 were measured in the basolateral supernatant of the biopsies in the Ussing Chambers after being exposed to proteins for $2 h$ on the apical side. Addition of pea protein or wheat protein to human duodenal biopsies increased the release of GLP-1 compared to the negative control. All other proteins did not show effects on GLP-1 release. Exposure of rat duodenum to proteins did not affect GLP-1 release. Results are expressed as mean \pm SEM. $(* p<0.05)$ 


\section{Electrical Measurements}

The electrical parameters PD, ISC, and TER were followed over time. Basal electrical properties of all biopsies were measured. After an equilibration period of $40 \mathrm{~min}$, the mean PD of rat tissue was $-0.9 \mathrm{mV} \pm 0.03$; the TER $17.3 \Omega . \mathrm{cm}^{2} \pm 0.8$; and the Isc was $54.9 \mu \mathrm{A} / \mathrm{cm}^{2} \pm 2.9$. In human tissue, we observed a PD of $-1.6 \mathrm{mV} \pm 0.2$; the mean TER was $38 \Omega . \mathrm{cm}^{2} \pm 1.6$; and the mean Isc was $44 \mu \mathrm{A} / \mathrm{cm}^{2} \pm 5.1$.

Table 1 shows the electrical properties of the rat tissue and table 2 shows the electrical properties of human tissue over a time period of 120 minutes. Directly after addition of protein to the apical side, an increase in TER and a decrease in Isc were observed in both, rat and human tissue, with all proteins. After 60 min and 120 min the TER decreased, whereas the Isc increased for all proteins. There were no significant differences in changes over time compared to the negative control.

\begin{tabular}{|c|c|c|c|c|c|c|}
\hline & \multicolumn{2}{|c|}{$t=0 \mathrm{~min}$} & \multicolumn{2}{|c|}{$t=60 \mathrm{~min}$} & \multicolumn{2}{|c|}{$t=120 \mathrm{~min}$} \\
\hline & $\begin{array}{c}\Delta \text { TER } \\
\left(\Omega . \mathrm{cm}^{2}\right)\end{array}$ & $\begin{array}{c}\Delta \mathrm{lsc} \\
\left(\mu \mathrm{A} / \mathrm{cm}^{2}\right)\end{array}$ & $\begin{array}{c}\Delta \text { TER } \\
\left(\Omega . \mathrm{cm}^{2}\right)\end{array}$ & $\begin{array}{c}\Delta \mathrm{lsc} \\
\left(\mu \mathrm{A} / \mathrm{cm}^{2}\right)\end{array}$ & $\begin{array}{c}\Delta \text { TER } \\
\left(\Omega . \mathrm{cm}^{2}\right)\end{array}$ & $\begin{array}{c}\Delta \mathrm{lsc} \\
\left(\mu \mathrm{A} / \mathrm{cm}^{2}\right)\end{array}$ \\
\hline Negative Control & $2,6 \pm 0,7$ & $-6,0 \pm 3,1$ & $-2,7 \pm 0,3$ & $12,5 \pm 4,3$ & $-5,1 \pm 0,6$ & $22,2 \pm 6,4$ \\
\hline Codfish & $2,7 \pm 0,5$ & $-12,2 \pm 3,0$ & $-4,2 \pm 0,5$ & $8,6 \pm 3,9$ & $-7,3 \pm 0,8$ & $21,9 \pm 6,4$ \\
\hline Egg protein & $2,4 \pm 0,5$ & $-10,6 \pm 3,1$ & $-2,8 \pm 0,7$ & $11,1 \pm 3,8$ & $-4,8 \pm 1,1$ & $23,0 \pm 6,4$ \\
\hline Ovomucoid & $1,8 \pm 1,0$ & $-12,2 \pm 3,2$ & $-6,4 \pm 3,4$ & $13,9 \pm 4,0$ & $-5,4 \pm 1,1$ & $13,2 \pm 7,1$ \\
\hline Pea protein & $3,7 \pm 2,0$ & $-11,7 \pm 3,3$ & $-2,7 \pm 0,2$ & $11,4 \pm 4,0$ & $-4,7 \pm 0,4$ & $20,9 \pm 7,2$ \\
\hline Wheat protein & $3,2 \pm 1,3$ & $-14,3 \pm 2,4$ & $-3,5 \pm 0,4$ & $3,6 \pm 3,5$ & $-6,8 \pm 1,3$ & $8,7 \pm 6,8$ \\
\hline
\end{tabular}

Table 1. Effects of several dietary proteins on TER and Isc of rat duodenum over time. The electrophysiological parameters of duodenal biopsies of rat were followed over time after addition of different proteins. At time point 0 min the proteins were added to the apical side of the tissue. No significant electrophysiological changes were observed over time for all proteins compared to the negative control.

Results are expressed as means \pm SEM.

\begin{tabular}{|c|c|c|c|c|c|c|}
\hline & \multicolumn{2}{|c|}{$t=0 \mathrm{~min}$} & \multicolumn{2}{|c|}{$t=60 \mathrm{~min}$} & \multicolumn{2}{|c|}{$t=120 \mathrm{~min}$} \\
\hline & $\begin{array}{c}\Delta \mathrm{TER} \\
\left(\Omega . \mathrm{cm}^{2}\right)\end{array}$ & $\begin{array}{c}\Delta \mathrm{lsc} \\
\left(\mu \mathrm{A} / \mathrm{cm}^{2}\right)\end{array}$ & $\begin{array}{c}\Delta \text { TER } \\
\left(\Omega . \mathrm{cm}^{2}\right)\end{array}$ & $\begin{array}{c}\Delta \mathrm{lsc} \\
\left(\mu \mathrm{A} / \mathrm{cm}^{2}\right)\end{array}$ & $\begin{array}{c}\Delta \mathrm{TER} \\
\left(\Omega . \mathrm{cm}^{2}\right)\end{array}$ & $\begin{array}{c}\Delta \mathrm{lsc} \\
\left(\mu \mathrm{A} / \mathrm{cm}^{2}\right)\end{array}$ \\
\hline Negative Control & $2,5 \pm 2,2$ & $5,6 \pm 6,7$ & $-6,6 \pm 1,4$ & $-8,8 \pm 7,5$ & $-9,5 \pm 1,7$ & $-7,2 \pm 9,6$ \\
\hline Codfish & $3,8 \pm 1,3$ & $0,5 \pm 5,4$ & $-5,5 \pm 1,2$ & $13,6 \pm 7,3$ & $-9,5 \pm 1,7$ & $11,3 \pm 9,7$ \\
\hline Egg protein & $4,1 \pm 1,2$ & $0,6 \pm 5,4$ & $-10,7 \pm 1,3$ & $22,0 \pm 7,7$ & $-13,9 \pm 2,0$ & $20,8 \pm 9,8$ \\
\hline Ovomucoid & $4,7 \pm 1,2$ & $-4,1 \pm 5,7$ & $-10,4 \pm 1,2$ & $11,9 \pm 7,8$ & $-14,8 \pm 1,9$ & $17,6 \pm 9,4$ \\
\hline Pea protein & $3,8 \pm 1,9$ & $-7,9 \pm 5,9$ & $-6,3 \pm 1,6$ & $9,6 \pm 5,2$ & $-8,9 \pm 2,0$ & $11,9 \pm 7,5$ \\
\hline Wheat protein & $5,4 \pm 1,9$ & $-4,8 \pm 5,8$ & $-8,1 \pm 1,7$ & $3,5 \pm 5,0$ & $-12,4 \pm 2,0$ & $2,5 \pm 6,7$ \\
\hline
\end{tabular}

Table 2. Effects of several dietary proteins on TER and ISC of human duodenum over time. The electrophysiological parameters of duodenal biopsies of human were followed over time after addition of different proteins. At time point 0 min the proteins were added to the apical side of the tissue. No significant electrophysiological changes were observed over time for all proteins compared to the negative control. Results are expressed as means \pm SEM. 


\section{DISCUSSION}

The present study is the first to investigate the effects of luminal exposure to proteins on Gl hormone secretions of human duodenal tissue ex vivo. We demonstrated that intact dietary proteins increased the release of the satiety hormones CCK and GLP1 from human duodenal tissue, whereas dietary proteins were not able to stimulate duodenal tissue from rat to secrete increased levels of these hormones. Exposing human duodenal tissue to either pea protein or wheat protein resulted in elevated levels of both CCK and GLP-1. Exposure to codfish protein resulted in increased secretion of CCK.

The satiety hormones CCK and GLP-1 are secreted from enteroendocrine cells in response to ingested food. Once these hormones are secreted, they promote meal termination [5]. Even though all macronutrients contribute to satiation, proteins have a stronger effect on short-term satiety in humans than fat or carbohydrates [16]. Ingestion of high protein meals induces satiety and fullness, and hunger, appetite, desire to eat, and estimated quantity to eat were suppressed by high protein diets compared to normal protein diets $[17,18]$. The protein source, in addition to protein quantity, degree of hydrolysis, or concentration in food, may be a determinant of the satiating efficacy of protein, but very limited data from studies in humans exist on this topic [19], and the literature is equivocal. Diepvens et al found that consumption of pea hydrolysate did not increase the release of satiety hormones in peripheral blood, even though subjects reported less hunger, less desire to eat, and less thirst prior to the next meal compared to milk protein and whey protein [20]. Weickert et al showed that consumption of wheat fiber significantly altered both PYY and ghrelin levels, but there was no change in hunger perception [21]. Borzoei et al showed that after the consumption of a lunch rich in fish protein, hunger scores were lower and satiety scores were higher compared to a lunch containing beef protein [22]. They also demonstrated that subjects who ate the fish protein lunch decreased their energy intake at the evening meal without feeling less satiated. However, no satiety hormone levels were measured in that study.

These studies suggest that the rise of systemic levels of satiety hormones may play an important role in satiety. Remarkably, none of these studies measured CCK, which is the most important hormone for short-term satiation. The fact that pea, wheat, and codfish protein in our study were effective on elevating CCK release ex vivo, suggests that the results on satiation found in the former in vivo studies may be correlated with a significant rise in plasma CCK levels. However, more research has to be done in in vivo studies to answer this question.

In all published in vivo studies, the proteins were ingested orally. Intact proteins are hydrolyzed to some extent in the stomach, and the hydrolyzed proteins that are present in the duodenum, in combination with gastric emptying and meal 
completion will influence the effects on satiety hormone release. To our knowledge, no literature is present describing how much of the ingested intact protein reaches the duodenum. In the present study, only effects of intact proteins were determined because previous studies from our laboratory demonstrated the greatest effects on in vitro hormone release for these proteins.

Nutrient-induced changes in satiety hormone levels are well studied in rats. Keenan et al demonstrated that the use of resistant starch in the diet as a bioactive functional food component is a natural, endogenous way to increase gut hormones that are effective in reducing energy intake [23]. Sufian et al showed that pork peptone was able to increase CCK levels in vitro, and that this peptone also suppressed appetite in rats [24]. In our study, duodenal tissue from male rats was used to study the effects of several intact proteins on satiety hormone release. There were no significant changes in both CCK and GLP-1 release after exposure to any of the proteins, compared to the negative control. This suggests that release of these satiety hormones from the rat intestine is not dependent on the source of intact proteins. This is in line with the study of Anderson et al [20]. They showed that variation in the pattern of amino acids during intragastric infusion did not affect food intake in rats [25], whereas in humans, there is an indication that proteins may differ in their satiating capacities [26, 27]. Thus, the rat does not seem a suitable model for studying satiety hormone release.

Although these results are in line with the literature, we have to take into account that the pretreatment of the rat intestine could have influenced the results. Removing the muscle layer from the intestine may have caused stress, resulting in changed physiology of the intestine. Also, taking biopsies from rat intestine is very difficult. We standardized the location of taking the samples, but not all biopsies taken from that location were viable, which forced us to take samples from a more distal part of the duodenum. The basal release of GLP-1 from duodenal tissue was also very low. We observed large differences between the sensitivity of the intestine in rats and humans. Liddle et al described that CCK release in rats was only stimulated by fatty acids [28], but more recent literature described that CCK levels are also elevated in rats fed high protein diets $[24,29,30]$. In humans, both fatty acids and proteins are potent stimulators of elevated levels of CCK. However, to obtain a better understanding how nutrients trigger the enteroendocrine cells to release these satiety hormones, rodent studies are necessary. In these models it is possible to knock out genes, or block several receptors. However, as was shown in this study, rodents and humans differ in the way they respond to nutrients, and we have to be careful when drawing conclusions from rodent studies.

The present study demonstrates that the Ussing chamber technology can be used to study intestinal hormone release. We are the first to show that exposing endoscopic biopsies to dietary proteins results in a detectable increase in hormone release. The 
electrical parameters measured in this study are widely accepted for monitoring the viability and integrity of segments in the Ussing Chambers. In general, PD reflects the voltage gradient generated by the tissue, TER reflects the tissue integrity, and Isc reflects the ionic fluxes across the epithelium $[11,12,31]$. The results from our study were comparable with the literature, and therefore we may conclude that all biopsies used in this study were viable and that addition of protein to the apical side did not affect resistance and short circuit current.

Summarizing, human duodenal tissue is sensitive to luminal protein exposure to release CCK and GLP-1, and the source of the protein is important for the satiating capacities, whereas secretion of satiety hormones by rat duodenal tissue is not sensitive in this respect. We showed that pea protein, wheat protein, and codfish protein are the most potent stimulators of CCK release. Furthermore, we are the first to show that Ussing Chamber model can be used to study nutritional effects on intestinal samples and that CCK and GLP-1 secretion can be measured from this tissue. Overall, we conclude that pea-protein and wheat-protein are the most potent stimulators for CCK and GLP-1 release and that these proteins may be used as dietary supplements for weight management. However, in vivo studies must be performed to confirm this hypothesis. 


\section{REFERENCES}

1. Saris, W.H. and M.A. Tarnopolsky, Controlling food intake and energy balance: which macronutrient should we select? Curr Opin Clin Nutr Metab Care, 2003. 6(6): p. 609-13.

2. Tome, D., Protein, amino acids and the control of food intake. Br J Nutr, 2004. 92 Suppl 1: p. S2730 .

3. Westerterp-Plantenga, M.S. and M.P. Lejeune, Protein intake and body-weight regulation. Appetite, 2005. 45(2): p. 187-90.

4. Bensaid, A., et al., Protein is more potent than carbohydrate for reducing appetite in rats. Physiol Behav, 2002. 75(4): p. 577-82.

5. Cummings, D.E. and J. Overduin, Gastrointestinal regulation of food intake. J Clin Invest, 2007. $117(1)$ : p. 13-23.

6. Brubaker, P.L. and Y. Anini, Direct and indirect mechanisms regulating secretion of glucagon-like peptide-1 and glucagon-like peptide-2. Can J Physiol Pharmacol, 2003. 81 (11): p. 1005-12.

7. Savastano, D.M. and M. Covasa, Intestinal nutrients elicit satiation through concomitant activation of CCK(1) and 5-HT(3) receptors. Physiol Behav, 2007. 92(3): p. 434-42.

8. Li H, Sheppard DN, Hug MJ: Transepithelial electrical measurements with the ussing chamber. J Cyst Fibros 2004;3 Suppl 2:123-126.

9. Boudry, G., The Ussing chamber technique to evaluate alternatives to in-feed antibiotics for young pigs. anim. Res., 2005. 54: p. 219-230.

10. Davis, J.L., et al., Mucosal permeability of water-soluble drugs in the equine jejunum: a preliminary investigation. J Vet Pharmacol Ther, 2006. 29(5): p. 379-85.

11. Larsen, R., et al., Novel modified Ussing chamber for the study of absorption and secretion in human endoscopic biopsies. Acta Physiol Scand, 2001. 173(2): p. 213-22.

12. Reims, A., B. Strandvik, and H. Sjovall, Epithelial electrical resistance as a measure of permeability changes in pediatric duodenal biopsies. J Pediatr Gastroenterol Nutr, 2006. 43(5): p. 619-23.

13. Wallon, C., et al., Endoscopic biopsies in Ussing chambers evaluated for studies of macromolecular permeability in the human colon. Scand J Gastroenterol, 2005. 40(5): p. 586-95.

14. Wallon, C., et al., Corticotropin-releasing hormone (CRH) regulates macromolecular permeability via mast cells in normal human colonic biopsies in vitro. Gut, 2008. 57(1): p. 50-8.

15. Soderholm, J.D., et al., Integrity and metabolism of human ileal mucosa in vitro in the Ussing chamber. Acta Physiol Scand, 1998. 162(1): p. 47-56.

16. Anderson, G.H. and S.E. Moore, Dietary proteins in the regulation of food intake and body weight in humans. J Nutr, 2004. 134(4): p. 974S-9S.

17. Westerterp-Plantenga, M.S., et al., Dietary protein, metabolism, and body-weight regulation: dose-response effects. Int J Obes (Lond), 2006. 30 Suppl 3: p. S16-23.

18. van Erk, M.J., et al., High-protein and high-carbohydrate breakfasts differentially change the transcriptome of human blood cells. Am J Clin Nutr, 2006. 84(5): p. 1233-41.

19. Anderson, G.H., et al., Protein source, quantity, and time of consumption determine the effect of proteins on short-term food intake in young men. J Nutr, 2004. 134(11): p. 3011 1-5.

20. Diepvens, K., D. Haberer, and M. Westerterp-Plantenga, Different proteins and biopeptides differently affect satiety and anorexigenic/orexigenic hormones in healthy humans. Int J Obes (Lond), 2008. 32(3): p. 510-8.

21. Weickert, M.O., et al., Wheat-fibre-induced changes of postprandial peptide YY and ghrelin responses are not associated with acute alterations of satiety. Br J Nutr, 2006. 96(5): p. 795-8.

22. Borzoei, S., et al., A comparison of effects of fish and beef protein on satiety in normal weight men. Eur J Clin Nutr, 2006. 60(7): p. 897-902.

23. Keenan, M.J., et al., Effects of resistant starch, a non-digestible fermentable fiber, on reducing body fat. Obesity (Silver Spring), 2006. 14(9): p. 1523-34.

24. Sufian, M.K., et al., Pork peptone stimulates cholecystokinin secretion from enteroendocrine cells and suppresses appetite in rats. Biosci Biotechnol Biochem, 2006. 70(8): p. 1869-74. 
25. Lang, V., et al., Satiating effect of proteins in healthy subjects: a comparison of egg albumin, casein, gelatin, soy protein, pea protein, and wheat gluten. Am J Clin Nutr, 1998. 67(6): p. 1197204.

26. Uhe, A.M., G.R. Collier, and K. O'Dea, A comparison of the effects of beef, chicken and fish protein on satiety and amino acid profiles in lean male subjects. J Nutr, 1992. 122(3): p. 467-72.

27. Lieverse, R.J., et al., Obese women are less sensitive for the satiety effects of bombesin than lean women. Eur J Clin Nutr, 1998. 52(3): p. 207-12.

28. Liddle, R.A., J.D. Carter, and A.R. McDonald, Dietary regulation of rat intestinal cholecystokinin gene expression. J Clin Invest, 1988. 81 (6): p. 2015-9.

29. Bernard, C., et al., Peptones stimulate intestinal cholecystokinin gene transcription via cyclic adenosine monophosphate response element-binding factors. Endocrinology, 2001. 142(2): p. 721-9.

30. Cordier-Bussat, M., et al., Peptones stimulate cholecystokinin secretion and gene transcription in the intestinal cell line STC-1. Endocrinology, 1997. 138(3): p. 1137-44.

31. Grass, G.M. and S.A. Sweetana, In vitro measurement of gastrointestinal tissue permeability using a new diffusion cell. Pharm Res, 1988. 5(6): p. 372-6. 


\section{ChAPTER 6}

\section{INTRADUODENAL ADMINISTRATION OF INTACT PEA PROTEIN EFFECTIVELY REDUCES FOOD INTAKE IN BOTH LEAN AND OBESE MALE SUBJECTS}

MAARTJE C.P. GERAEDTS, FREDdy J. Troost, MARJET J.M. MUNSTERS, ROGIER J. DE RIDDER, JOSE M. CONCHILLO, JoAnna W. KRUimel, Ad A.M. Masclee, Wim H.M. SARIS 


\section{ABSTRACT}

Human duodenal mucosa secretes increased levels of satiety signals upon exposure to intact protein. However, after oral protein ingestion, gastric digestion leaves little intact proteins to enter the duodenum. This study investigated whether bypassing the stomach, through intraduodenal administration, affects hormone release and food-intake to a larger extent than orally administered protein in both lean and obese subjects.

Ten lean (BMl: $23.0 \pm 0.7 \mathrm{~kg} / \mathrm{m}^{2}$ ) and ten obese (BMl: $33.4 \pm 1.4 \mathrm{~kg} / \mathrm{m}^{2}$ ) healthy male subjects were included. All subjects randomly received either pea protein solutions ( $250 \mathrm{mg} / \mathrm{kg}$ bodyweight in $0.4 \mathrm{ml} / \mathrm{kg}$ bodyweight of water) or placebo $(0.4 \mathrm{ml} / \mathrm{kg}$ bodyweight of water), either orally or intraduodenally via a nasoduodenal tube. Appetite-profile, plasma GLP-1, CCK, and PYY concentrations were determined over a $2 \mathrm{~h}$ period. After $2 \mathrm{~h}$, subjects received an ad libitum meal and food-intake was recorded.

CCK levels were increased at $10(p<0.02)$ and $20(p<0.01)$ minutes after intraduodenal protein administration (IPA), in obese subjects, compared to lean subjects, but also compared to oral protein administration (OPA) $(p<0.04)$. GLP-1 levels increased after IPA in obese subjects after $90(p<0.02)$ to $120(p<0.01)$ minutes, compared to OPA. Food-intake was reduced after IPA both in lean and obese subjects $(-168.9 \pm 40 \mathrm{kcal}$ $(p<0.01)$ and $-298.2 \pm 44 \mathrm{kcal}(p<0.01)$, respectively), compared to placebo. Also, in obese subjects, food intake was decreased after IPA $(-132.6 \pm 42 \mathrm{kcal} ; \mathrm{p}<0.01)$, compared to OPA.

Prevention of gastric proteolysis through bypassing the stomach effectively reduces food intake, and seems to affect obese subjects to a greater extent than lean subjects. Enteric coating of intact protein supplements may provide an effective dietary strategy in the prevention/treatment of obesity. 


\section{INTRODUCTION}

Food ingestion triggers a number of stimuli, such as the release of the gastrointestinal hormones cholecystokinin (CCK), glucagon-like peptide 1 (GLP-1) and peptide YY (PYY). These hormones are known to be involved in the modulation of appetite sensations. CCK is produced by I-cells in the duodenal and jejunal mucosa, and is secreted in response to luminal food compounds, especially lipids and proteins [1]. GLP-1 is produced primarily by the L-cells in the more distal small intestine and colon. Ingested nutrients stimulate CCK-, GLP-1-, and PYY secretion indirectly by neurohumoral mechanisms, e.g. feedback mechanisms of hormones from a more distal part of the small intestine, as well as by direct sensing mechanisms at the intestinal mucosa [2, 3].

Previously, it was demonstrated that the plasma levels of GLP-1 were elevated in obese rats, compared to lean rats [4]. Others found that levels of ghrelin and obestatin were decreased in obese children, compared to lean children [5]. These data indicate that there are significant differences between lean and obese subjects with respect to hormone release, and that the gut may respond different to ingested nutrients in obese subjects, compared to lean subjects.

Among all properties of food, the total energy content and the macronutrient composition appear to be the major determinants of the control of food intake. Recent literature points to the effect of dietary protein in reducing food intake by improving satiety sensations [6, 7]. It seems that proteins have the highest satiating effect when compared to carbohydrates and in particular fats in humans and rats $[8,9]$, although the nature of the protein can influence its satiating effects. In most cases, high-protein meals increase feelings of satiety and decrease subsequent energy intake compared with high-carbohydrate or high-fat meals [10].

From previous work it is well known that proteins have the ability to affect food intake and appetite in several species, including humans. A variety of physiological mechanisms activated by protein ingestion may act in concert to exert their satiating effect. One of the physiological processes through which proteins appear to induce satiety is by stimulating satiety hormone secretion [11]. However, little is known about the satiating properties of proteins originating from different sources. In previous studies we showed that proteins and especially codfish, egg, pea, and wheat exert strong effects on satiety hormone release in an in vitro setting. Remarkably, the hydrolysates showed weaker effects with respect to hormone release, than the intact protein. We also demonstrated that these intact proteins exert different effects on satiety hormone release in human duodenal tissue. Exposing intestinal tissue to intact pea and wheat protein induced an increase in the release of both CCK and GLP-1, whereas all the other tested proteins did not affect the hormone release [12]. 
It was shown previously in rats that intraduodenal infusion of dietary protein resulted in increased plasma levels of CCK compared to intragastric infusion [13]. We hypothesize that 1) intraduodenal infusion of intact dietary proteins in humans will induce stronger effects on satiety hormone release and satiation, when compared to orally ingested dietary proteins, and that 2) there are differences in hormone secretion between lean and obese subjects. To investigate this, the effects of different administration routes of pea protein on plasma satiety hormone levels, feelings of hunger and satiety, and food intake were investigated in both lean and obese subjects.

\section{SUBJECTS AND METHODS}

\section{Subjects}

Twenty male subjects participated in this study. We included only male subjects, because with female subjects, the hormonal fluctuations may influence the satiety hormone levels during this study. The subjects were recruited by advertisements on boards at the university and in local newspapers. Selection took place according to health criteria (no diabetes, no gastrointestinal diseases, and no medical treatment) and body weight (BW) criteria (for lean subjects: body mass index (BMI) 18-25 kg/ $\mathrm{m}^{2}$, and for obese subjects: BMl>30 kg/m²). Baseline characteristics of the subjects are presented in table 1. The nature and risks of the experimental procedure were explained to the subjects, and all subjects gave their written informed consent. This study was conducted according to the guidelines laid down in the Declaration of Helsinki [14]. The Medical Ethical Committee of the University Hospital Maastricht approved all procedures involving human subjects.

\begin{tabular}{lcc}
\hline & Lean $(n=10)$ & Obese $(n=10)$ \\
\hline Age (years) & $25 \pm 2$ & $41 \pm 6$ \\
BMl $\left(\mathrm{kg} / \mathrm{m}^{2}\right)$ & $23.0 \pm 0.7$ & $33.4 \pm 1.4^{*}$ \\
HbAlc $(\%)$ & $5.0 \pm 0.1$ & $5.0 \pm 0.1$ \\
Basal glucose $(\mathrm{mmol} / \mathrm{L})$ & $4.8 \pm 0.2$ & $4.5 \pm 0.1$ \\
\hline
\end{tabular}

Table 1. Subject characteristics at baseline

All data are mean \pm SEM

* Difference between lean and obese subjects ( $p<0.05)$

\section{Nasointestinal catheter}

Participants were intubated with a $145 \mathrm{~cm}$ nasoduodenal catheter (Flocare Bengmark, Nutricia, Zoetermeer, The Netherlands). This catheter is designed for transnasal feeding directly into the duodenum or jejunum. The tip of the catheter 
was lubricated with lidocainne gel to sedate the nostril. The catheter was introduced into the stomach and the tip was positioned in the duodenum under radiological guidance and verification.

\section{Experimental design}

In this single-blind, randomized controlled crossover design, each participant participated in four experiments on four occasions with 1 week between visits. All subjects received a standardized evening meal $(9 \mathrm{~g}$ protein, 39,5 g carbohydrates, $16 \mathrm{~g}$ fat per meal) on the day prior to the test day to standardize macronutrient intake. On each occasion, subjects arrived after fasting overnight. The nasoduodenal catheter and an intravenous blood sampling catheter were placed during each test day, and a fasting blood sample was taken. Subjects then completed an appetite and well-being questionnaire. The test-drink (for composition see 'dietary protocol') was consumed at time 0 . During oral consumption of the test drink, subjects were instructed to consume the drink within 5 minutes. During intraduodenal infusion of the drink, the fluid was infused for 30 minutes, at a rate depending on the volume of the test-drink, which was based on total body weight of the volunteer. Subsequent blood samples were collected at $0,5,10,15,30,45,60,75,90$, and 120 min, respectively. An appetite questionnaire was completed 0, 5, 15, 30, 60, 90, and 120 min, respectively. A well-being questionnaire was completed 0, 5, 30, 60, 90 , and $120 \mathrm{~min}$, respectively. After $120 \mathrm{~min}$, the nasoduodenal catheter and the intravenous catheter were removed, and subjects were offered an ad libitum meal approximately 10 minutes after the removal of the catheter. Instructions were given to eat until comfortably satiated. The meal was weighed before and after eating, and total food intake was determined by the difference in weight.

\section{Dietary protocol}

The protein tested was provided as part of a drink ( $4 \mathrm{ml}$ per $\mathrm{kg}$ of bodyweight), which contained either pea protein $(250 \mathrm{mg}$ per $\mathrm{kg}$ of body weight)(Dutch Protein Services, Tiel, The Netherlands) or only water as placebo. The drinks were uniformly flavored with $5 \mathrm{~g}$ cream vanilla flavor (Quest International, Naarden, The Netherlands) per liter beverage to mask the taste of the pea protein. The drinks were provided in covered flasks so that the subjects did not know which product they received.

The ad libitum meal consisted of Lasagne Bolognese $(671 \mathrm{~kJ}, 7.5 \mathrm{~g}$ protein, $12.3 \mathrm{~g}$ carbohydrates, $9.0 \mathrm{~g}$ fat per $100 \mathrm{grams})$. Food was weighed prior to the meal and after the subjects left the laboratory. Food intake was assessed by difference.

\section{Questionnaires}

The appetite questionnaire was a Visual Analogue Scale questionnaire (VAS, on a $100 \mathrm{~mm}$ scale) with questions about feelings of hunger, fullness, satiety, thirst, and desire to eat [15]. Opposing extremes of each feeling were described at either end of a $100-\mathrm{mm}$ horizontal line, and subjects marked the line to indicate how they felt 
at that moment.

Well-being was determined using a questionnaire on the occurrence of complaints (headache, nausea, stomach-ache, diarrhea, and other symptoms). Symptoms were graded on a 10-point scale with the grade 1 representing 'Not present', to 10 'Strongly present'. Subjects were asked to mark how they felt at that moment.

\section{Blood parameters}

Blood samples were collected for analysis of CCK, GLP-1, and PYY. The blood samples were mixed with EDTA to prevent clotting. The blood samples for CCK (5 $\mathrm{ml}$ ) analysis were mixed with 2000 KIU Aprotinin (VWR International, Amsterdam, The Netherlands). Samples for GLP-1 (5 ml) were mixed with $40 \mu$ l of a dipeptidyl peptidase IV (DPP-IV) inhibitor (Linco Research Inc., St Charles, Missouri, USA) to prevent degradation. Plasma CCK levels were determined by a RIA (EuriaCCK, Eurodiagnostica AB, Malmö, Sweden), and plasma GLP-1 levels were also determined by a RIA (GLP1A-53HK, Linco Research Inc., St Charles, Missouri, USA), both according to the manufacturers instructions.

\section{Statistical analysis}

Data are presented as mean \pm standard error of the mean (SEM), unless otherwise indicated. Statistical analysis was performed using SPSS 16.0 for Mac OS X software (SPSS Inc, Chicago, Illinois, USA). Mixed-model ANOVA was used to determine possible effects between the conditions. Differences between food intake between conditions and groups was calculated with the Students t-test. Correction for multiple comparisons was applied. All statistical tests were performed two-tailed and a p-value of <0.05 was considered statistically significant.

\section{RESULTS}

\section{Satiety and well-being scores}

All fasting scores did not differ between treatments for both lean and obese subjects. There was also no difference between placebo treatments in both groups. For lean subjects, feelings of hunger increased over time (figure 1A), but there were no significant differences between treatments. Obese subjects reported decreased feeling of hunger after 30 minutes with the oral protein treatment (figure 1B), compared to the other treatments. After 120 minutes, no differences were observed in feelings of hunger between treatments in obese subjects. Also, obese subjects reported to feel less hungry at 120 minutes after intraduodenal protein treatment when compared to lean subjects with the same treatment.

Even though we did not see differences in feeling of hunger in lean subjects, these subjects felt more full after the intraduodenal treatment (figure 1C), compared to the placebo treatment. There were no differences in the oral treatment. Between 
60 and 90 minutes, obese subjects felt more full after intraduodenal protein treatment (figure 1D), compared to placebo treatment. However, there were no differences between the lean and obese group. Satiety feelings did not change over time for lean subjects (figure 1E), whereas for obese subjects, satiety feelings were significantly increased at 120 minutes after oral protein ingestion, compared to oral placebo ingestion (figure $1 \mathrm{~F}$ ).

There were no differences in feelings of thirst, desire to eat, or feelings of well-being between the treatments and between the groups. Subjects scored no feelings of nausea, intestinal cramps, diarrhea, headache, or dizziness during any treatment.

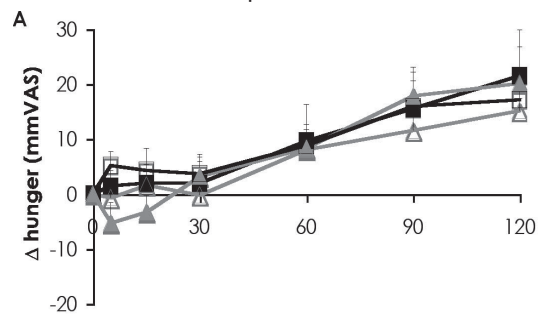

Time (min)
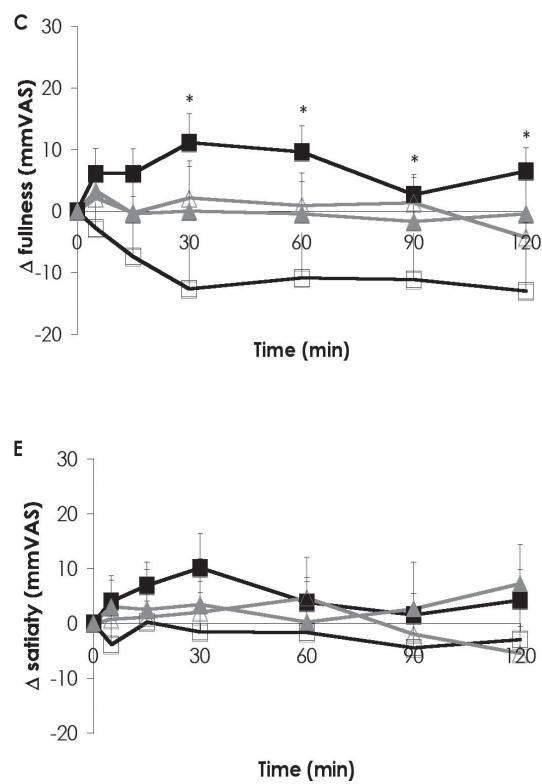

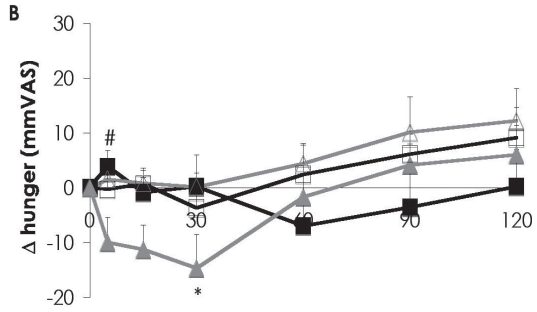

Time (min)
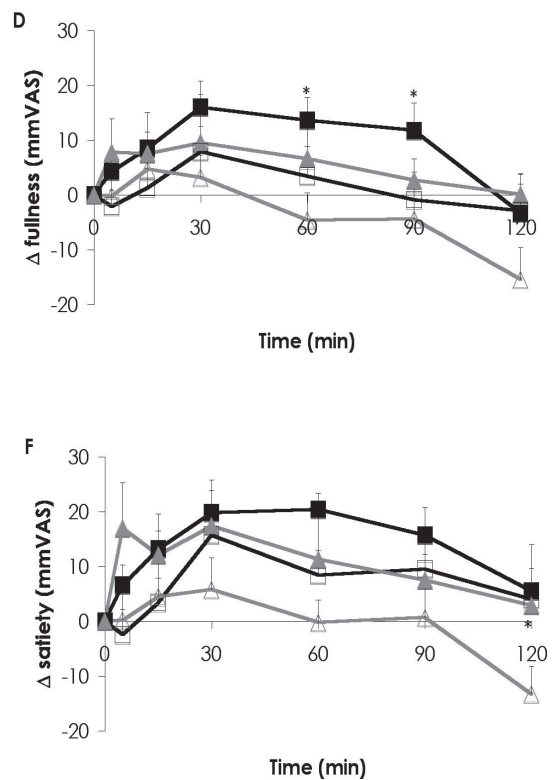

Figure 1. Changes in hunger, fullness, and satiety (mmVAS) after oral and intraduodenal treatments with pea protein and placebo. Feelings of hunger did not change in lean subjects after between treatments (A), whereas in obese subjects, hunger decreased at 30 minutes after the oral pea protein ingestion (B). Feelings of fullness were increased after intraduodenal pea protein treatment for both lean (C) and obese (D) subjects. Satiety did not change over time when compared to placebo treatments for both lean (E) and obese (F) subjects. Values are expressed as mean \pm SEM. * Significantly different from placebo treatment $(p<0.05)$. \# Significantly different from oral protein treatment $(p<0.05)$. 


\section{Plasma CCK}

Baseline plasma CCK concentrations did not differ between study days, and between groups (figure 2). Placebo treatments did not affect the plasma CCK levels in all treatments in both groups. Oral ingestion of pea protein in lean subjects (figure $2 \mathrm{~A})$ resulted in significantly increased levels of CCK for the first 10 minutes, whereas after intraduodenal infusion of pea, CCK levels where significantly increased during the first 15 minutes. After 30 minutes, CCK levels returned to baseline for both protein treatments. More pronounced differences were observed in obese subjects (figure 2B). After oral protein ingestion, CCK levels were significantly increased for the first 10 minutes, when compared to the placebo treatment. However, after intraduodenal administration of pea protein, CCK levels were significantly increased during the first 15 minutes, when compared to the placebo treatment, but also when compared to the oral treatments. Intraduodenal protein treatment showed stronger effects on CCK release in obese subjects than in lean subjects.
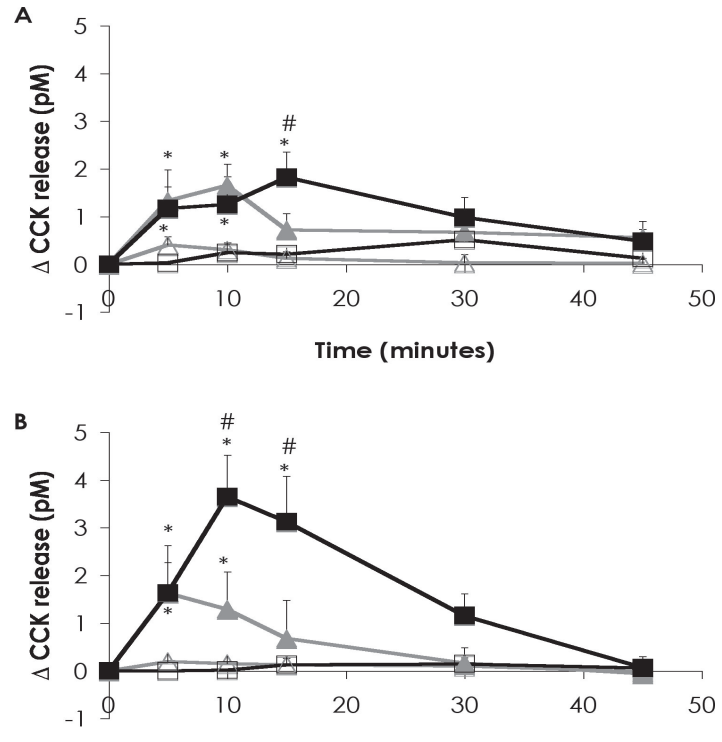

Time (min)
Figure 2. Changes in plasma CCK release (pM) after oral and intraduodenal treatments with pea protein and placebo. CCK release was increased during the first 10 minutes after oral pea protein ingestion in both lean (A) and obese (B) subjects. However, after intraduodenal pea protein administration, CCK levels remained elevated for 15 minutes, and the levels were higher when compared to oral protein administration. Values are expressed as mean \pm SEM. * Significantly different from placebo treatment $(p<0.05)$. \# Significantly different from oral protein treatment $(\mathrm{p}<0.05)$.

\section{Oral protein $\triangle$ Oral placebo}

Intraduodenal protein

廿- Intraduodenal placebo

\section{Plasma active GLP-1}

Baseline plasma GLP-1 concentrations did not differ between study days, and between groups (figure 3). Placebo treatments did not affect the plasma GLP-1 levels in all treatments in both groups. Both protein treatments showed no effect on GLP-1 release in lean subjects (figure 3A), with the exception of the oral protein treatment at time point 15 minutes. Here GLP-1 levels were significantly increased when compared to the placebo treatment. In obese subjects, the oral protein 
treatment did not affect GLP-1 release when compared to the placebo treatment (figure 3B). Intraduodenal protein administration in obese subjects resulted in significantly increased levels after 90 minutes until the end of the test, compared to the placebo treatment, but also compared to the oral treatment.

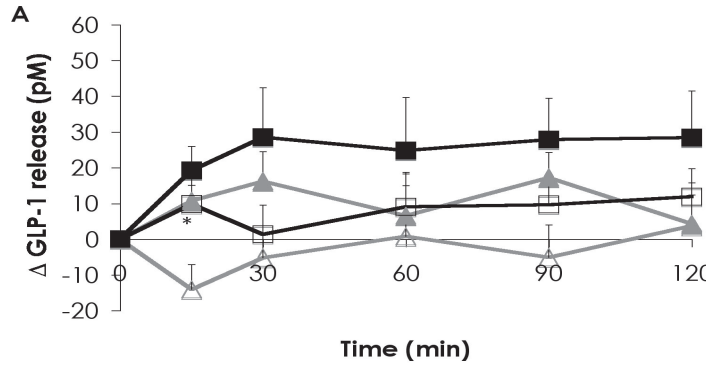

B

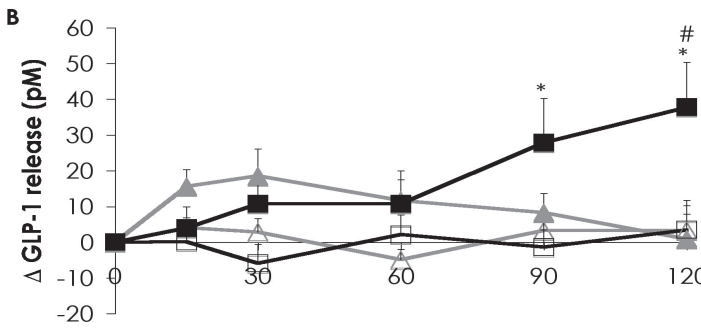

Time (min)
Figure 3. Changes in plasma GLP-1 release (pM) after oral and intraduodenal treatments with pea protein and placebo. GLP-1 levels did not change over time after pea protein ingestion in lean subjects ( $A$ ), when compared \# to the placebo treatments. In obese subjects, GLP-1 levels were significantly increased from 90 minutes after intraduodenal pea protein administration until the end of the test (B) . Oral pea protein administration did not affect GLP-1 release. Values are expressed as mean \pm SEM. * Significantly different from placebo treatment $(p<0.05)$. \# Significantly different from oral protein treatment $(p<0.05)$.

- Oralprotein $\Perp$ Oralplacebo Intraduodenal protein

$\square$ Intraduodenal placebo

\section{Plasma PYY}

Baseline plasma PYY concentrations did not differ between study days, and between groups. Placebo treatments did not affect the plasma PYY levels in all treatments in both groups. In lean subjects, intraduodenal protein administration induced stronger effects on PYY release compared to oral protein ingestion (figure 4A). PYY levels were increased after 15 minutes, until the end of the test, whereas during the oral treatment, PYY levels were only increased after 60 minutes, compared to the placebo. The effects of protein administration in obese subjects did not differ between oral and intraduodenal treatment (figure 4B). For both treatments, PYY levels were significantly increased after 30 minutes, until the end of the test, compared to the placebo treatment. 


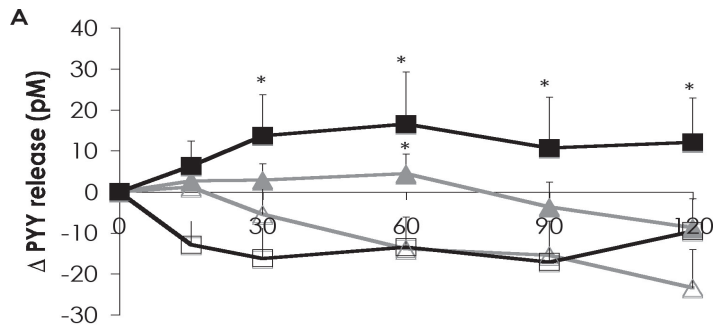

Time (min)

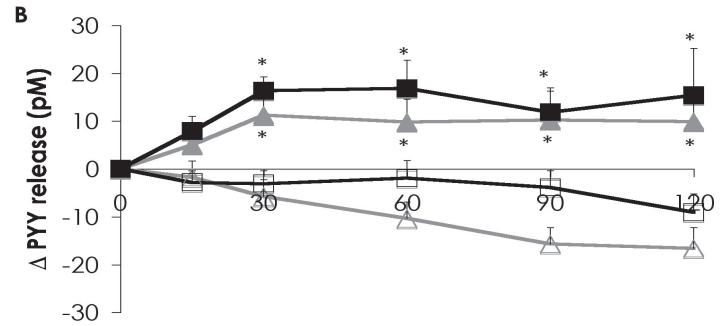

Figure 4. Changes in plasma PYY release (pM) after oral and intraduodenal treatments with pea protein and placebo. Oral pea protein ingestion did not affect PYY release in lean subjects (A), whereas intraduodenal pea protein administration significantly increased the release of PYY from 15 minutes after pea protein administration until the end of the test. In obese subjects (B), PYY release was significantly increased from 30 minutes until the end of the test for both protein treatments. Values are expressed as mean \pm SEM. * Significantly different from placebo treatment $(p<0.05)$. \# Significantly different from oral protein treatment $(p<0.05)$.

\footnotetext{
Time (min)

Oralprotein $\triangle$ Oralplacebo

Intraduodenal protein

廿 Intraduodenal placebo
}

\section{Food intake}

Consumption of the ad libitum meal did not differ between lean and obese subjects. Orally ingested protein did not affect the consumption of the meal, whereas intraduodenally administered protein decreased food intake in both lean and obese subjects $(-168.9 \pm 40 \mathrm{kcal}(p<0.01)$ and $-298.2 \pm 44 \mathrm{kcal}(p<0.01)$, respectively). Obese subjects also consumed significantly less after the intraduodenal protein treatment when compared to the oral protein treatment $(-132.6 \pm 42 \mathrm{kcal} ; p<0.01)$ (figure 5).

\section{\#}

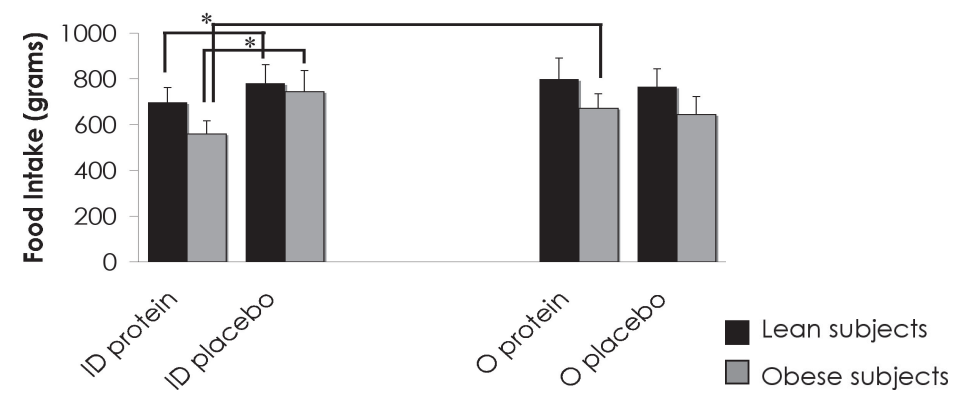

Figure 5. Ad libitum food intake ( $g$ ) after oral and intraduodenal treatments with pea protein and placebo. Oral protein ingestion did not affect food intake. Both lean and obese subjects decreased food intake after intraduodenal protein administration compared to the placebo treatment. Moreover, obese subjects decreased their food intake also when compared to oral protein treatment, whereas this was not the case for lean subjects. ID: Intraduodenal treatment; O: oral treatment. Valves are expressed as mean \pm SEM * Significantly different from intraduodenal placebo treatment $(\mathrm{p}<0.05)$. \# Significantly different from oral protein treatment $(p<0.05)$. 


\section{DISCUSSION}

This study demonstrated for the first time that in both lean and obese humans, intraduodenal administration of intact pea protein is effective in reducing food intake, whereas no differences between placebo and treatment were observed after oral administration of the protein. This effect was not seen when the protein was given orally to the same subjects. Also, intraduodenal infusion of protein resulted in stronger effects on CCK release in obese subjects than in lean subjects, whereas effects on GLP-1 and PYY release were comparable in both groups.

Digestion of proteins takes place in different stages. The initial phase of protein digestion and absorption occurs in the stomach, followed by protein digestion in the small intestine. Until now, it was commonly accepted that proteins that are more rapidly absorbed in the body (also called fast proteins) appear to have a larger effect on satiety than slow proteins, which coagulate in the stomach and induce lower levels of amino acids in the bloodstream [16]. In humans, it has been demonstrated that whey, a fast protein, was more satiating and induced stronger postprandial hormone release than casein, a slow protein [17]. It could also be possible that the 'fast' proteins are not digested well in the stomach, leaving more intact protein to enter the duodenum, which in turn might result in higher satiation. However, no literature is available on the levels of intact proteins that reach the duodenum.

In the present study, the effects of pea protein on food intake were studied. This protein contains large amounts of arginine, asparagine, and glutamine, and is digested by approximately $93 \%$ in the stomach [18]. The study of Diepvens et al showed that pea protein hydrolysates had a more pronounced effect on PYY release and feelings of hunger, compared to whey and whole milk proteins [19]. However, in a recent study from our group we demonstrated that intact pea proteins were more potent in stimulating hormone release from enteroendocrine cells, than protein hydrolysates and specific peptides. In another study, we demonstrated that intact pea and wheat protein stimulated CCK and GLP-1 release from human duodenal tissue to a greater extent than egg and codfish protein and negative control (unpublished data). Unlike other common protein sources such as milk, soy, or wheat proteins, pea protein has a very low allergenic potential, which makes this protein more suitable for dietary interventions than wheat protein.

The present study shows that intact pea protein is more satiating than its digested products. However, we do not know whether the subjects compensated the decreased portion size with an increased portion size during the next meal. Also, the amount of protein given is relatively high. Subjects received $250 \mathrm{mg}$ per $\mathrm{kg}$ of bodyweight, which is comparable with a fourth of the daily total protein intake (approximately 1 gram per kg of body weight per day [20]). It has previously been 
demonstrated that this amount of protein affects satiety [21], and therefore, this amount was also used in the present study. However, future studies should be designed to identify the lowest effective dose of this protein. Also, options for delivering intact proteins to the duodenum will have to be investigated. There are some studies describing coatings for enteric delivery, such as $\mathrm{pH}$-triggered (micro) coatings, pressure-sensitive coatings, or time-release coatings [22-26]. For duodenal delivery of a large amount of protein, a pH-sensitive coating seems suitable. It should be noted that, under physiological circumstances, little intact protein will reach the duodenum. Administering large amounts of intact protein to the duodenum might result in decreased feelings of well-being. Here we demonstrated that these amounts of protein did not affect feelings of nausea, stomach ache, diarrhoea and other factors of well-being. As was demonstrated in the past, undigested lipids infused more distal in the ileum caused similar effects [27]. This phenomenon called 'ileal brake' could also be active in the present situation of undigested protein proximal in the small intestinal tract. The exact mechanisms are still not fully explained as in the lipid infusion studies as in our intact protein infusions not all gut hormones respond similar in relation to satiety response. Other local neurohumoral factors could be involved.

There are indications that obese subjects are less sensitive for satiety signals compared to lean subjects. In rats it was shown that the minimal effective dose of satiety hormones was 3-4 times greater in obese than in lean rats [28, 29]. Here we demonstrated that after the same protein load, CCK levels in obese subjects were higher when compared to lean subjects, whereas GLP-1 and PYY levels did not differ between both groups. This would indicate that there is an impaired balance between protein load sensitivity and release of CCK in obese subjects. Even though the CCK levels were higher, both lean and obese subjects decreased food intake following protein ingestion to the same extent. This suggests that obese subjects are less sensitive to the satiety signals. We should take into consideration that perhaps obese subjects are also more sensitive to external cues that influence the amount of food eaten [30]. Hence, the laboratory setting may have influenced eating behaviour in the obese subjects to a larger extent than the lean. However, there were no significant differences between lean and obese subjects in relation with the appetite ratings. VAS are often used to measure subjective appetite sensations and the validity and reproducibility has been shown in several studies [15, 31]. Both groups showed the same changes over time, which may also explain why both groups consumed the same amount of food.

In conclusion, food intake was decreased after intraduodenal protein administration in both lean and obese subjects, in contrast to food intake after oral ingestion of the protein. Although there were no differences in appetite ratings between both groups, we observed elevated levels of CCK in obese subjects, and GLP-1 and PYY 
were elevated in both groups. This suggests that by preventing gastric pea protein degradation may be an effective dietary strategy in the prevention and treatment of obesity. However, more studies will have to be performed to identify the lowest effective dose of the protein, and whether (micro)encapsulated proteins show the same effects on food intake. Also, long-term intervention studies will have to be performed to demonstrate the effects of intraduodenal pea protein administration on weight loss and weight maintenance. 
1. Cummings, D.E. and J. Overduin, Gastrointestinal regulation of food intake. J Clin Invest, 2007. 117(1): p. 13-23.

2. Brubaker, P.L. and Y. Anini, Direct and indirect mechanisms regulating secretion of glucagon-like peptide-1 and glucagon-like peptide-2. Can J Physiol Pharmacol, 2003. 81 (11): p. 1005-12.

3. Savastano, D.M. and M. Covasa, Intestinal nutrients elicit satiation through concomitant activation of CCK(1) and 5-HT(3) receptors. Physiol Behav, 2007. 92(3): p. 434-42.

4. Parnell, J.A. and R.A. Reimer, Differential secretion of satiety hormones with progression of obesity in JCR:LA-corpulent rats. Obesity (Silver Spring), 2008. 16(4): p. 736-42.

5. Balagopal, P.B., et al., Changes in Circulating Satiety Hormones in Obese Children: A Randomized Controlled Physical Activity-Based Intervention Study. Obesity (Silver Spring).

6. Saris, W.H. and M.A. Tarnopolsky, Controlling food intake and energy balance: which macronutrient should we select? Curr Opin Clin Nutr Metab Care, 2003. 6(6): p. 609-13.

7. Tome, D., Protein, amino acids and the control of food intake. Br J Nutr, 2004. 92 Suppl 1: p. S2730 .

8. Westerterp-Plantenga, M.S. and M.P. Lejeune, Protein intake and body-weight regulation. Appetite, 2005. 45(2): p. 187-90.

9. Bensaid, A., et al., Protein is more potent than carbohydrate for reducing appetite in rats. Physiol Behav, 2002. 75(4): p. 577-82.

10. Anderson, G.H. and S.E. Moore, Dietary proteins in the regulation of food intake and body weight in humans. J Nutr, 2004. 134(4): p. 974S-9S.

11. Blom, W.A., et al., Effect of a high-protein breakfast on the postprandial ghrelin response. Am J Clin Nutr, 2006. 83(2): p. 211-20.

12. Geraedts, M.C., et al., Release of satiety hormones in response to specific dietary proteins is different between human and murine small intestinal mucosa. Ann Nutr Metab, 2010. 56(4): p. 308-13.

13. Guan, D. and G.M. Green, Significance of peptic digestion in rat pancreatic secretory response to dietary protein. Am J Physiol, 1996. 271 (1 Pt 1): p. G42-7.

14. Goodyear, M.D., K. Krleza-Jeric, and T. Lemmens, The Declaration of Helsinki. Bmj, 2007. 335(7621): p. 624-5.

15. Flint, A., et al., Reproducibility, power and validity of visual analogue scales in assessment of appetite sensations in single test meal studies. Int J Obes Relat Metab Disord, 2000. 24(1): p. 38-48.

16. Hall, W.L., et al., Casein and whey exert different effects on plasma amino acid profiles, gastrointestinal hormone secretion and appetite. Br J Nutr, 2003. 89(2): p. 239-48.

17. Bowen, J., M. Noakes, and P.M. Clifton, Appetite regulatory hormone responses to various dietary proteins differ by body mass index status despite similar reductions in ad libitum energy intake. J Clin Endocrinol Metab, 2006. 91 (8): p. 2913-9.

18. Eggum, B.O., I. Hansen, and T. Larsen, Protein quality and digestible energy of selected foods determined in balance trials with rats. Plant Foods Hum Nutr, 1989. 39(1): p. 13-21.

19. Diepvens, K., D. Haberer, and M. Westerterp-Plantenga, Different proteins and biopeptides differently affect satiety and anorexigenic/orexigenic hormones in healthy humans. Int J Obes (Lond), 2008. 32(3): p. 510-8.

20. www.voedingscentrum.nl.

21. Veldhorst, M.A., et al., Comparison of the effects of a high-and normal-casein breakfast on satiety, 'satiety' hormones, plasma amino acids and subsequent energy intake. Br J Nutr, 2009. 101 (2): p. 295-303.

22. Bodmeier, R., H.G. Chen, and O. Paeratakul, A novel approach to the oral delivery of micro- or nanoparticles. Pharm Res, 1989. 6(5): p. 413-7.

23. Dhaliwal, S., et al., Mucoadhesive microspheres for gastroretentive delivery of acyclovir: in vitro and in vivo evaluation. Aaps J, 2008. 10(2): p. 322-30. 
24. Ichikawa, H. and Y. Fukumori, [Design of nanohydrogel-incorporated microcapsules for appropriate controlled-release of peptide drugs]. Yakugaku Zasshi, 2007. 127(5): p. 813-23.

25. Malik, D.K., et al., Recent advances in protein and peptide drug delivery systems. Curr Drug Deliv, 2007. 4(2): p. 141-51.

26. Mustata, G. and S.M. Dinh, Approaches to oral drug delivery for challenging molecules. Crit Rev Ther Drug Carrier Syst, 2006. 23(2): p. $111-35$.

27. Maljaars, J., et al., Effect of ileal fat perfusion on satiety and hormone release in healthy volunteers. Int J Obes, 2008. 32: p. 1633-1639.

28. Stricker-Krongrad, A., et al., Increased threshold concentrations of neuropeptide $Y$ for a stimulatory effect on food intake in obese Zucker rats--changes in the microstructure of the feeding behavior. Brain Res, 1994. 660(1): p. 162-6.

29. Lieverse, R.J., et al., Obese women are less sensitive for the satiety effects of bombesin than lean women. Eur J Clin Nutr, 1998. 52(3): p. 207-12.

30. Herman, C.P. and J. Polivy, External cues in the control of food intake in humans: the sensorynormative distinction. Physiol Behav, 2008. 94(5): p. 722-8.

31. Rogers, P.J. and J.E. Blundell, Umami and appetite: effects of monosodium glutamate on hunger and food intake in human subjects. Physiol Behav, 1990. 48(6): p. 801-4. 


\section{ChAPTER 7}

\section{VALIDATION OF USSING CHAMBER TECHNOLOGY TO STUDY SATIETY HORMONE RELEASE FROM HUMAN DUODENAL SPECIMENS}

MAARTJE C.P. GERAEDTS, FREDDY J. TROOST, ROGIER J.J. DE RIDDER, Alexander G.L. Bodelier, Ad A.M. MAsclee, WiM H.M. SARIS 


\section{ABSTRACT}

A better understanding of the effects of different food ingredients on hormone release and satiety is important for the development of novel, effective diets to treat and prevent obesity. By developing a novel screening technology to test the effects of food ingredients on hormone release, which is comparable to the in vivo situation, fewer tests may have to be performed using volunteers, whereas it still provides information that can be extrapolated to the human situation.

In an in vivo intervention study, ten lean (BMI: $20-25 \mathrm{~kg} / \mathrm{m}^{2}$ ) and ten obese (BMI>30 $\mathrm{kg} / \mathrm{m}^{2}$ ) were recruited. All subjects randomly received pea protein (PP) solutions or placebo (C), orally and intraduodenally via a naso-duodenal tube. CCK and GLP-1 release was measured over 2 hours. During the oral interventions, gastrointestinal fluids were retrieved. For the present ex vivo study, 15 out of the 20 subjects participating in the in vivo study were willing to participate. Duodenal biopsies were taken and placed in the Ussing chambers. The luminal side was exposed to PP, C, human intraduodenal fluid after oral PP- or oral C intake in vivo, a commercial pea hydrolysate, and a negative control, respectively, for 2 hours. CCK and GLP-1 levels were measured at the serosal side.

After intraduodenal PP vs C administration in vivo, the AUC for CCK release was $48.6 \pm 7$ vs $12.1 \pm 3(p<0.02)$ in the lean and $75.4 \pm 8$ vs $3.9 \pm 1(p<0.01)$ in the obese subjects. The AUC for GLP-1 release was $1117 \pm 226$ vs $379.5 \pm 83$ in the lean and 880 \pm 150 vs $4.9 \pm 84$ in the obese subjects. In the ex vivo study, exposure to PP resulted in significantly elevated levels of CCK $(22.6 \pm 1.5 \mathrm{pM}$ in lean subjects, $32.2 \pm 2.1 \mathrm{pM}$ in obese subjects) and GLP-1 (5.9 $\pm 0.2 \mathrm{pM}$ in lean subjects, $6.1 \pm 0.8 \mathrm{pM}$ in obese subjects) compared to all other test solutions $(\mathrm{p}<0.05)$.

These results indicate that the ex vivo Ussing chamber technology is a valid alternative for in vivo studies to study the release of satiety hormones from the gastrointestinal tract, and may therefore serve as a suitable screening tool for studying the effects of nutritional compounds on the release of satiety hormones. 


\section{INTRODUCTION}

Feelings of satiety and satiation are important factors in the physiological process of weight control. Satiety feelings are among others determined by gastrointestinal (GI) signals [1], such as the release of satiety hormones cholecystokinin (CCK) and glucagon like peptide 1 (GLP-1) [2]. Most hormones are secreted upon food intake, especially the appearance of proteins and fat in the gastrointestinal tract. These peptides, after secretion, contribute to termination of the meal. Since overweight and obesity have become a major health problem [3], several types of diets have focused on favourable macronutrient compositions in order to increase satiety leading to lower energy intake [4-9]. Of all diets that were previously tested, highprotein diets seem to have the largest effects on satiety and food intake [10, 11]. It is not known whether this effect is the same for different proteins. Moreover, recent data indicate that proteins from different sources affect satiety differently [9, 12-14]. A better knowledge on the capacity of different proteins to induce peptide release and satiety is crucial for developing diets effective for treatment and prevention of obesity. The golden standard to study the effects of proteins on secretion of satiety hormones and food intake is an intervention in human volunteers. However, a major drawback of application in humans is that only one product can be tested at the time, resulting in several demanding, time-consuming and costly human experiments. High-throughput systems to test the effects of several nutritional compounds on their effects on secretion of satiety hormones offer the possibility to reduce the amount of in vivo experiments, shorten the total study time and reduce the burden to volunteers.

A screening tool with a strong potential for high-throughput testing using an ex vivo tissue model is provided by the Ussing chamber technology. The Ussing chamber was first described in 1951 by the Danish physiologists Ussing and Zerhan [15]. It provides a powerful technique, in which tissue samples are kept viable outside of the body for several hours, and has many applications. It is mostly used to study ion transport, drug and protein absorption, and several pathophysiological processes both in animals and humans [16-19]. In addition to the possible applications of Ussing chambers, it provides a suitable model to study effects of a variety of compounds on tissue secretions. We recently showed that different types of proteins exert different effects on the release of CCK and GLP-1 by human intestinal mucosa (unpublished data). Pea and wheat protein were shown to be the most potent proteins to modulate the release of these satiety hormones. However, it is not known whether these results are also true for the human in vivo situation, and whether the increase of satiety hormones is actually correlated with food intake.

The aim of the present study was to validate the use of Ussing chambers for the study of satiety and food intake in humans. To this purpose, subjects that participated in a 
human in vivo study, which aimed to determine whether orally and intraduodenally administered proteins administration affect satiety hormone production and food intake regulation, were recruited for this validation study. In this study, the effects of the same proteins and breakdown products of these proteins after gastric transit in vivo were sampled and investigated in an ex vivo experiment on freshly obtained tissue from the duodenum of the same subject, using an Ussing chamber system. The Ussing chamber results on CKK and GLP-1 release was related to the outcome of the physiological outcome of the clinical intervention.

\section{MATERIAL AND METHODS}

\section{Subjects}

In the in vivo intervention study, twenty healthy male subjects were recruited. Of these twenty subjects, fifteen subjects were willing to participate in the additional study. Exclusion criteria were diabetes, gastrointestinal disorders and chronic medical treatment. Inclusion criteria for body mass index (BMI) was $18-25 \mathrm{~kg} /$ $\mathrm{m}^{2}$ for the healthy control group, and $>30 \mathrm{~kg} / \mathrm{m}^{2}$ for the obese group. Baseline characteristics of the subjects are presented in table 1. The nature and risks of the experimental procedure were explained to the subjects, and all subjects gave their written informed consent. This study was conducted according to the guidelines laid down in the Declaration of Helsinki [20] and the Medical Ethical Committee of the University Hospital Maastricht approved all procedures involving human subjects.

\begin{tabular}{lcc}
\hline & Lean $(\mathrm{n}=6)$ & Obese $(\mathrm{n}=9)$ \\
\hline Age (years) & $27 \pm 3$ & $44 \pm 6^{*}$ \\
BMl $\left(\mathrm{kg} / \mathrm{m}^{2}\right)$ & $23.6 \pm 0.5$ & $33.1 \pm 1.4^{*}$ \\
HbAlc $(\%)$ & $5.0 \pm 0.1$ & $5.0 \pm 0.1$ \\
Basal glucose $(\mathrm{mmol} / \mathrm{L})$ & $4.5 \pm 0.2$ & $4.5 \pm 0.1$ \\
\hline
\end{tabular}

Table 1. Subject characteristics

All data are mean \pm SEM

* Difference between lean and obese subjects $(p<0.05)$

\section{Study design}

In the in vivo protein intervention study (unpublished data), each subject participated in four experiments on separate occasions with 1 week between visits. On each occasion, subjects arrived after fasting overnight, and a nasoduodenal catheter (Flocare Bengmark, Nutricia, Zoetermeer, The Netherlands) was placed under fluoroscopic guidance. Subsequently, an intravenous catheter was placed in an antecubital vein in the forearm to enable venous blood sampling. The test drinks (for composition see 'Test solutions') were consumed at time 0 min. During 
the intraduodenal infusion of the drinks, the solution was infused for 30 minutes. During oral consumption of the test drinks, subjects were instructed to consume the solutions within 5 minutes. Subsequent blood samples were collected at $0,5,10$, $15,30,45,60,75,90$, and 120 minutes to measure satiety hormone levels. The area under the curve (AUC) over the 2 hours period was then calculated to compare the in vivo hormone release with the ex vivo hormone release, determined in the Ussing chamber experiments (see below). In addition, after the oral ingestion of the test drinks, gastrointestinal fluids from the duodenum were retrieved at 5-min intervals via the nasoduodenal catheter. The samples taken at 30 minutes after ingestion were used in the ex vivo study to mimic the oral protein and placebo ingestion.

For the ex vivo study, duodenal biopsies (for tissue sampling procedure see 'Duodenal biopsy specimens') were taken on a separate occasion, within 3 weeks after the last test day from the in vivo study. The biopsies were placed in the Ussing chambers, and exposed to a negative control (HBSS buffer), intact pea protein, placebo (water with vanilla), gastrointestinal fluid after oral protein ingestion from the same subject, gastrointestinal fluid after placebo ingestion from the same subject, and a commercial pea protein hydrolysate. Satiety hormone levels were measured after 2 hours of exposure to the test solutions. Details on the Ussing chamber experiments are provided below. Results from the ex vivo study on hormone release were compared to the previous findings in the in vivo study (unpublished data).

\section{Test solutions}

Proteins were provided in a drink ( $4 \mathrm{ml}$ per kg of body weight), containing either pea protein (250 mg per kg of bodyweight) (Dutch Protein Services, Tiel, The Netherlands) or water as placebo in a covered bottle. The drinks were uniformly flavored with $5 \mathrm{~g}$ cream vanilla flavor (Quest International, Naarden, The Netherlands) per liter beverage to make the taste comparable.

\section{Duodenal biopsy specimens}

All subjects received a standardized meal $19 \mathrm{~g}$ protein, $39.5 \mathrm{~g}$ carbohydrates, 16 $g$ fat) for the evening prior to the day that a biopsies were taken to standardize macronutrient intake. After an overnight fast, eight mucosal tissue samples from the horizontal part of the duodenum were obtained by flexible gastroduodenoscopy using standard biopsy forceps. The diameter of the biopsies taken varied from 2.0 $\mathrm{mm}$ to $2.2 \mathrm{~mm}$. During this procedure, no sedatives were given to the subjects. After sampling, the biopsies were placed in ice-cold Krebs-Ringer bicarbonate buffer (KRB) and arrived at the laboratory within $15 \mathrm{~min}$.

\section{Ussing Chamber experiments}

Duodenal biopsies were mounted in modified Ussing Chambers (Harvard Apparatus Inc., Holliston, Mass., USA) with a 9-mm opening and reduced to an exposed tissue area of $1.76 \mathrm{~mm}^{2}$, using a technique previously described by Wallon et al [21, 22]. Mucosal compartments were filled with $1.5 \mathrm{ml} 10 \mathrm{mM}$ mannitol in KRB and the serosal 
compartments were filled with $10 \mathrm{mM}$ glucose in KRB. The chambers were kept at $37^{\circ} \mathrm{C}$ and continuously oxygenated, $95 \% \mathrm{O}_{2} / 5 \% \mathrm{CO}_{2}$ and circulated by gas flow. Before the experiments were started, tissues were equilibrated for $40 \mathrm{~min}$ in the chambers to achieve steady-state conditions in transepithelial potential difference (PD), with replacement of mannitol or glucose KRB at 20 min. A four-electrode system was used, as described previously [23]. One pair of $\mathrm{Ag} / \mathrm{Cl}$ electrodes with $3 \mathrm{M} \mathrm{NaCl}$ / $2 \%$ agar bridges was used for measurement of transepithelial PD and another pair of $\mathrm{Ag} / \mathrm{Cl}$ electrodes was used to monitor current. The electrodes were coupled to an external 6-channel electronic unit with a voltage controlled current source. Data sampling was computer controlled via an A/D D/A board (Lab NB, National Instruments, USA) by a program developed in LabVIEW (National Instruments, USA) by Wikman-Larhed et al [24]. Every other minute, direct pulses of -3, 3, and $0 \mu \mathrm{A}$, with a duration of 2 seconds each, were sent across the tissue segments and the voltage response was measured. During each measurement, the mean voltage response of 2 seconds was calculated. A linear-squares fit was performed on the current (I) voltage (U) pair relationship: $U$ = PD + TER $\times$ I. The TER was obtained from the slope of the $\mathrm{I}-\mathrm{U}$ line and the PD from the intersection of the voltage.

After the equilibration period, the mucosal side of the biopsies were exposed to a negative control, intact pea protein, placebo, gastrointestinal fluid after oral protein ingestion from the same subject, gastrointestinal fluid after placebo ingestion from the same subject, and a commercial pea protein hydrolysate (DSM, Food Specialties, Delft, The Netherlands). Serosal samples (1.25 ml) were collected at the end of the experiment (after $2 \mathrm{~h}$ ) for CCK- and GLP-1 analysis.

Biopsies with PD less negative than $-0.5 \mathrm{mV}$ were excluded for further analysis because of malfunction in the ability to uphold normal electrophysiology.

\section{Hormone assays}

CCK levels were determined using the RIA from Euria-CCK, Euro-Diagnostica AB, Malmö, Sweden. According to the manufacturers instructions, the detection limit of this kit was $0.3 \mathrm{pmol} / \mathrm{L}$. The intra-assay variation ranges from 2.0 to $5.5 \%$ and the inter-assay variation from 4,1 to $13,7 \%$. Cross-reaction with gastrin is $0.5 \%$. Total GLP1 levels were determined using the RIA from Linco Research, Missouri, USA. The detection limit of this kit was 3 to $333 \mathrm{pM}$. The intra-assay variation ranges from 10 to $23 \%$ and the inter-assay variation from 22 to $38 \%$. There is no cross-reaction with GLP2 and glucagon $(0.01 \%$ and $0.2 \%$, respectively). GLP-1 samples were spiked with 100 PM of GLP-1 to be within range of the detection limit. Both RIAs can be used for the analysis of both rat and human samples.

\section{Statistical Analyses}

The descriptive and statistical analyses were performed with SPSS, version 11.0. Comparison of the electrophysiological parameters was done using the Wilcoxon signed rank test. Comparison of means of the secreted hormones between groups 
was done using an unpaired Student t-test. Comparison of mean of the secreted hormones within a group was done using a paired Student t-test. All Student t-tests were corrected for multiple testing using the Bonferroni correction. The means of the variables are presented with their standard error (mean \pm SEM). A P-value of less than 0.05 was considered statistically significant.

\section{RESULTS}

\section{Hormone release}

In the ex vivo study, basal CCK levels of $5.9 \mathrm{pM} \pm 1.1$ were observed in lean subjects, whereas basal CCK levels of obese subjects were significantly higher compared to the lean, namely $14.4 \mathrm{pM} \pm 3.1 \quad(\mathrm{p}<0.05)$ (figure $1 \mathrm{~A})$. Addition of intact pea protein or gastric digested pea protein to biopsies of lean subjects resulted in CCK levels of $22.6 \mathrm{pM} \pm 1.5$ and $6.6 \mathrm{pM} \pm 0.9$, respectively. For obese subjects CCK levels were significantly higher compared to lean subjects $(32.2 \mathrm{pM} \pm 2.1$ and 12.9 $\mathrm{pM} \pm 2.0$, respectively; $\mathrm{p}<0.05)$. Also, addition of intact protein to the duodenal biopsies resulted in significantly increased CCK levels when compared to all other test products $(p<0.05)$. All other test products did not affect CCK release when compared to the negative control. In the in vivo study, areas under the curve (AUC) CCK levels were increased in both lean (48.6 pM \pm 7) and obese subjects (75.4 pM \pm 8 ) after intraduodenal protein administration (figure 1B). Oral ingestion of pea protein in lean subjects resulted in significantly increased AUC CCK levels $(p<0.05)$ when compared to the placebo.

Basal GLP-1 secretions levels of $4.5 \mathrm{pM} \pm 0.4$ (figure $2 \mathrm{~A}$ ) were observed in the ex vivo study, with no differences between lean and obese subjects. Addition of intact pea protein to the luminal side significantly increased GLP-1 levels (5.9 PM \pm 0.2 in lean subjects, and $6.1 \mathrm{pM} \pm 0.8$ in obese subjects) when compared to negative control and all other test products $(p<0.05)$. All other test products did not affect GLP-1 release when compared to the negative control. Intraduodenal pea protein infusion in the in vivo study resulted in significantly increased AUC GLP-1 levels when compared to the placebo treatment $(p<0.05)$ for both the lean (1117.1 $p M \pm 226$ ) and obese subjects (880.7 pM \pm 150 ) (figure 2B). 
A

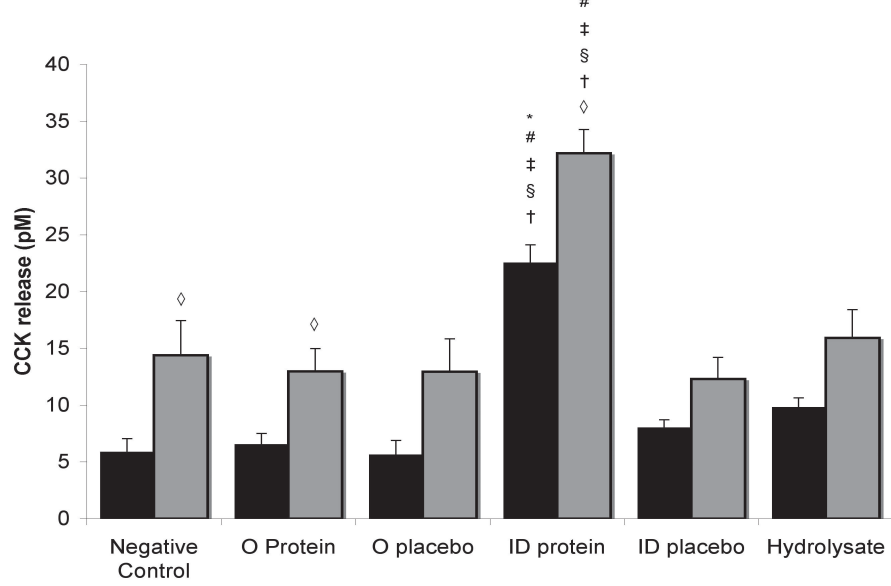

B

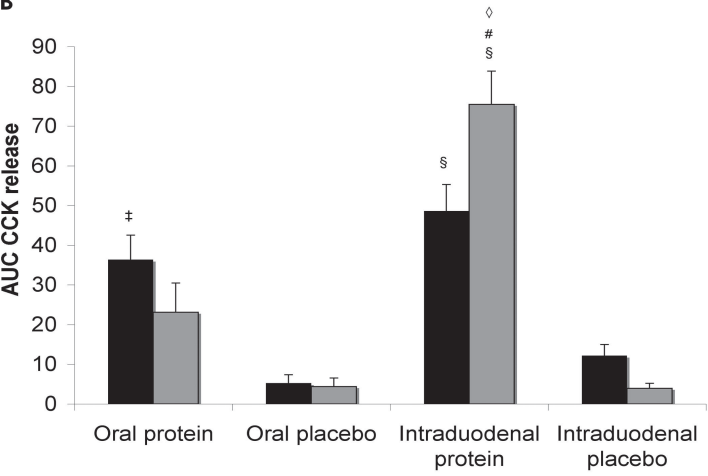

Figure 1. CCK release from human duodenal biopsies in Ussing Chambers (A) and from the in vivo intervention study (B). The CCK concentrations were determined at the basolateral side of the biopsies in the Ussing chambers after apical exposure to intraduodenal fluid, obtained upon ingestion of placebo (O Placebo) and pea protein (O Protein), and after addition of placebo (ID placebo), pea protein (ID Protein), and a pea hydrolysate, respectively (O: Oral; ID: Intraduodenal), to the apical side of the Ussing chambers for a period of $2 \mathrm{~h}$ (A). AUC levels of the CCK release measured in the in vivo intervention study are presented in figure B. Results are expressed as mean \pm SEM. * Significantly different from negative control $(p<0.05)$. \# Significantly different from oral protein $(p<0.05)$. $\ddagger$ Significantly different from oral pla. cebo ( $p<0.05)$. § Significar $\ y$ different from intraduodenal placebo $(p<0.05)$. + Significantly different from pea hydrolysate $(p<0.05)$. Significantly different from lean group $(p<0.05)$. 
A
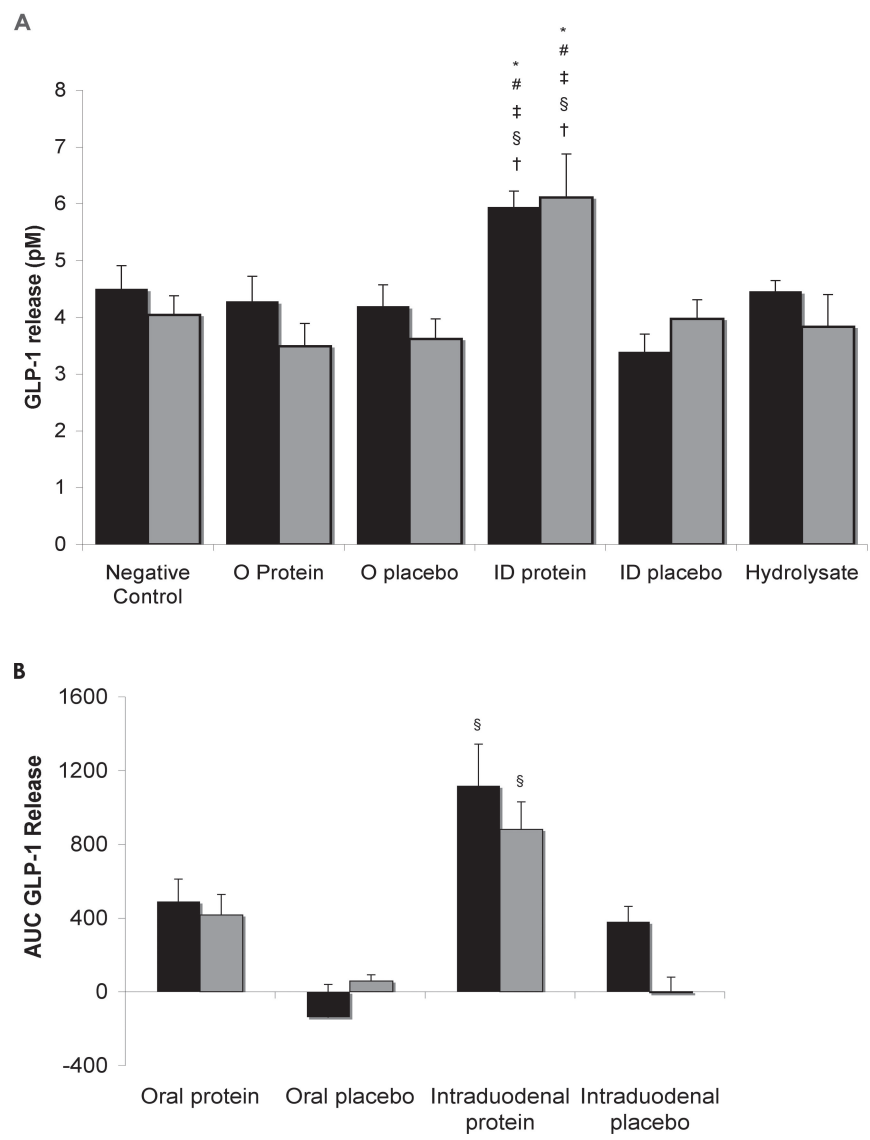

Figure 2. GLP-1 release from human duodenal biopsies in Ussing Chambers (A) and from the in vivo intervention study (B). The GLP-1 concentrations were determined at the basolateral side of the biopsies in the Ussing Chambers after apical exposure to intraduodenal fluid, obtained upon ingestion of placebo (O Placebo) and pea protein (O Protein), and after addition of placebo (ID placebo), pea protein (ID Protein), and a pea hydrolysate, respectively (O: Oral; ID: Intraduodenal), to the apical side of the Ussing chambers for a period of $2 \mathrm{~h}$ (A). AUC levels of the GLP-1 release measured in the in vivo intervention study are presented in figure B. * Significantly different from negative control $(p<0.05)$. \# Significantly different from oral protein $(p<0.05)$. I Significantly different from oral placebo $(p<0.05)$. $\S$ Significantly different from intraduodenal placebo ( $p<0.05)$. † Significantly different from pea hydrolysate $(p<0.05)$.

\section{Electrical Measurements}

The electrical parameters PD, ISC, and TER were followed over time. Basal electrical properties of all biopsies were measured. After an equilibration period of $40 \mathrm{~min}$, the mean PD of $-1.8 \mathrm{mV} \pm 0.3$ was observed. Overall, no changes in PD, TER, and Isc were observed in the following 120 minutes compared to the negative control. 


\section{DISCUSSION}

The present study clearly shows that exposing duodenal biopsies ex vivo to dietary ingredients gives similar results compared to in vivo intervention studies. Intact pea protein induced larger effects on both CCK and GLP-1 release by the tissue than partly digested pea protein, which was sampled from the intestinal lumen after gastric transit upon oral protein intake. This confirms recent findings from the in vivo intervention study, in which intraduodenal administration of pea protein was shown to affect satiety hormones and more importantly food intake to a larger extent than oral intake of the same protein (submitted).

Many in vitro and in vivo studies have been performed to study the effects of nutritional compounds on the release of satiety hormones and food intake. However, the translation from in vitro results to in vivo remains very difficult. Effects found in in vitro studies may not be applicable in the human situation. Even human in vivo studies are subject to specific concerns. In general, many subjects have to be tested in a placebo controlled cross-over design, which is very labour- and costs intensive. Also, the choice of test population is important. By using the Ussing chambers as an alternative model to study effects of dietary interventions on human physiological processes, the translation from in vitro to in vivo findings might be easier. The original method described by Ussing was complex and subsequent modified in 1988 by Grass and Sweetana [25].

The main advantage of the Ussing chamber technology is that more experiments can be performed at the same time, using tissue from a single subject. Also, since the Ussing chambers provide a tool to study human physiology ex vivo on human tissue, containing a variety of different cell types that reside in the human intestinal mucosa, it is likely that this bears more relevance to the human in vivo situation than in vitro studies, in which in most cases a single cell line is studied. However, since there is no literature available on satiety hormone secretion in Ussing chambers, it was previously unclear whether the effects found are representative for the in vivo situation. In the present study, we demonstrated that the significant increase in CCK and GLP-1 levels after addition of intact pea protein to duodenal tissue samples, observed in the Ussing chamber study, confirmed the findings from the human in vivo study. In the in vivo study, we showed that intraduodenal infusion of intact protein induced the strongest effects on hormone release and decreased food intake significantly when compared to intraduodenal administration of placebo and also compared to oral protein- and placebo ingestion.

Even though the CCK release was significantly higher in obese subjects after intraduodenal protein administration compared to lean subjects, it was quite surprising that the release of CCK from intestinal tissue, as determined in the Ussing chamber experiments, was also significantly different between lean and obese 
subjects. Biopsies used in this study had a diameter of approximately $2.0 \mathrm{~mm}$ to $2.2 \mathrm{~mm}$, and the exposed area was $1.76 \mathrm{~mm}^{2}$ in each experiment. Secretion from such a small piece tissue is very low but apparently, high enough to differentiate between lean and obese subject. We have to take into account that the distribution of the enteroendocrine cells may not be the same in each tissue sample. This means that the differences in hormone secretion found in the present study may not only be due to the stimulation of the proteins, but are also due to the amount of enteroendocrine cells present in the biopsy, although this is unlikely because such differences in tissue composition will probably have been the same on average in both groups. Ideally, the obtained specimens should also be characterised for enteroendocrine cell expression to correct for any differences in tissue composition. However, due to the lack of sufficient amounts of tissue to study tissue histology, this was not possible in the present study. Because the effects found in Ussing chambers match the in vivo data, we can assume that the differences found are indeed caused by the addition of the proteins, and that the distribution of enteroendocrine cells does not affect the study outcome.

Electrical parameters, which are monitored in the Ussing chambers, are widely accepted for monitoring the viability and integrity of tissue in the Ussing Chambers. In general, PD reflects the voltage gradient generated by the tissue, TER reflects the tissue integrity, and Isc reflects the ionic fluxes across the epithelium [25-27]. In the present study, basal electrical parameters varied over a wide range. This variability has also been noticed in previous studies on human tissue samples from jejunum [28] and colon [29]. Moreover, the reported electrical parameters from investigators using different Ussing chambers on biopsy specimens from the same gastrointestinal region have been associated with a large variability. To correct for this variability, the areas under the curves have been calculated, after correcting for baseline values for each biopsy. The electrophysiology results from our study were comparable with those found in literature, and showed that all biopsies used in this study were viable throughout the experiments. Addition of the test products to the apical side did not affect resistance and short circuit current compared to the negative control.

In conclusion, we have developed and validated a new tool to study the effects of dietary interventions on intestinal hormone secretion. This study showed that the Ussing chamber technology provides a valid screening tool to select the most successful nutrients or other compounds to affect parameters that are associated with the development of obesity, which can subsequently be studied in a human intervention study. 
1. Woods, S.C. 2004. Gastrointestinal satiety signals I. An overview of gastrointestinal signals that influence food intake. Am J Physiol Gastrointest Liver Physiol 286:G7-13.

2. Strader, A.D., and Woods, S.C. 2005. Gastrointestinal hormones and food intake. Gastroenterology 128:175-191.

3. 2000. Obesity: preventing and managing the global epidemic. Report of a WHO consultant. World Health Organ Tech Rep Ser 894:1-253.

4. Adam, T.C., Lejeune, M.P., and Westerterp-Plantenga, M.S. 2006. Nutrient-stimulated glucagonlike peptide 1 release after body-weight loss and weight maintenance in human subjects. $\mathrm{Br} \mathrm{J}$ Nutr 95:160-167.

5. Anderson, G.H., and Moore, S.E. 2004. Dietary proteins in the regulation of food intake and body weight in humans. J Nutr 134:974S-979S.

6. Blom, W.A., Lluch, A., Stafleu, A., Vinoy, S., Holst, J.J., Schaafsma, G., and Hendriks, H.F. 2006. Effect of a high-protein breakfast on the postprandial ghrelin response. Am J Clin Nutr 83:21 1-220.

7. Westerterp-Plantenga, M.S., and Lejeune, M.P. 2005. Protein intake and body-weight regulation. Appetite 45:187-190.

8. Bernard, C., Sutter, A., Vinson, C., Ratineau, C., Chayvialle, J., and Cordier-Bussat, M. 2001. Peptones stimulate intestinal cholecystokinin gene transcription via cyclic adenosine monophosphate response element-binding factors. Endocrinology 142:721-729.

9. Hall, W.L., Millward, D.J., Long, S.J., and Morgan, L.M. 2003. Casein and whey exert different effects on plasma amino acid profiles, gastrointestinal hormone secretion and appetite. Br J Nutr 89:239-248.

10. Westerterp-Plantenga, M.S. 2003. The significance of protein in food intake and body weight regulation. Curr Opin Clin Nutr Metab Care 6:635-638.

11. Saris, W.H., and Tarnopolsky, M.A. 2003. Controlling food intake and energy balance: which macronutrient should we select? Curr Opin Clin Nutr Metab Care 6:609-613.

12. Anderson, G.H., Tecimer, S.N., Shah, D., and Zafar, T.A. 2004. Protein source, quantity, and time of consumption determine the effect of proteins on short-term food intake in young men. $J$ Nutr 134:3011-3015.

13. Bowen, J., Noakes, M., and Clifton, P.M. 2006. Appetite regulatory hormone responses to various dietary proteins differ by body mass index status despite similar reductions in ad libitum energy intake. J Clin Endocrinol Metab 91:2913-2919.

14. Lang, V., Bellisle, F., Oppert, J.M., Craplet, C., Bornet, F.R., Slama, G., and Guy-Grand, B. 1998. Satiating effect of proteins in healthy subjects: a comparison of egg albumin, casein, gelatin, soy protein, pea protein, and wheat gluten. Am J Clin Nutr 67:1 197-1204.

15. Ussing, H.H., and Zerahn, K. 1999. Active transport of sodium as the source of electric current in the short-circuited isolated frog skin. Reprinted from Acta. Physiol. Scand. 23: 110-127, 1951. J Am Soc Nephrol 10:2056-2065.

16. Holtug, K., Hansen, M.B., and Skadhauge, E. 1996. Experimental studies of intestinal ion and water transport. Scand J Gastroenterol Suppl 216:95-110.

17. Hillgren, K.M., Kato, A., and Borchardt, R.T. 1995. In vitro systems for studying intestinal drug absorption. Med Res Rev 15:83-109.

18. Smith, P.L. 1996. Methods for evaluating intestinal permeability and metabolism in vitro. Pharm Biotechnol 8:13-34.

19. Heyman, M., Boudraa, G., Sarrut, S., Giraud, M., Evans, L., Touhami, M., and Desjeux, J.F. 1984. Macromolecular transport in jejunal mucosa of children with severe malnutrition: a quantitative study. J Pediatr Gastroenterol Nutr 3:357-363.

20. Goodyear, M.D., Krleza-Jeric, K., and Lemmens, T. 2007. The Declaration of Helsinki. Bmj 335:624625.

21. Wallon, C., Braaf, Y., Wolving, M., Olaison, G., and Soderholm, J.D. 2005. Endoscopic biopsies 
in Ussing chambers evaluated for studies of macromolecular permeability in the human colon. Scand J Gastroenterol 40:586-595.

22. Wallon, C., Yang, P.C., Keita, A.V., Ericson, A.C., McKay, D.M., Sherman, P.M., Perdue, M.H., and Soderholm, J.D. 2008. Corticotropin-releasing hormone (CRH) regulates macromolecular permeability via mast cells in normal human colonic biopsies in vitro. Gut 57:50-58.

23. Soderholm, J.D., Hedman, L., Artursson, P., Franzen, L., Larsson, J., Pantzar, N., Permert, J., and Olaison, G. 1998. Integrity and metabolism of human ileal mucosa in vitro in the Ussing chamber. Acta Physiol Scand 162:47-56.

24. Wikman-Larhed, A., and P., A. 1995. Co-cultures of human intestinal goblet (HT29-H) and absorptive (Caco-2) cells for studies of drug and peptide absorption Eur J Pharm Sci 3:171-183.

25. Grass, G.M., and Sweetana, S.A. 1988. In vitro measurement of gastrointestinal tissue permeability using a new diffusion cell. Pharm Res 5:372-376.

26. Karlsson, J., and Artursson, P. 1992. A new diffusion chamber system for the determination of drug permeability coefficients across the human intestinal epithelium that are independent of the unstirred water layer. Biochim Biophys Acta $1111: 204-210$.

27. Larsen, R., Mertz-Nielsen, A., Hansen, M.B., Poulsen, S.S., and Bindslev, N. 2001. Novel modified Ussing chamber for the study of absorption and secretion in human endoscopic biopsies. Acta Physiol Scand 173:213-222.

28. Reims, A., Strandvik, B., and Sjovall, H. 2006. Epithelial electrical resistance as a measure of permeability changes in pediatric duodenal biopsies. J Pediatr Gastroenterol Nutr 43:619-623.

29. Taylor, C.J., Baxter, P.S., Hardcastle, J., and Hardcastle, P.T. 1988. Failure to induce secretion in jejunal biopsies from children with cystic fibrosis. Gut 29:957-962.

30. Tominaga, M., Tsukada, H., Hosokawa, M., Nakamura, H., Taniguchi, T., Ueda, S., Sakai, M., and Okuma, M. 1996. ONO-1078 antagonizes diarrhea-causing changes in ion transport and smooth muscle contraction induced by peptidoleukotrienes in rat and human colon in vitro. J Pharmacol Exp Ther 278:1058-1063. 


\section{ChApter 8}

\section{DIFFERENT TASTANTS AND LOW- CALORIC SWEETENERS INDUCE DIFFERENTIAL EFFECTS ON THE RELEASE OF SATIETY HORMONES}

MAARTJE C.P. GERAEDTS, FREDDY J. TROOST, WIM H.M. SARIS 


\section{ABSTRACT}

Recent studies have found different types of taste receptors located along the intestine. However, the effect of tastants, and in particular sweet tastants, on satiety hormone release is still unknown.

STC-1 cells were incubated with different concentrations of bitter, sour, sweet, salty, and umami tastants. After incubation with different time-periods, CCK and GLP-1 concentrations were measured in the supernatant using RIA.

All tastants increased CCK levels both dose- and time-dependently. GLP-1 release dose-dependently increased after addition of all tastants, with the exception of HAc. GLP-1 was released in a time-dependent manner after addition of all tastants, but bitter tastants stimulated GLP-1 release only during the first 15 minutes of exposure. All commercial sweeteners elevated CCK and GLP-1 levels, with Tagatesse ${ }^{\circledR}$ exerting the strongest effects.

Tastants, and in particular sweet, play a role in the regulation of satiety hormone release, both in a concentration- and time-dependent manner. 


\section{INTRODUCTION}

The endocrine and paracrine responses of the gastrointestinal (Gl) tract to food ingestion are complex. After food intake, a number of peptide hormones, such as cholecystokinin (CCK) and glucagon-like peptide 1 (GLP-1), are released from the GI tract to mediate among others satiation [1]. For centuries it was believed that especially the macronutrient composition and caloric density of the diet, triggered the release of these hormones [2]. However, in the past few years, taste receptors that are commonly found on the tongue were also found in the Gl tract. It is now generally believed that the epithelium lining the inner surface of the GI tract can sense chemical components of the luminal contents through the gustatory system [3], and that the release of satiety hormones can be mediated by these chemical components.

The gustatory system is known to detect umami, sweet, salty, sour, and bitter tasting substances. Evidence that the mammalian Gl tract may be able to sense taste comes from studies in cell lines and animal models. Sweet taste receptors (T1R2 and T1R3), bitter taste receptors (T2Rs), and $\alpha$-gustducin have recently been reported to be expressed in enteroendocrine cells of the small intestine and colon, which secrete CCK and GLP-1 [4-7]. Addition of tastants representing different tastes to enteroendocrine cells increased the intracellular $\mathrm{Ca}^{2+}$ in a dose dependent manner [8]. Chen et al [9] showed that bitter tastants affect CCK release from the enteroendocrine STC-1 cells. In a human L cell line ( $\mathrm{NCl}-\mathrm{H} 716)$, glucose and sucralose induced GLP-1 secretion. This effect was prevented by addition of the sweet taste receptor antagonist lactisole [10].

In relation to the current obesity epidemic, suggestions have been made about the possible role of an increased consumption of sweetened beverages. Rodent data suggest that sweeteners alter feeding behaviour. Rats given low-energy saccharinflavoured gelatin are hyperphagic and become obese, relative to rats fed highenergy saccharin-flavoured food [11]. In a human study, ingestion of sucralose, delivered by intragastric infusion, did not stimulate insulin, GLP-1, or GIP release, and gastric emptying rate was not inhibited, whereas intragastric infusion of sucrose did stimulate insulin, GLP-1, and GIP release and inhibit gastric emptying rate [12]. These data suggest that there may be differences in gut responses after exposure to different types of equally sweet compounds.

The primary aim of the current study was to confirm that gastrointestinal cells respond in both a dose- and time dependent way to tastants. Secondly, this study aimed to determine whether the gastrointestinal peptide hormone release differs between sweeteners commonly used as sugar replacers. STC-1 cells are used as a model system to investigate the secretory responses initiated by the basic tastes in enteroendocrine GI cells. The STC-1 cells have been used previously for studying 
the regulation of GI hormone release, such as CCK, GLP-1, and PYY in response to nutrients such as fatty acids [13] and proteins [14,15]. It was also previously established that this cell line expresses gustatory receptors $[16,17]$.

\section{MATERIALS AND METHODS}

\section{Tastants}

A total of ten different tastants were investigated. For bitter taste, denatonium bezoate (DB) and quinine (both products from Sigma-Aldrich, Germany) were used. For sweet taste, sucrose, sucralose, and erythritol were used. For umami taste, monosodium glutamate (MSG) was used. For salty taste, sodium chloride (SigmaAldrich, Germany) was used, and for sour taste, hydrochlorid acid (HCl) and acetic acid (HAC) (both products from Merck, VWR International, The Netherlands) were used.

\section{Sweeteners}

Splenda ${ }^{\circledR}$ (Sucralose, Splenda, Washigton, USA), Tagatesse ${ }^{\circledR}$ (Sucralose, Damhert, Heusden-Zolder, Belgium), Natrena ${ }^{\circledR}$ (Acesulfame-K, Natrena, Den Haag, The Netherlands), Candare ${ }^{\circledR}$ (Aspartame, Candarel, Zoetermeer, The Netherlands), and Stevia ${ }^{\circledR}$ (Stevia, Stevia, Terneuzen, The Netherlands) were used to investigate the differences between sweeteners. Sucrose was used as control.

\section{Cell culture conditions}

The STC-1 cell line is derived from an intestinal endocrine tumor that developed in a double-transgenic mouse expressing the rat insulin promotor linked to the simian virus 40 large $T$ antigen and the polyoma small T antigen [18]. STC-1 cells (kindly provided by Dr. D. Hanahan, University of California, San Francisco) were maintained in Dulbecco's Modified Eagles Medium (DMEM) with 10\% fetal bovine serum (FBS), 2 mM L-glutamine, 100 units/ml penicillin, and $100 \mu \mathrm{g} / \mathrm{ml}$ streptomycin as additional supplements, at $37^{\circ} \mathrm{C}$ in $5 \% \mathrm{CO}_{2}$ /air humidity. All products were obtained from Invitrogen, Carlsbad, California, USA, unless stated otherwise.

\section{Secretion of CCK and GLP-1 from STC-1 cells}

To determine the secretion of CCK and GLP-1 from STC-1 cells, suspensions of these cells were plated at $1.0 \times 10^{5}$ cells/well in 24-well plates (Costar) and assays were performed on cultures that reached at least $80 \%$ confluency. Before treatment with tastants and/or inhibitors, culture medium was removed and dishes were rinsed with HBSS. Cells were then incubated with various concentrations of tastants according to the previously described study of Saitoh et al. [8]. In that study, different concentrations of tastants were used to monitor the calcium influx. In the present study, we used the same concentrations to measure the effects of the different tastants on the release of CCK and GLP-1. After the determination of the 
optimal concentration, the cells were incubated with these tastants at $37^{\circ} \mathrm{C}$ for various time periods $(5,15,30,45,60,90$, and $120 \mathrm{~min}$, respectively). The supernatant was collected for the measurement of CCK and GLP-1. As a negative control, HBSS buffer was used for both concentration and time dependent studies.

All sweeteners were tested in an increasing range of concentrations. As control, sugar cubes (sucrose) were used. Either 1, 2, 4, or 8 sugar cubes were dissolved in $300 \mathrm{ml}$ of HBSS $(200 \mathrm{ml}$ as volume) for one coffee or thee consumption, and $100 \mathrm{ml}$ as basal gastric juice volume. All other sweeteners were dissolved accordingly to match the sweetness of the sugar dosages, meaning 1, 2, 4, or 8 tablets in $300 \mathrm{ml}$ of HBSS buffer.

\section{Extracellular $\mathrm{Ca}^{2+}$ influx inhibition assay}

To investigate the role of the influx of extracellular $\mathrm{Ca}^{2+}$, cells were pretreated in the absence (HBSS) or in the presence of $1 \mu \mathrm{M}$ nitrendipine (a calcium channel blocker) for $30 \mathrm{~min}$ or $1.25 \mathrm{mM}$ EGTA (a calcium chelator) for $2 \mathrm{~min}$. After addition of the tastants, cultures were incubated at $37^{\circ} \mathrm{C}$ for $30 \mathrm{~min}$. Subsequently, the supernatant was collected for the measurement of CCK and GLP-1. All analysis were performed in triplicate, using three biological replicate samples.

\section{Measurement of CCK and GLP-1}

CCK levels were determined using radio-immuno assays (RIA) (Euria-CCK, EuroDiagnostica $A B$, Malmo, Sweden), according to the manufacturers instructions. GLP-1 levels were determined using RIA (GLPIT-36HK, Linco Research, Missouri, USA), according to the manufacturers instructions. All analyses were performed in triplicate, using three biological replicate samples.

\section{Statistical analysis}

The descriptive analyses were performed with SPSS, version 11.0. The delta of the means of the variables is presented with their standard error of the mean (mean \pm SEM). The means of the secreted hormones of the different groups were compared using a paired Student t-test with unequal variance. All Student t-tests were corrected for multiple testing using the Bonferroni correction. A P-value of less than 0.05 was considered statistically significant.

\section{RESULTS}

\section{Concentration dependent release of satiety hormones}

The effects of the different tastant concentrations are presented in figure 1. Five different concentrations of the bitter tastants, ranging from 0.63 to $10 \mathrm{mM}$ of DB and quinine were tested on the STC-1 cells. DB induced CCK and GLP-1 release in a dose dependent manner, with highest concentrations of CCK (21.0 pM \pm 3.1$)$ and GLP-1 (195.9 $\mathrm{pM} \pm 21.8$ ) after addition of $10 \mathrm{mM}$ DB. Quinine also stimulated the hormone 
release in a dose dependent manner, with highest CCK levels of $10.3 \mathrm{pM} \pm 0.8$, and GLP-1 levels of $86.3 \mathrm{pM} \pm 2.0$ after addition of $10 \mathrm{mM}$ quinine. To study the effects of sweet tastants on the release of hormones, we used the tastants sucrose, sucralose, and erythritol, respectively. Because sucralose and erythritol are perceived as more sweet, compared to sucrose, we used different concentrations. For sucrose, the tested concentrations ranged from $37.5 \mathrm{mM}$ to $600 \mathrm{mM}$, and for sucralose and erythritol we used concentrations ranging from $3 \mathrm{mM}$ to $300 \mathrm{mM}$. Only the highest concentration of sucrose (600 mM) and sucralose (150 mM and $300 \mathrm{mM})$ were able to stimulate CCK and GLP-1 levels. Erythritol did not stimulate CCK and GLP-1 release. Addition of the umami tastant MSG to the STC-1 cells induced CCK release, but not in a dose dependent manner. All concentrations of MSG (ranging from 3.75 $\mathrm{mM}$ to $60 \mathrm{mM}$ ) affected CCK release to the same extent (CCK levels ranged from $6.5 \mathrm{mM}$ to $10.2 \mathrm{mM}$ ). GLP-1 release was affected dose-dependently by the addition of MSG. The highest concentration of MSG induced significantly higher levels of GLP-1 compared to the negative control. The sour tastant $\mathrm{NaCl}$ affected CCK and GLP-1 release dose-dependently. Both CCK and GLP-1 reached highest levels after addition of $400 \mathrm{mM} \mathrm{NaCl}(21.2 \mathrm{pM} \pm 6.3$ and $560.9 \mathrm{pM} \pm 15.1$, respectively). Only the sour tastant $\mathrm{HCl}$ affected the release of both CCK and GLP-1. Addition of different concentrations (ranging from $0.75 \mathrm{mM}$ to $12 \mathrm{mM}$ ) of $\mathrm{HCl}$ increased CCK release to the same extent, whereas GLP-1 release increased dose-dependently. Addition of $\mathrm{HAc}$ to the cells resulted in an increase of CCK release only after addition of the highest concentration. It did not affect GLP-1 release.

\section{Time dependent release of satiety hormones}

The time-dependent effects of the different tastant on CCK and GLP-1 are presented in figure 2. The lowest effective concentrations of each tastant were used to study the release over time. CCK concentrations gradually increased over time after addition of both DB and quinine (figure 2A). GLP-1 release showed a different pattern over time (figure 2B). The levels of GLP-1 reached peak concentrations within 15 minutes after exposure to quinine (599.1 pM \pm 31.8 ), and within 30 minutes with $\mathrm{DB}$ (599.5 pM \pm 15.1 ) and subsequently the GLP-1 levels decreased. After exposure to the sweet tastants, sucrose and sucralose stimulated increasing CCK and GLP-1 levels over time. Sucrose induced the strongest effects on CCK release (figure 2C), whereas sucralose induced the strongest effects on GLP-1 release (figure 2D). The release of CCK over time (figure 2E) increased after addition of MSG. GLP-1 release (figure 2F) was not time-dependently affected by addition of MSG. 45 minutes after addition of MSG, GLP-1 levels reached a maximum of $211.9 \mathrm{pM} \pm 2.2$. $\mathrm{NaCl}$ affected the release of CCK and GLP-1 over time. As can be seen in figure 2G, the release of CCK increased over time, and reached highest levels after 90 minutes of exposure to $\mathrm{NaCl}$, whereas GLP-1 release reached highest levels after 120 minutes (figure $2 \mathrm{H}$ ). Release of CCK over time (figure 2I) increased gradually after addition of $\mathrm{HCl}$. 
After addition of HAc, however, the release of CCK fluctuated between $22.5 \mathrm{pM} \pm$ 1.4 and $36.7 \mathrm{pM} \pm 0.7$. GLP-1 release increased over time (figure 2J) after addition of $\mathrm{HCl}$. Highest levels of GLP-1 release after addition of $\mathrm{HCl}$ where reached within 5 minutes, and decreased over time.
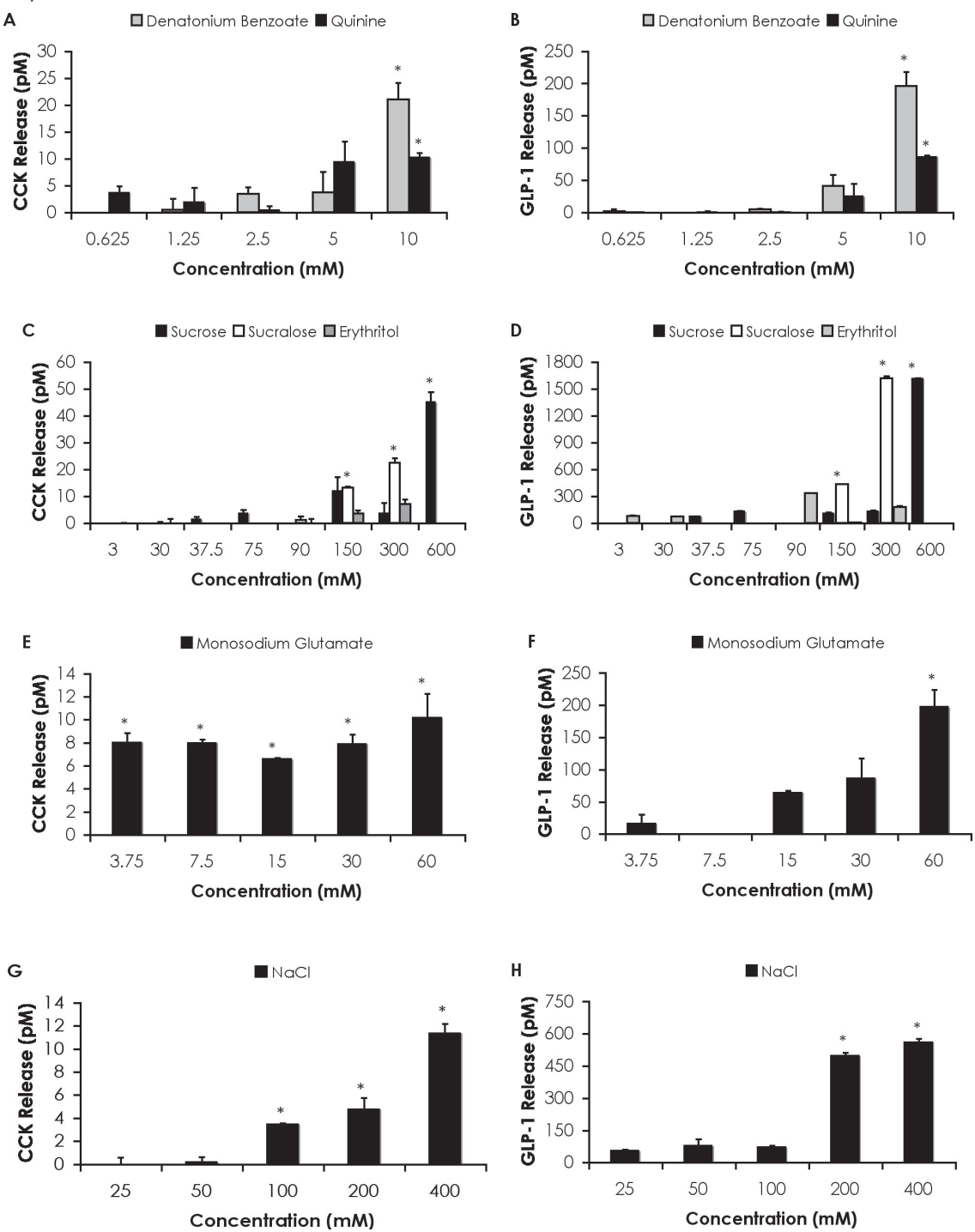

Figure 1: Effects of tastants on the release of CCK and GLP-1 from STC-1 cells over time. STC-1 cells were exposed to different concentrations of tastants. Samples were taken from the supernatant and levels for the determination of CCK and GLP-1. Addition of the highest concentrations of the bitter tastants resulted in significantly elevated levels of CCK (A) and GLP-1 (B). Addition of sweet tastants in concentrations of $150 \mathrm{mM}$ and higher also resulted in significant elevated levels of CCK (C) and GLP-1 (D). MSG stimulated CCK release (E) with all concentrations used, whereas GLP-1 release (F) increased with increasing concentrations of MSG. Addition of NaCl resulted in increased levels of CCK (G) and GLP-1 (H) with increasing concentrations. Addition of the sour tastant $\mathrm{HCl}$ resulted in elevated levels of CCK (I) and GLP-1 (J), but not concentration dependently, whereas the other sour tastant HAc showed no effect on hormone release. Results are expressed as mean \pm SEM. * Significantly different from negative control, $p<0.05$ ) 

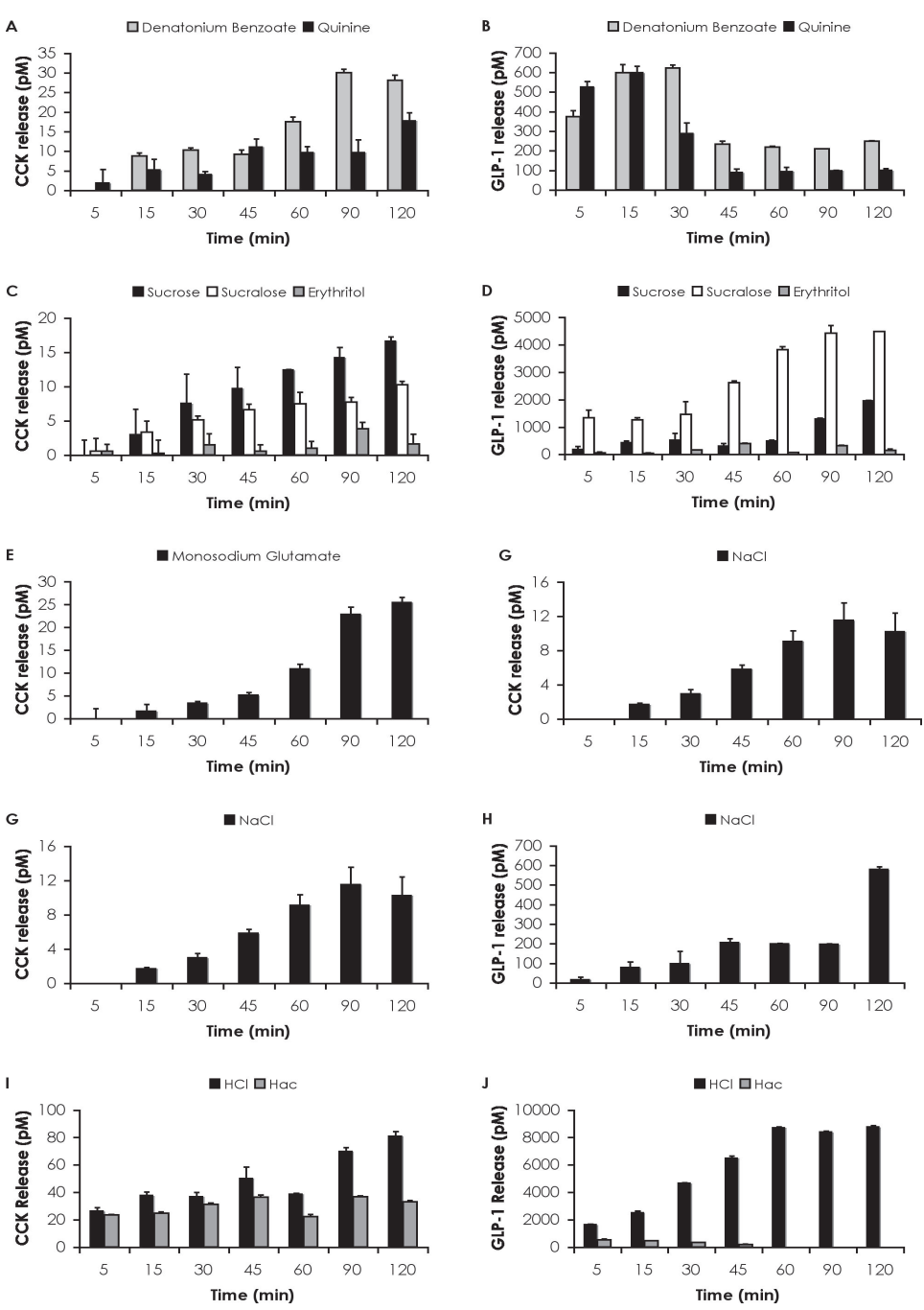

Figure 2: Effects of tastants on the release of CCK and GLP-1 from STC-1 cells over time. STC-1 cells were exposed to different concentrations of tastants. After several time points, samples from the supernatant were taken and CCK- and GLP-1 concentrations were measured using RIAs. Both quinine and denatonium benzoate affected CCK- (A) and GLP-1 (B) release in a time-dependent manner. Within 15 minutes, the release of GLP-1 reached its maximum, and subsequently decreased. Sucrose induced the strongest increase in CCK release (C), whereas addition of sucralose induced the strongest increase in GLP-1 release (D). Erythritol showed the weakest effects on CCK and GLP-1 release. MSG affected CCK release (E) in a time-dependent manner, whereas MSG showed minor effects on GLP-1 release (F). NaCl affected CCK release $(G)$ and $G L P-1$ release $(H)$ in a time-dependent manner. $\mathrm{HCl}$ affected $C C K$ release (I) in a timedependent manner, whereas HAc induced no temporal effects on CCK release. GLP-1 release (J) was strongly affected, in a time-dependent manner, after addition of $\mathrm{HCl}$, whereas $\mathrm{HAC}$ stimulated GLP-1 release after 5 minutes, followed by a decrease in GLP-1 levels over time. Results are expressed as mean \pm SEM. * Significantly different from negative control, $\mathrm{p}<0.05$ ) 


\section{Effects of $\mathrm{Ca}^{2+}$ influx inhibition on hormone release}

To study the effects of the influx of extracellular $\mathrm{Ca}^{2+}$ on the hormone release, EGTA or nitrendipine was added to the medium prior to exposure to the tastants. EGTA binds to free $\mathrm{Ca}^{2+}$ in the medium, whereas nitrendipine binds to the calcium channels that are present at the apical side of epithelial cells in humans. Both the addition of EGTA or nitrendipine resulted in total loss of the release of CCK (figure 3A) and GLP-1 (figure 3B). Also, after the addition of the different tastants in the presence of either EGTA or nitrendipine, no CCK or GLP-1 could be detected in the supernatant.

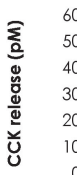

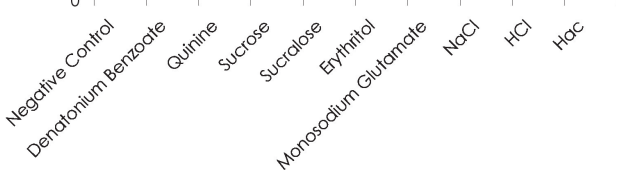

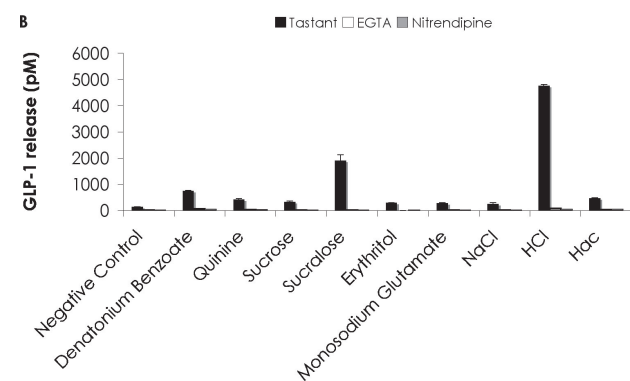

Figure 3: Effects of $\mathrm{Ca}^{2+}$ inhibitors on CCK and GLP-1 release affer stimulation with different tastants. To block the influx of calcium, EGTA and nitrendipine were added to the STC-1 cells, prior to the incubation with the different tastants. Both the addition of EGTA or nitrendipine resulted in total loss of the release of CCK (A) and GLP-1 (B). Also, after the addition of the different tastants in the presence of either EGTA or nitrendipine, no CCK or GLP-1 could be detected in the supernatant. Results are expressed as mean \pm SEM. * Significantly different from negative control, $p<0.05$ )

\section{Effects of sweeteners on hormone release}

Effects of non-caloric sweeteners on the release of CCK (A) and GLP-1 (B) are different when compared to sucrose (100\%) (Figure 4). CCK release was significantly higher after addition of Splenda ${ }^{\circledR}$, Candare $\|^{\circledR}$, Stevia ${ }^{\circledR}$, and Tagatesse ${ }^{\circledR}$, respectively. Natrena $^{\circledR}$ did not affect CCK release compared to sucrose, but GLP-1 levels were increased after addition of all concentrations. Stevia ${ }^{\circledR}$ was also able to induce significant elevated levels of GLP-1, and Tagatesse ${ }^{\circledR}$ only induced higher levels of GLP-1 in high concentrations (equivalents of 4 or more sugar cubes).

\section{DISCUSSION}

In this study, the effects of the five basic tastes, bitter, sweet, umami, sour, and salty, on the release of satiety hormones were investigated. We confirmed that the enteroendocrine STC-1 cell line is sensitive for all tastants used in this study, and that the release of the satiety hormones CCK and GLP-1 differs after addition of compounds representing the same taste. Also, several commercially available sweeteners were tested on their effects on the release of satiety hormones. We 


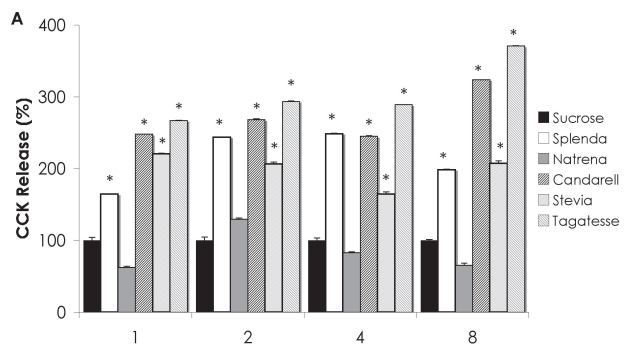

Amount of sugar cubes or sweetener tablets

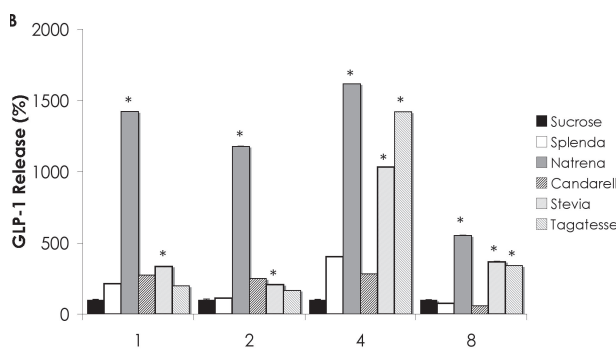

Amount of sugar cubes or sweetener tablets

Figure 4: The effects of commercially available sweeteners on hormone release. Effects of non-caloric sweeteners on the release of CCK (A) and GLP-1 (B) were different compared to sucrose (set at 100\%). CCK release was significantly higher after addition of Splenda, Candarell, Stevia, and Tagatesse. Natrena did not affect CCK release compared to sucrose, but GLP-1 levels were increased after addition of all concentrations. Stevia was also able to induce significant elevated levels of GLP-1, and Tagatesse only induced higher levels of GLP-1 in high concentrations (equivalents of 4 or more sugar cubes). Results are expressed as mean \pm SEM. * Significantly different from sucrose, $\mathrm{p}<0.05$ )

demonstrated that most equally sweet sweeteners induce stronger effects on CCK release after comparison with sucrose, whereas GLP-1 levels are only elevated after addition of Stevia ${ }^{\circledR}$, Tagatesse ${ }^{\circledR}$, and in particular Natrena ${ }^{\circledR}$, even at low dosages, compared to sucrose.

After ingestion, nutrients induce several physiological changes in the body, for example, they trigger the secretion of appetite-modulating hormones, such as CCK and GLP-1, resulting in a reduction in appetite, and affect intestinal motility movements and gastric emptying rate [19]. Recently, studies suggested that not only the macronutrient composition of the food plays a major role in these physiological changes, but also taste might trigger these responses. Taste plays an important role in the decision to ingest or reject food. It helps to limit the intake of potentially harmful toxins (bitter) and spoiled food (sour) and favours the ingestion of calorie-rich (sweet), sodium-rich (salty), or protein-rich (umami) food [20]. The gustatory system, made up of taste receptor cells which are clustered in taste buds at the surface of the tongue and the soft palate, plays a key role in the decision to ingest or reject food and thereby is essential in protecting organisms against ingestion of potentially harmful toxins. Additionally, the taste system plays a pivotal role in selecting the most appropriate nutrients for consumption. Recently, $T 1 R$ and T2R taste receptors expressed on the tongue were also found along the $\mathrm{Gl}$ tract. Bezençon et al demonstrated that several taste signalling proteins are expressed in solitary epithelial cells of the intestine, and that the distribution of taste receptors differs between duodenum, jejunum, ileum, and colon [20]. Recent studies demonstrated that these receptors in the GI tract play important roles in the responses to bitter, sweet, and umami [21,22].

GLP-1 is secreted by gut enteroendocrine $L$ cells in response to stimulation 
with natural and artificial sweeteners [10]. In in vitro experiments using murine enteroendocrine cells (GLUTag cells), Margolskee et al. demonstrated that these cells increase the secretion of GLP-1 after exposure to sucralose [23]. However, Fuijta et al. demonstrated that GLP-1 release from the gut is not enhanced by artificial sweeteners, but only by glucose [24]. Since Saitoh et al demonstrated that all tastants tested were able to induce calcium influx, it is reasonable to postulate that all tastants are able to induce release of CCK and GLP-1. In the present study, we showed that addition of all tastants resulted in a dose- and time dependent release of both CCK and GLP-1. The two tastants representing sour taste used in this study induced the largest response on CCK release compared to the other tastants used in this study. $\mathrm{HCl}$ was more potent in stimulating $\mathrm{CCK}$ release over time compared to HAc. $\mathrm{HCl}$ also induced the largest release of GLP-1 compared to the other tastants used in this study, whereas HAc did not show an effect on GLP-1 release dose-dependently after 2 hours of exposure. Remarkably, we did find that HAC stimulates GLP-1 release in a time-dependent fashion, during the first 45 minutes after exposure to the compound, with highest levels occuring within 5 minutes. This decrease in GLP-1 release after exposure to HAc, may be due to the capacity of the intestinal cells to neutralise the acid. The strong effects of $\mathrm{HCl}$ on hormone release may be explained by the fact that $\mathrm{HCl}$ is commonly produced in the stomach, and directly neutralized in the duodenum by the buffering capacity of neutralizing compounds, such as bile and $\mathrm{HCO}_{3}^{-}$. If this buffering capacity fails, and $\mathrm{HCl}$ levels increase in the intestine, a signal leading to induce secretion of CCK and GLP-1 may protect the intestine from acid-induced damage; the high increase in release of satiety hormones may inhibit gastric emptying rate and food intake, giving the intestine the possibility to neutralize the intestinal fluids.

The tastants representing sweet taste induced the second largest response on CCK and GLP-1 release. In this study, we used the natural sweeteners sucrose and erythritol, and the artificial sweetener sucralose. Both erythritol and sucralose are sweeteners that are almost non-caloric, whereas sucrose provides calories. This may be the main underlying reason why sucrose induced the largest response on CCK, both dose- and time-dependently. Sucralose also induced a strong release of CCK, but erythritol showed little effect on CCK release. Addition of $300 \mathrm{mM}$ sucralose or $600 \mathrm{mM}$ sucrose induced release of GLP-1 to the same extent. Also the release of GLP-1 over time is highest after addition of sucralose. These data could indicate that the caloric load of the compound triggers the release of CCK, whereas the release of GLP-1 is triggered by the 'taste' of the compound.

The strongest variation in CCK and GLP-1 release was found with tastants representing sweet taste. With the increasing prevalence of obesity, ingestion of non-caloric sweeteners is preferred over ingestion of caloric sweeteners. However, in the absence of a source of calories taste receptor activation, nutrient assimilation 
and appetite sensations may be unbalanced, leading to an increase in appetite and overeating of unnecessary calories when they are readily available [25]. However, our results show that CCK release is increased after exposing STC-1 cells to non-caloric sweeteners, compared to sucrose. At present, many different artificial sweeteners are commercially available, and used as replacement of the traditional sugar cubes. However, ingestion of sugar or sweeteners can result in very different endocrine and metabolic states [26]. Remarkable are the differences between Splenda ${ }^{\circledR}$ and Tagatesse ${ }^{\circledR}$, which are both sweeteners using sucralose as the sweet compound. Tagatesse ${ }^{\circledR}$ seems to be more potent in stimulating CCK and GLP-1 release. Perhaps, the composition of the sweetener also plays a role. Tagatesse ${ }^{\circledR}$ contains a small amount of inulin, a dietary fiber, which also can contribute to the release of CCK and GLP-1. Another sweetener, Natrena ${ }^{\circledR}$, is only able to increase GLP-1 levels when compared to sucrose. Natrena ${ }^{\circledR}$ is a sweetener that contains acesulfame-K as the sweetening compound. Even at low concentrations, GLP-1 release is strongly affected by this sweetener. It has been previously demonstrated that acesulfame-K has been shown to stimulate dose-dependent insulin secretion in rats, though no hyperglycemia was observed [27]. The strong increase in GLP-1 levels may contribute to this insulin secretion. However, as most sweeteners, acesulfame-K has a bitter after taste, which also might contribute to the increased levels of GLP-1. Tastants representing bitter induced strong GLP-1 release during the first 30 minutes of incubation. The observation that bitter tastants increase the release of GLP-1 within 15 minutes to a maximum might be due to the fact that bitter taste is associated with harmful toxins. The strong increase in GLP-1 release may provide a mechanism to protect the intestine from these potential toxins, by fast inhibition of food intake after ingestion of these bitter tasting substances. DB is a compound that is commonly used in denatured alcohol, antifreeze, nail biting preventions, animal repellents, liquid soaps, and shampoos, whereas quinine is a compound that is added to sodas such as bitter lemon to add the bitter flavour to the product. This suggests that, even though both compounds are perceived as bitter, DB is regarded as the most bitter substance perceived by humans and is widely used in taste warning [5].

Umami is a savory flavor that is found in many foods, including tomatoes, parmesan cheese, truffles, and many kinds of meat and seafood. The umami taste primarily detects the amino acid glutamate (hence the popularity of the food additive MSG). The umami taste is commonly perceived as pleasurable, and induces satiation quickly after ingestion, due to the caloric content, but the feeling of fullness does not last long [28]. Our results demonstrate that addition of MSG to the STC-1 cells induces secretions of CCK, whereas MSG, compared to other tastants, poorly stimulates the release of GLP-1. The large amount of secreted CCK might be the cause of the previously described quick satiation after ingestion of foods with umami taste, but because MSG is not able to stimulate release of other satiety 
hormones, such as GLP-1, the feeling of satiation is not prolonged.

The last taste tested in this study is salt. The perceived taste of $\mathrm{NaCl}$, physiologically the most important dietary salt, varies to some extent with the subject's sodium needs. Sodium-depleted subjects display a lower salt taste threshold than sodiumreplete subjects [29]. Addition of $\mathrm{NaCl}$ to the STC-1 cells resulted in both a dose- and time dependent secretion of CCK and GLP-1, but compared to other tastants used in this study, the salty tastant induced minor effects on hormone release. This might be due to the depletion of sodium in the medium, and that the STC-1 cells need more $\mathrm{NaCl}$ than is added to the medium, and therefore are not releasing satiety hormones.

Wu et al [6] demonstrated previously that the STC-1 cells express these G proteincoupled receptors and respond to bitter tastants by increasing the intracellular $\mathrm{Ca}^{2+}$ influx. Saitoh et al [8] showed that by exposing the STC-1 cell line to five basic taste stimuli, the intracellular $\mathrm{Ca}^{2+}$ concentration increased, compared to the HEK293 cell line, transfected with the taste receptors, but lacking the underlying mechanism. In the study of Chen et al., it was shown that addition of unrelated structurally bitter stimuli of denatonium benzoate or phenylthiocarbamide increased the intracellular $\mathrm{Ca}^{2+}$ in STC-1 cells, leading to CCK release from the cells [9]. The putative underlying mechanism described by Sternini et al [19] implies that the influx of $\mathrm{Ca}^{2+}$ into the cell triggers the release of satiety hormones. Our results show that by inhibiting the influx of $\mathrm{Ca}^{2+}$, by either blocking the Calcium-channels, or by binding free $\mathrm{Ca}^{2+}$ present in the medium, the release of both CCK and GLP-1 was completely inhibited with all tastants. This confirms the mechanism proposed by Sternini et al. Tastants bind to taste receptors present in the gut, and induce intracellular $\mathrm{Ca}^{2+}$ increase resulting in release of peptides, which regulate a variety of $\mathrm{Gl}$ functions.

We conclude that taste plays an important role in the regulation of the release of satiety hormones, and that the influx of $\mathrm{Ca}^{2+}$ is necessary for the $\mathrm{Gl}$ cells to be able to secrete both CCK and GLP-1. There seems to be a difference in satiety hormone release after exposure to different commercial available sweeteners in concentrations resembling the same sweetness equivalent, and that the composition of the commercial sweetener product, e.g. the addition of other macronutrients to the product, might affect the activation of the taste receptors. Overall, this study shows that taste stimuli, with $\mathrm{HCl}$ being the most potent, are involved in the stimulation of satiety hormone release and, hence, may provide a novel dietary tool to control appetite and food intake. 
1. Capasso, R. and A.A. Izzo, Gastrointestinal regulation of food intake: general aspects and focus on anandamide and oleoylethanolamide. J Neuroendocrinol, 2008. 20 Suppl 1: p. 39-46.

2. Cummings, D.E. and J. Overduin, Gastrointestinal regulation of food intake. J Clin Invest, 2007. $117(1):$ p. 13-23.

3. Hofer, D., B. Puschel, and D. Drenckhahn, Taste receptor-like cells in the rat gut identified by expression of alpha-gustducin. Proc Natl Acad Sci U S A, 1996. 93(13): p. 6631-4.

4. Dyer, J., et al., Expression of sweet taste receptors of the T1R family in the intestinal tract and enteroendocrine cells. Biochem Soc Trans, 2005. 33(Pt 1): p. 302-5.

5. Rozengurt, E., Taste receptors in the gastrointestinal tract. I. Bitter taste receptors and alphagustducin in the mammalian gut. Am J Physiol Gastrointest Liver Physiol, 2006. 291 (2): p. G171-7.

6. WU, S.V., et al., Expression of bitter taste receptors of the $T 2 R$ family in the gastrointestinal tract and enteroendocrine STC-1 cells. Proc Natl Acad Sci U S A, 2002. 99(4): p. 2392-7.

7. Young, R.L., et al., Expression of taste receptor molecules in the upper gastrointestinal tract in humans with and without type 2 diabetes. Gut, 2008.

8. Saitoh, O., A. Hirano, and Y. Nishimura, Intestinal STC-1 cells respond to five basic taste stimuli. Neuroreport, 2007. 18(18): p. 1991-5.

9. Chen, M.C., et al., Bitter stimuli induce Ca2+ signaling and CCK release in enteroendocrine STC1 cells: role of L-type voltage-sensitive Ca2+ channels. Am J Physiol Cell Physiol, 2006. 291 (4): p. C726-39.

10. Jang, H.J., et al., Gut-expressed gustducin and taste receptors regulate secretion of glucagonlike peptide-1. Proc Natl Acad Sci U S A, 2007. 104(38): p. 15069-74.

11. Pierce, W.D., et al., Overeating by young obesity-prone and lean rats caused by tastes associated with low energy foods. Obesity (Silver Spring), 2007. 15(8): p. 1969-79.

12. Ma, J., et al., Effect of the artificial sweetener, sucralose, on gastric emptying and incretin hormone release in healthy subjects. Am J Physiol Gastrointest Liver Physiol, 2009. 296(4): p. G7359.

13. Tanaka, T., et al., Free fatty acids induce cholecystokinin secretion through GPR120. Naunyn Schmiedebergs Arch Pharmacol, 2008. 377(4-6): p. 523-7.

14. Cordier-Bussat, M., et al., Peptones stimulate cholecystokinin secretion and gene transcription in the intestinal cell line STC-1. Endocrinology, 1997. 138(3): p. 1137-44.

15. Foltz, M., et al., Protein hydrolysates induce CCK release from enteroendocrine cells and act as partial agonists of the CCK1 receptor. J Agric Food Chem, 2008. 56(3): p. 837-43.

16. Hoon, M.A., et al., Putative mammalian taste receptors: a class of taste-specific GPCRs with distinct topographic selectivity. Cell, 1999. 96(4): p. 541-51.

17. Adler, E., et al., A novel family of mammalian taste receptors. Cell, 2000. 100(6): p. 693-702.

18. Rindi, G., et al., Development of neuroendocrine tumors in the gastrointestinal tract of transgenic mice. Heterogeneity of hormone expression. Am J Pathol, 1990. 136(6): p. 1349-63.

19. Sternini, C., L. Anselmi, and E. Rozengurt, Enteroendocrine cells: a site of 'taste' in gastrointestinal chemosensing. Curr Opin Endocrinol Diabetes Obes, 2008. 15(1): p. 73-8.

20. Bezencon, C., J. le Coutre, and S. Damak, Taste-signaling proteins are coexpressed in solitary intestinal epithelial cells. Chem Senses, 2007. 32(1): p. 41-9.

21. Ruiz, C.J., et al., Behavioral evidence for a role of alpha-gustducin in glutamate taste. Chem Senses, 2003. 28(7): p. 573-9.

22. Wong, G.T., K.S. Gannon, and R.F. Margolskee, Transduction of bitter and sweet taste by gustducin. Nature, 1996.381 (6585): p. 796-800.

23. Margolskee, R.F., et al., TIR3 and gustducin in gut sense sugars to regulate expression of $\mathrm{Na}^{+}$ glucose cotransporter 1. Proc Natl Acad Sci U S A, 2007. 104(38): p. 15075-80.

24. Fujita, Y., et al., Incretin release from gut is acutely enhanced by sugar but not by sweeteners in vivo. Am J Physiol Endocrinol Metab, 2009. 296(3): p. E473-9. 


\section{CHAPTER 9}

\section{ADDITION OF SUCRALOSE ENHANCES \\ THE RELEASE OF SATIETY HORMONES IN COMBINATION WITH PEA PROTEIN}

MAARTJE C.P. GERAEDTS, FREDDY J. TROOST, WiM H.M. SARIS

SUBMITTED TO AMERICAN JOURNAL OF PHYSIOLOGY -

GASTROINTESTINAL AND LIVER PHYSIOLOGY 


\section{ABSTRACT}

Recent data demonstrate that exposing the intestine to proteins or tastants, and in particular sweet, affect the release of satiety hormones. There are indications that each sweetener has different effects on this release, and that combining sweeteners with other nutrients might exert synergistic effects on hormone release. STC-1 cells were incubated with acesulfame K, aspartame, saccharine, sucralose, sucrose, pea, and combination of pea protein with each sweetener. After a 2-hour incubation period, CCK and GLP-1 concentrations were measured in the supernatant. Also, the mucosal side of human duodenal biopsies were exposed to sucrose, sucralose, pea, and a combination of pea with each sweetener using Ussing chamber technology. CCK and GLP-1 levels were measured in basolateral secretions of the biopsies.

Exposure to aspartame, sucralose, sucrose, pea, and pea with sucralose secreted elevated levels of CCK, whereas GLP-1 levels were increased after addition of all test-products. Addition of sucrose and sucralose to human duodenal biopsies did not affect CCK and GLP-1 release; addition of pea did stimulate CCK and GLP-1 secretion (31 $\mathrm{pM} \pm 1$ and $9.2 \mathrm{pM} \pm 0.1$ respectively). Combining pea protein with sucrose and sucralose induced even higher levels of CCK (30 pM \pm 3 and $63.7 \mathrm{pM} \pm 2$, respectively) and GLP-1 (15.8 pM \pm 1 and $24.1 \mathrm{pM} \pm 1$, respectively).

Synchronous addition of pea protein and sucralose to enteroendocrine cells induce higher levels of CCK and GLP-1, than addition of each compound alone. This study shows that the combinations of dietary compounds may provide a novel dietary tool to control appetite and food intake. 


\section{INTRODUCTION}

Nutrient induced gut-to-brain signalling plays a major role in the control of the digestive function, appetite, and energy intake [1]. These effects are mediated by a number of interrelated factors, including the release of signalling peptides from enteroendocrine cells, such as cholecystokinin (CCK) and glucagon-like peptide 1 (GLP-1). Most of these hormones are secreted upon food intake, and contribute to the termination of the meal. Since overweight and obesity have become a major health problem [2], several types of diets have focused on favourable macronutrient compositions in order to stimulate the release of these satiety hormones [3-8].

Of all diets tested, high-protein diets seem to have the largest effects on food intake $[9,10]$. The effects of several protein hydrolysates on the release of CCK from the enteroendocrine STC-1 cell line were determined previously [11]. It was shown that all hydrolysates were able to induce elevated levels of CCK, but there were no differences between the hydrolysates. We demonstrated that intact proteins were the most potent in stimulating CCK and GLP-1 release versus hydrolysates and specific peptides, with intact pea protein being one of the most potent ones. Pea hydrolysate was considered as most effective in suppressing hunger and stimulating satiety when compared to whole milk protein [12], and in the human study we demonstrated that intraduodenal infusion of the intact pea protein effectively reduced food intake in both lean and obese subjects (unpublished data).

Over the past few years, not only food intake, but also consumption of soft drinks has increased [13]. This high consumption of sugar-sweetened beverages has been linked with increased energy intake and obesity [14]. It was demonstrated that overweight subjects who consumed large amounts of caloric-sweetened beverages increased energy intake, body weight, fat mass, and blood pressure after a 10 week intervention, whereas this was not observed in a similar group receiving artificial sweeteners [15]. It has been suggested that intake of low-caloric sweetened beverages is linked to obesity, related to the potential mediating role of energy intake, e.g. that intake of caloric sweetened beverages brings less satiation, causing a higher amount of calories consumed at a given meal and thereby a higher daily energy intake $[16,17]$. It has also been suggested that the intake of caloric sweetened beverages fail to trigger physiological satiety mechanisms, providing imprecise and incomplete energy compensation [18].

More recently, it has been demonstrated that the upper gut may be able to sense sweetness, resulting in the release of satiety hormones. In a human $L$ cell line, glucose and sucralose were able to induce the release of GLP-1 [19]. However, in a previous study performed in our laboratory, we demonstrated that non-caloric sweeteners show increased levels of CCK and GLP-1, when compared to sucrose. Remarkably, Tagatesse $^{\circledR}$, (a sweetener that contains inulin) showed the strongest effect on the 
release of both CCK and GLP-1. This lead us to believe that combining non-caloric sweeteners with specific macronutrients, and in particular pea protein, may induce stronger effects on hormone release than the sweeteners or macronutrients alone. The aim of the current study was to investigate whether combining sweeteners with pea protein induced elevated effects on CCK and GLP-1 release, when compared to only sweeteners or the pea protein.

\section{MATERIAL AND METHODS}

The present study consists of two parts. In the first part, all sweeteners, and the combination of sweetener with pea protein will be tested on their effects on satiety hormone release in vitro. The best results will then be tested in an ex vivo study, using healthy male volunteers.

\section{In vitro assay \\ Test products}

All sweeteners were dissolved in $300 \mathrm{ml}$ of HBSS $(200 \mathrm{ml}$ as volume for one coffee or thee consumption, and $100 \mathrm{ml}$ as basal gastric juice volume). All sweeteners were dissolved accordingly to match the sweetness of the sugar dosages, according to its known sweetness equivalent relative to sucrose. Five different tastants were used, namely sucrose (6g, Sigma-Aldrich, St. Louis, MO, USA), aspartame (0.03g), acesulfame K (0.04g), saccharine (0.012g) (all from Supelco, Bellefonte, PA, USA), and sucralose $(0.01 \mathrm{~g}$, Tate\&Lyle, London, UK). From previous studies it was shown that pea protein is a very potent protein to stimulate the release of CCK and GLP1 , and it also reduces food intake in male subjects, when infused intraduodenally (unpublished data). Pea protein $10.1 \mathrm{mg} / \mathrm{ml}$, Dutch Protein Services, Tiel, The Netherlands) was added to the sweeteners.

\section{Cell culture conditions}

The STC-1 cell line is derived from an intestinal endocrine tumor that developed in a double-transgenic mouse expressing the rat insulin promotor linked to the simian virus 40 large $T$ antigen and the polyoma small T antigen [20]. STC-1 cells (kindly provided by Dr. D. Hanahan, University of California, San Francisco) were maintained in Dulbecco's Modified Eagles Medium (DMEM) with 10\% fetal bovine serum (FBS), 2 $\mathrm{mM} \mathrm{L}$-glutamine, 100 units $\mathrm{ml}-1$ penicillin, and $100 \mu \mathrm{g} \mathrm{ml}-1$ streptomycin as additional supplements, at $37^{\circ} \mathrm{C}$ in $5 \% \mathrm{CO} 2$ /air humidity. All products were obtained from Invitrogen, Carlsbad, California, USA, unless stated otherwise.

\section{Secretion of CCK and GLP-1 from STC-1 cells}

To determine the secretion of CCK and GLP-1 from STC-1 cells, suspensions of these cells were plated at $1.0 \times 105$ cells/well in 24-well plates (Costar) and assays were 
performed on cultures that reached at least $80 \%$ confluency. Before treatment with the testproducts, culture medium was removed and dishes were rinsed with HBSS. Cells were then incubated with HBSS (negative control), the sweeteners, and the combination of sweeteners with pea protein, and were incubated at $37^{\circ} \mathrm{C}$ for 2 hours. The supernatant was collected for the measurement of CCK and GLP-1. All analysis were performed in triplicate, using three biological replicate samples. The best results were then tested in the Ussing Chambers.

\section{Human Ex vivo assay}

\section{Subjects}

In this study, ten (five lean and five obese) healthy male subjects were recruited. Selection took place according to health criteria (no diabetes, no gastrointestinal diseases, and no medical treatment) and body weight (BW) criteria (for lean subjects: body mass index (BMI) $18-25 \mathrm{~kg} / \mathrm{m}^{2}$, and for obese subjects: BMl<30 kg/ $\mathrm{m}^{2}$ ). Baseline characteristics of the subjects are presented in table 1. The nature and risks of the experimental procedure were explained to the subjects, and all subjects gave their written informed consent. This study was conducted according to the guidelines laid down in the Declaration of Helsinki and the Medical Ethical Committee of the University Hospital Maastricht approved all procedures involving

\begin{tabular}{lll}
\hline & Lean $(\mathrm{n}=5)$ & Obese $(\mathrm{n}=5)$ \\
\hline Age (years) & $27 \pm 5$ & $37 \pm 10$ \\
$\mathrm{BMI}\left(\mathrm{kg} / \mathrm{m}^{2}\right)$ & $24.2 \pm 1$ & $32.8 \pm 2 *$ \\
$\mathrm{HbAlc}(\%)$ & $4.6 \pm 0.2$ & $4.4 \pm 0.2$ \\
Basal glucose $(\mathrm{mmol} / \mathrm{L})$ & $4.9 \pm 0.2$ & $4.8 \pm 0.2$ \\
\hline
\end{tabular}

Table 1. Subject characteristics. All data are mean \pm SEM. * Difference between lean and obese subjects $(p<0.05)$

\section{Duodenal tissue sampling for ex vivo experiments}

All subjects received a standardized meal $(9 \mathrm{~g}$ protein, 39,5 g carbohydrates, 16 $\mathrm{g}$ fat) for the evening prior to the test day to standardize macronutrient intake. After an overnight fast, eight mucosal tissue samples from the horizontal part of the duodenum were obtained by flexible gastroduodenoscopy using standard biopsy forceps. During this procedure, no sedatives were given to the subjects. The diameter of the biopsies varied from $2.0 \mathrm{~mm}$ to $2.2 \mathrm{~mm}$. After sampling, the biopsies were placed in ice-cold Krebs-Ringer bicarbonate buffer (KRB) and arrived at the laboratory within 15 min.

\section{Ussing Chamber experiments}

Duodenal biopsies were mounted in modified Ussing Chambers (Harvard Apparatus Inc., Holliston, Mass., USA) with a 9-mm opening and reduced to an exposed tissue 
area of $1.76 \mathrm{~mm}^{2}$, using a technique previously described by Wallon et al [21, 22]. Mucosal compartments were filled with $1.5 \mathrm{ml} 10 \mathrm{mM}$ mannitol in KRB and the serosal compartments were filled with $10 \mathrm{mM}$ glucose in KRB. The chambers were kept at $37^{\circ} \mathrm{C}$ and continuously oxygenated with 95\% O2 / 5\% CO2 and circulated by gas flow. Before the experiments were started, tissues equilibrated for 40 min in the chambers to achieve steady-state conditions in transepithelial potential difference (PD), with replacement of mannitol of glucose KRB at $20 \mathrm{~min}$. A four-electrode system was used, as described previously [23]. One pair of $\mathrm{Ag} / \mathrm{Cl}$ electrodes with $3 \mathrm{M} \mathrm{NaCl}$ / $2 \%$ agar bridges was used for measurement of transepithelial PD and another pair of $\mathrm{Ag} / \mathrm{Cl}$ electrodes was used to monitor current. The electrodes were coupled to an external 6-channel electronic unit with a voltage controlled current source. Data sampling was computer controlled via an A/D D/A board (Lab NB, National Instruments, USA) by a program developed in LabVIEW (National Instruments, USA) by Wikman-Larhed et al [24]. Every other minute, direct pulses of $-3,3$, and $0 \mu A$, with a duration of 2 seconds each, were sent across the tissue segments and the voltage response was measured. In each measurement, the mean voltage response of 2 seconds was calculated. A linear-squares fit was performed on the current (I) voltage (U) pair relationship: $U=P D+T E R \times I$. The TER was obtained from the slope of the $\mathrm{I}-\mathrm{U}$ line and the PD from the intersection of the voltage.

After the equilibration period, the mucosal side of the biopsies were exposed to sucrosel, sucralose, pea, pea with sucrose, and pea with sucralose. Serosal samples $(1.25 \mathrm{ml})$ were collected the end of the experiment (after $2 \mathrm{~h}$ ) for CCK- and GLP-1 analysis.

Biopsies with PD less negative than $-0.5 \mathrm{mV}$ were excluded from all tested $(n=3)$ because of malfunction in the ability to uphold normal electrophysiology.

\section{Hormone assays}

CCK levels were determined using the RIA from Euria-CCK, Euro-Diagnostica AB, Malmö, Sweden. According to the manufacturers instructions, the detection limit of this kit was $0.3 \mathrm{pmol} / \mathrm{L}$. The intra-assay variation ranges from 2.0 to $5.5 \%$ and the inter-assay variation from 4,1 to $13,7 \%$. Cross-reaction with gastrin is $\leq 0.5 \%$. Total GLP-1 levels were determined using the RIA from Linco Research, Missouri, USA. The detection limit of this kit was 3 to $333 \mathrm{pM}$. The intra-assay variation ranges from 10 to $23 \%$ and the inter-assay variation from 22 to $38 \%$. There is no cross-reaction with GLP2 and glucagon $(0.01 \%$ and $0.2 \%$, respectively). GLP-1 samples were spiked with 100 PM of GLP-1 to be within range of the detection limit. Both RIAs can be used for the analysis of both rat and human samples.

\section{Statistical Analyses}

The descriptive and statistical analyses were performed with SPSS, version 11.0. With regard to the cell culture results, the means of the secreted hormones were compared using the one-sample t-test. With regard to the Ussing chambers, the electrophysiological parameters were compared using the Wilcoxon signed rank 
test. Means of the secreted hormones between groups were compared using an unpaired Student t-test. Means of the secreted hormones within a group was were compared using a paired Student t-test. All Student t-tests were corrected for multiple testing using the Bonferroni correction. The means of the variables are presented with their standard error (mean \pm SEM). A P-value of less than 0.05 was considered statistically significant.

\section{RESULTS}

\section{Hormone release from STC-1 cells}

The release of CCK and GLP-1 from the enteroendocrine STC-1 cells are presented in figure 1. As can be seen in figure 1A, CCK release was significantly increased after addition of aspartame, sucralose, sucrose, pea, and pea with sucralose, when compared to the negative control. Highest levels of CCK release were found after addition of the combination of pea with sucralose (82.5 pM \pm 0.7 ). As can be seen in figure 1B, addition of all test products significantly increased the release of GLP-1 from the STC-1 cells when compared to the negative control (only HBSS buffer). Addition of acesulfame K, pea with acesulfame K, pea with sucrose, or pea with sucralose $(2442.2 \mathrm{pM} \pm 60,3039.5 \mathrm{pM} \pm 22,4336.6$ $\mathrm{pM} \pm 93$, and $4690.9 \mathrm{pM} \pm 38$, respectively) induced the highest levels of GLP-1.
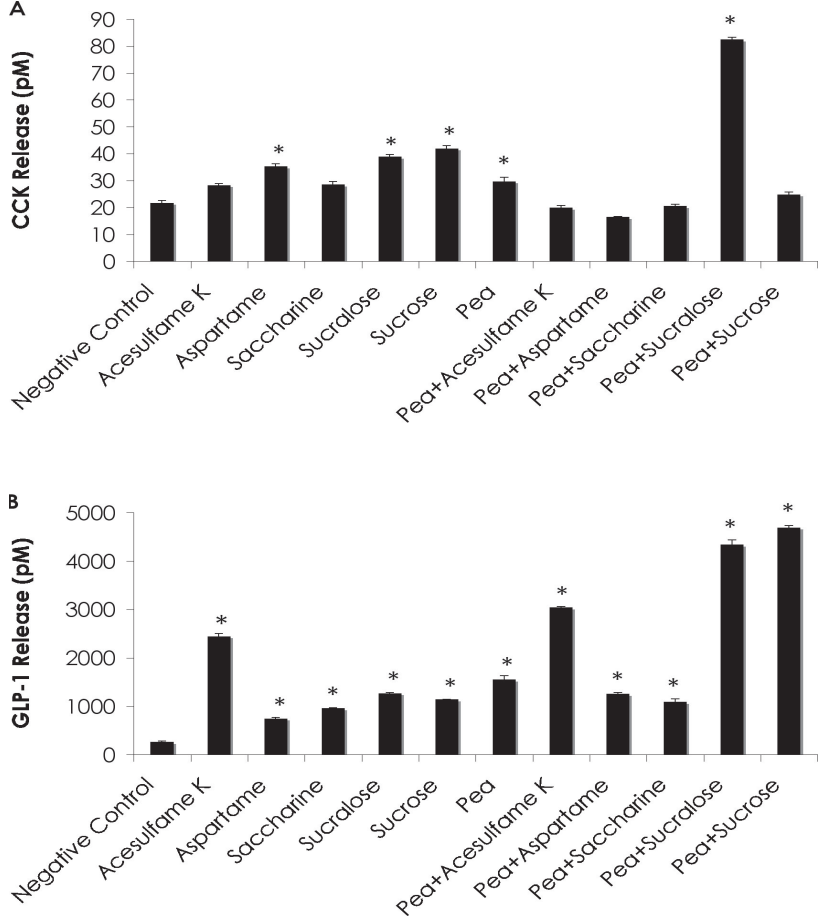

Figure 1. Hormone release from STC-1 cells after $2 \mathrm{~h}$ exposure to several sweeteners, pea protein, and combinations of pea protein with the sweeteners STC-1 cells were exposed to different sweeteners, pea protein, and a combination of pea protein with sweeteners for 2 hours. After the incubation period, CCK (A) and GLP1 (B) levels were measured in the supernatant. Results are expressed as mean \pm SEM. * Significantly different from negative control, $\mathrm{p}<0.05$ ) 


\section{Hormone release from Ussing chamber experiments}

In duodenal tissue of lean subjects we observed basal CCK secretion levels of 6.4 $\mathrm{pM} \pm 2$ in lean subjects, whereas basal CCK levels in obese subjects were $9.7 \mathrm{pM}$ \pm 4 (figure 2A). After addition of pea, pea with sucrose, or pea with sucralose, the levels of CCK were significantly increased compared to the negative control, for both lean (27.1 pM $\pm 1,22.6 \mathrm{pM} \pm 3$, and $56.7 \mathrm{pM} \pm 1$, respectively) and obese subjects (37.3 $\mathrm{pM} \pm 2,38.2 \mathrm{pM} \pm 3$, and $74.7 \mathrm{pM} \pm 2$, respectively). Also, addition of these compounds to the duodenal biopsies resulted in significantly increased CCK levels in obese subjects when compared to lean subjects. Addition of sucrose and sucralose alone did not affect CCK release when compared to the negative control. GLP-1 secretion from duodenal biopsies is presented in figure 2B. Basal GLP-1 secretions levels of $3.7 \mathrm{pM} \pm 0.4$ from lean subjects and $4.1 \mathrm{pM} \pm 0.5$ from obese subjects were observed. Addition of intact pea protein to the luminal side significantly increased GLP-1 levels (8.4 pM 0.2 in lean subjects, and $9.3 \mathrm{pM} \pm 0.2$ in obese subjects) when compared to negative control and to addition of sucrose. Also, addition of intact pea protein induced significantly higher levels of GLP-1 when compared to lean subjects. Addition of the combination of pea with sucrose or pea with sucralose also induces significant elevated levels of GLP-1 (14.4 pM \pm 0.1 and $23.8 \mathrm{pM} \pm 1$, respectively, for lean subjects, $16.6 \mathrm{pM} \pm 0.7$ and $24.7 \mathrm{pM} \pm 1$, respectively, for obese subjects), when compared to the negative control and addition of only sucrose.

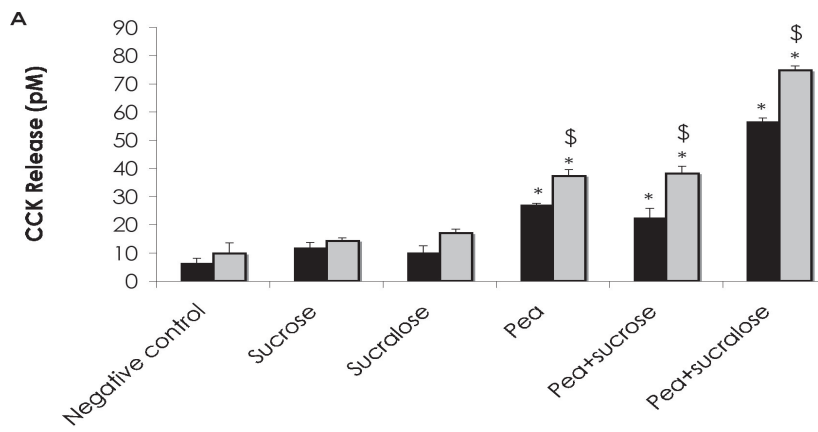

Figure 2. Hormone release from human duodenal biopsies in Ussing chambers after $2 \mathrm{~h}$ exposure to sucrose, sucralose, pea protein, and combinations of pea protein with the sucralose or sucrose Duodenal biopsies of lean and obese subjects were exposed to either, sucrose, sucralose, pea protein, or

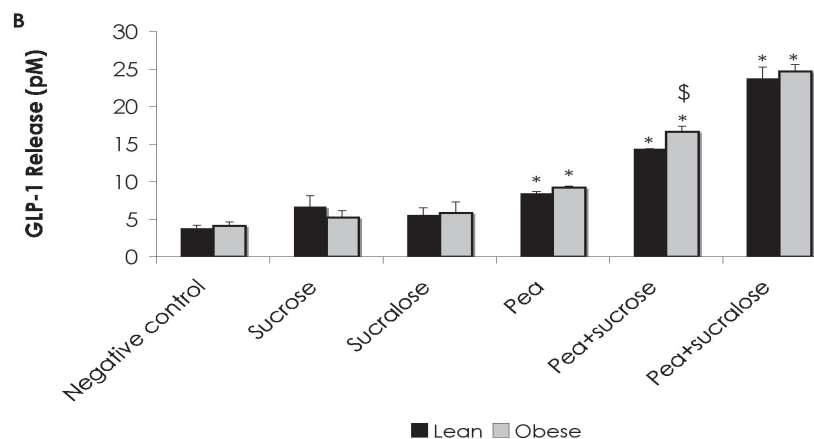
a combination of pea protein with sucrose or sucralose. The levels of CCK (A) and GLP-1 (B) were measured in the supernatant of basolateral side of the biopsies in the Ussing Chambers after being exposed to proteins for $2 h$ to the apical side. Results are expressed as mean \pm SEM. * Significantly different from negative control, $p<0.05$ ) $\$$ Significantly different from lean subjects 


\section{Electrical Measurements}

The electrical parameters PD, ISC, and TER were followed over time. Basal electrical properties of all biopsies were measured. After an equilibration period of $40 \mathrm{~min}$, the mean PD of $-1.4 \mathrm{mV} \pm 0.2$ was observed. Overall, no changes in PD were observed in the following 120 minutes. A decrease in TER and an increase in ISc were observed. The TER was significantly less decreased after addition of pea with sucrose $\left(-29.2 \Omega . \mathrm{cm}^{2} \pm 1\right)$, when compared to the negative control (-51.4 $\Omega . \mathrm{cm}^{2} \pm 3$ ) in obese subjects. All other products did not affect TER when compared to the negative control for both lean and obese subjects. Addition of sucrose, sucralose, and pea with sucrose resulted in an increased IsC (242.7 $\Omega . \mathrm{cm}^{2} \pm 32,246.9 \Omega . \mathrm{cm}^{2} \pm 25$, and $235.4 \Omega . \mathrm{cm}^{2} \pm 26$, respectively) when compared to the negative control $\left(49.7 \Omega . \mathrm{cm}^{2} \pm 19\right)$ in lean subjects. Also, addition of sucralose or pea with sucrose to biopsies from lean subjects resulted in increased Isc when compared to obese subjects. Addition of sucrose or pea with sucralose to the luminal side of biopsies from obese subjects resulted in an increased Isc $\left(195.9 \mu \mathrm{A} / \mathrm{cm}^{2} \pm 34\right.$ and $387.1 \mu \mathrm{A} / \mathrm{cm}^{2} \pm$ 32 , respectively) when compared to the negative control $\left(31.8 \mu \mathrm{A} / \mathrm{cm}^{2} \pm 11\right)$.

\section{DISCUSSION}

In the present study, the effects of five sweeteners in the presence or absence of pea protein on satiety hormone release were investigated. We demonstrated that the combination of pea protein with the artificial sweeteners sucralose and sucrose induce stronger effects on satiety hormone release compared to the compounds seperatly, both in vitro and ex vivo. It was also shown that addition of sucrose or sucralose to STC-1 cells stimulated the release of CCK and GLP-1, whereas addition of the sweeteners to human duodenal biopsies did not result in hormone release. Carbohydrate is an adequate stimulus for secretion of GLP-1. Failure of non-nutritive sweeteners to elicit the release of such peptides could theoretically result in lower satiety and augment energy intake. It was previously shown that sucralose induced GLP-1 secretion [19]. In contrast, aspartame does not stimulate GLP-1 secretion [25]. Thus the hypothesis that non-nutritive sweeteners will be less effective stimuli for carbohydrate responsive satiety hormones is uncertain. In the study of Fujita et al, it was demonstrated that sweeteners do not acutely enhance the release of incretin hormones in vivo in rats [26]. However, GLP-1 release from human NCl-H716 cells was promoted by sugars and by the sweetener sucralose [19]. The present study demonstrated that most artificial sweeteners are able to induce CCK release, and that all sweeteners stimulate GLP-1 release from enteroendocrine STC-1 cells, but when human duodenal tissue is exposed to sucrose or sucralose, both CCK 
and GLP-1 release is not affected. Overall, sucrose, sucralose, and aspartame were the most potent sweeteners to stimulate satiety hormone release from STC-1 cells. Since sucrose was the only caloric sweetener and the most commonly used, this sweetener was used in the Ussing chambers as control.

Recently, it has been shown that dietary proteins reduce food intake by improving satiety sensations $[10,27]$. In most cases, high-protein meals increase feelings of satiety and decrease subsequent energy intake compared with high-carbohydrate or high-fat meals [4]. In the present study, pea protein was used. This protein contains large amounts of arginine, asparagine, and glutamine, and is digested in the stomach for approximately 93\% [28]. In a study of Cummings et al it was shown that a pea protein isolate exerted a greater effect on satiety, e.g. higher PYY levels, slower gastric emptying, than the control (no protein) [29] and in another study, pea protein ingestion had a more pronounced effect on PYY release and reduced feelings of hunger in human volunteers, when compared to whey and whole milk proteins [12]. In a recent study performed in our laboratory, we demonstrated that intact pea and wheat protein stimulated CCK and GLP-1 release from human duodenal tissue to a greater extent than egg and codfish protein. Unlike other common protein sources such as milk, soy, or wheat proteins, pea protein has a very low allergenic potential, which makes this protein more suitable for dietary interventions compared to wheat protein.

Since proteins are not usually ingested solely, but in combination with other macronutrients, a better understanding of how nutritional compounds interact with each other is necessary to develop new food products that contribute to weight management. The present study shows that most sweeteners were able to induce secretion of CCK and GLP-1 from STC-1 cells. However, combined with pea protein, the positive effects on the hormone release were diminished. Tested on human duodenal tissue, sucrose and sucralose did not affect hormone secretion when compared to the negative control. Combining the sweeteners, and in particular sucralose with pea protein, strongly activated hormone release.

In the present study, both lean and obese subjects were tested. There are indications that obese subjects are less sensitive for satiety signals compared to lean subjects. In rats it was shown that the minimal effective dose of satiety hormones was 3-4 times greater in obese than in lean rats $[30,31]$. Also, obese male subjects have higher blood levels of CCK after a protein infusion into the duodenum when compared to lean subjects (unpublished data). In the present study we found that obese subjects have higher release of CCK after exposure to the pea protein compared to the lean subjects, which is in line with previous studies (unpublished data). Also the combination of pea protein with sucrose and sucralose resulted in higher levels of CCK in obese subjects. In a previous study it was also demonstrated that after pea protein infusion into the duodenum, CCK levels were more increased in 
obese subjects, but food intake decreased to the same extent in both lean and obese subjects. Obese subjects probably are less sensitive to CCK and GLP-1, and therefore need higher circulating levels to reach a similar satiety effect.

The application of the STC-1 cells and the Ussing chambers as screening tools to identify potential nutritional compounds is very effective to select candidate food ingredients to determine whether these compounds are able to mediate food intake and weight management. It has previously been demonstrated that the STC-1 cells are suitable to screen macronutrients on their effects on release of several satiety hormones [1 1, 32-34], however, the translation to the in vivo situation is still very difficult. By using the Ussing chambers as an intermediate model to study effects of dietary interventions on human physiological processes, the extrapolation from in vitro to in vivo findings might be easier. Electrical parameters have also been measured in the present study. These parameters are widely accepted for monitoring the viability and integrity of tissue in the Ussing Chambers. In general, PD reflects the voltage gradient generated by the tissue, TER reflects the tissue integrity, and Isc reflects the ionic fluxes across the epithelium [35-37]. In the present study, basal electrical parameters varied over a wide range. This variability has also been noticed in previous studies on human tissue samples from jejunum [38] and colon [39]. Moreover, the reported electrical parameters from investigators using different Ussing chambers on biopsy specimens from the same gastrointestinal region have been associated with a large variability. To correct for this variability, the areas under the curves have been calculated, after correcting for baseline values for each biopsy. The electrophysiology results from our study were comparable with those found in literature, and showed that all biopsies used in this study were viable throughout the experiments. Addition of sweeteners, pea protein, or a combination of both did not affect the resistance of the tissue, but the Isc was significantly increased compared to the negative control. The Isc is a marker for transepithelial ion transport. Once food compounds stimulate enteroendocrine cells, $\mathrm{Ca}^{2+}$ will be transported into the cell, resulting in release of satiety hormones [40]. This influx may have been the cause of the increase in Isc.

We conclude that the combination of food ingredients plays an important role in the regulation of the release of satiety hormones. There seems to be a difference in satiety hormone release after exposure to different sweeteners, and the combination of sweeteners with pea protein. Combining pea protein with sucralose induced the strongest effects on CCK and GLP-1 release by both STC-1 cells and human duodenal tissue samples. The true efficacy of a combination of pea protein and artificial sweeteners on food intake should be investigated in a human intervention study. 
1. Read, N., S. French, and K. Cunningham, The role of the gut in regulating food intake in man. Nutr Rev, 1994. 52(1): p. 1-10.

2. Obesity: preventing and managing the global epidemic. Report of a WHO consultant. World Health Organ Tech Rep Ser, 2000. 894(i-xii): p. 1-253.

3. Adam, T.C., M.P. Lejeune, and M.S. Westerterp-Plantenga, Nutrient-stimulated glucagon-like peptide 1 release after body-weight loss and weight maintenance in human subjects. Br J Nutr, 2006. 95(1): p. 160-7.

4. Anderson, G.H. and S.E. Moore, Dietary proteins in the regulation of food intake and body weight in humans. J Nutr, 2004. 134(4): p. 974S-9S.

5. Blom, W.A., et al., Effect of a high-protein breakfast on the postprandial ghrelin response. Am J Clin Nutr, 2006. 83(2): p. 211-20.

6. Westerterp-Plantenga, M.S. and M.P. Lejeune, Protein intake and body-weight regulation. Appetite, 2005. 45(2): p. 187-90.

7. Bernard, C., et al., Peptones stimulate intestinal cholecystokinin gene transcription via cyclic adenosine monophosphate response element-binding factors. Endocrinology, 2001. 142(2): p. 721-9.

8. Hall, W.L., et al., Casein and whey exert different effects on plasma amino acid profiles, gastrointestinal hormone secretion and appetite. Br J Nutr, 2003. 89(2): p. 239-48

9. Westerterp-Plantenga, M.S., The significance of protein in food intake and body weight regulation. Curr Opin Clin Nutr Metab Care, 2003. 6(6): p. 635-8.

10. Saris, W.H. and M.A. Tarnopolsky, Controlling food intake and energy balance: which macronutrient should we select? Curr Opin Clin Nutr Metab Care, 2003. 6(6): p. 609-13.

11. Foltz, M., et al., Protein hydrolysates induce CCK release from enteroendocrine cells and act as partial agonists of the CCK1 receptor. J Agric Food Chem, 2008. 56(3): p. 837-43.

12. Diepvens, K., D. Haberer, and M. Westerterp-Plantenga, Different proteins and biopeptides differently affect satiety and anorexigenic/orexigenic hormones in healthy humans. Int J Obes (Lond), 2008. 32(3): p. 510-8.

13. Popkin, B.M. and S.J. Nielsen, The sweetening of the world's diet. Obes Res, 2003. 11 (11): p. 132532

14. Ludwig, D.S., K.E. Peterson, and S.L. Gortmaker, Relation between consumption of sugarsweetened drinks and childhood obesity: a prospective, observational analysis. Lancet, 2001. 357(9255): p. 505-8.

15. Raben, A., et al., Sucrose compared with artificial sweeteners: different effects on ad libitum food intake and body weight after 10 wk of supplementation in overweight subjects. Am J Clin Nutr 2002. 76(4): p. 721-9.

16. Bawa, S., The role of the consumption of beverages in the obesity epidemic. J R Soc Promot Health, 2005. 125(3): p. 124-8.

17. Molgaard, C., et al., [The impact of sugar on health]. Ugeskr Laeger, 2003. 165(44): p. 4207-10.

18. Almiron-Roig, E., Y. Chen, and A. Drewnowski, Liquid calories and the failure of satiety: how good is the evidence? Obes Rev, 2003. 4(4): p. 201-12.

19. Jang, H.J., et al., Gut-expressed gustducin and taste receptors regulate secretion of glucagonlike peptide-1. Proc Natl Acad Sci U S A, 2007. 104(38): p. 15069-74.

20. Rindi, G., et al., Development of neuroendocrine tumors in the gastrointestinal tract of transgenic mice. Heterogeneity of hormone expression. Am J Pathol, 1990. 136(6): p. 1349-63.

21. Wallon, C., et al., Endoscopic biopsies in Ussing chambers evaluated for studies of macromolecular permeability in the human colon. Scand J Gastroenterol, 2005. 40(5): p. 586-95.

22. Wallon, $\mathrm{C}$., et al., Corticotropin-releasing hormone $(\mathrm{CRH})$ regulates macromolecular permeability via mast cells in normal human colonic biopsies in vitro. Gut, 2008. 57(1): p. 50-8.

23. Soderholm, J.D., et al., Integrity and metabolism of human ileal mucosa in vitro in the Ussing 
chamber. Acta Physiol Scand, 1998. 162(1): p. 47-56.

24. Wikman-Larhed, A. and A. P., Co-cultures of human intestinal goblet (HT29-H) and absorptive (Caco-2) cells for studies of drug and peptide absorption Eur J Pharm Sci, 1995. 3(3): p. 171-183.

25. Hall, W.L., et al., Physiological mechanisms mediating aspartame-induced satiety. Physiol Behav, 2003. 78(4-5): p. 557-62.

26. Fujita, Y., et al., Incretin release from gut is acutely enhanced by sugar but not by sweeteners in vivo. Am J Physiol Endocrinol Metab, 2009. 296(3): p. E473-9.

27. Tome, D., Protein, amino acids and the control of food intake. Br J Nutr, 2004. 92 Suppl 1: p. S27-30.

28. Eggum, B.O., I. Hansen, and T. Larsen, Protein quality and digestible energy of selected foods determined in balance trials with rats. Plant Foods Hum Nutr, 1989. 39(1): p. 13-21.

29. Cummings, D.E. and J. Overduin, Gastrointestinal regulation of food intake. J Clin Invest, 2007. 117(1): p. 13-23.

30. Stricker-Krongrad, A., et al., Increased threshold concentrations of neuropeptide $Y$ for a stimulatory effect on food intake in obese Zucker rats--changes in the microstructure of the feeding behavior. Brain Res, 1994. 660(1): p. 162-6.

31. Lieverse, R.J., et al., Obese women are less sensitive for the satiety effects of bombesin than lean women. Eur J Clin Nutr, 1998. 52(3): p. 207-12.

32. Choi, S., et al., GPR93 Activation by Protein Hydrolysate Induces CCK Transcription and Secretion in STC-1 Cells. Am J Physiol Gastrointest Liver Physiol, 2007.

33. Cordier-Bussat, M., et al., Peptones stimulate both the secretion of the incretin hormone glucagon-like peptide 1 and the transcription of the proglucagon gene. Diabetes, 1998. 47(7): $\mathrm{p}$. 1038-45.

34. Geraedts, M.C., F.J. Troost, and W.H. Saris, Peptide-YY Is Released by the Intestinal Cell Line STC-1. J Food Sci, 2009. 74(2): p. H79-82.

35. Larsen, R., et al., Novel modified Ussing chamber for the study of absorption and secretion in human endoscopic biopsies. Acta Physiol Scand, 2001. 173(2): p. 213-22.

36. Grass, G.M. and S.A. Sweetana, In vitro measurement of gastrointestinal tissue permeability using a new diffusion cell. Pharm Res, 1988. 5(6): p. 372-6.

37. Reims, A., B. Strandvik, and H. Sjovall, Epithelial electrical resistance as a measure of permeability changes in pediatric duodenal biopsies. J Pediatr Gastroenterol Nutr, 2006. 43(5): p. 619-23.

38. Taylor, C.J., et al., Failure to induce secretion in jejunal biopsies from children with cystic fibrosis. Gut, 1988. 29(7): p. 957-62.

39. Tominaga, M., et al., ONO-1078 antagonizes diarrhea-causing changes in ion transport and smooth muscle contraction induced by peptidoleukotrienes in rat and human colon in vitro. J Pharmacol Exp Ther, 1996. 278(3): p. 1058-63.

40. Sternini, C., L. Anselmi, and E. Rozengurt, Enteroendocrine cells: a site of 'taste' in gastrointestinal chemosensing. Curr Opin Endocrinol Diabetes Obes, 2008. 15(1): p. 73-8. 


\section{ChAPTER 10}

GENERAL DISCUSSION 


\section{INTRODUCTION}

This thesis focuses on the modulating properties of dietary proteins with respect to secretion of satiety hormones, such as cholecystokinin (CCK) and glucagon-like peptide 1 (GLP-1), from the gastrointestinal tract. Increasing the release of these hormones is believed to accelerate the termination of a meal, and increases the duration between meals [1-4]. The extent to which dietary food ingredients affect the secretion of satiety hormones is unclear. This may also depend on the type of macronutrient or a combination.

The general discussion of this thesis first addresses the role of the gastrointestinal (GI) tract in the regulation of satiety. Secondly, the different methods (e.g. in vitro, ex vivo, and in vivo) used in this thesis to study the role of nutrients in satiety hormone release are evaluated. It is followed by a short discussion about the results we achieved in the past four years. Finally, the conclusions are presented followed by suggestions for future research.

\section{THE GASTROINTESTINAL TRACT AND FOOD INTAKE}

It is generally accepted that the $\mathrm{Gl}$ tract is one of the organs that contributes significantly to food intake regulation [5]. Nevertheless, the Gl tract has received little attention in the treatment of obesity and weight maintenance so far. It is the first organ to come into contact with food, and is therefore able to sense the amount eaten [1]. To loose weight, it's easier to decrease food intake with $100 \mathrm{kcals}$ per day (1/2 cup of cornflakes with $1 / 2$ cup of skimmed milk), than to increase energy expenditure with 100 kcals per day (walking for about $30 \mathrm{~min}$ ). Ingested food evokes satiety signals in the Gl tract primarily by two distinct ways, i.e. by mechanical stimulation and therefore stimulation of the nerve endings and by humoral stimulation, e.g. the release of peptide hormones [6]. Once these hormones are present in the circulation, they contribute to meal termination and prolong the interval between meals (chapter 1).

A better understanding of how dietary compounds affect the release of satiety hormones can contribute to the possible treatment of obesity. Receptors that are able to detect nutrients are present throughout the Gl tract. However, the current knowledge on how these receptors interact with the nutrients and stimulate hormone release is still limited (chapter 2). In recent years, new receptors that have a putative role in food intake regulation were discovered in the gut $[7,8]$. Most of these receptors are classified as $G$ protein-coupled receptors (GPCRs). The receptors can be divided into several groups, such as protein sensing receptors, fatty acid sensing receptors, and taste receptors [9]. The mechanism by which these 
receptors are involved in food intake regulation and interact with food components is largely unknown. However, on a whole body level we know much better how this interaction leads to satiety signals. For instance, it has previously been demonstrated that ingestion of proteins results in a decrease in food intake and ultimately leads to body weight loss [10], however, which type of protein affects food intake and how it is affected, is less known.

By developing high-throughput techniques to study the effects of dietary compounds within the Gl tract, new insights on which compounds are the most potent in stimulating satiety hormone release, may eventually deliver a new approach to prevent or treat obesity. In this thesis we have focused mainly on proteins since they turned out to be the most potent nutritional satiety initiator.

\section{High-throughput systems}

The different studies that are described in this thesis applied three techniques to study the effects of proteins on the release of satiety hormones. The first technique is the in vitro assay, using enteroendocrine STC-1 cells. The second technique is the ex vivo Ussing chamber technique, using human duodenal tissue samples. Thirdly, we designed a human intervention study with state of the art in vivo technology to determine the effects of pea protein ingestion on parameters that are related with satiety and food intake. Each technique has its advantages and disadvantages. Here, we discuss whether these techniques are suitable to study the release of satiety hormones, and what the implications are for human intervention studies.

\section{Cell culture technique}

The principle strength of the cell culture technique is its simplicity compared to the difficulties of studies using organs or humans. With cell cultures, it is possible to study small numbers of cells of a single type in a well-defined environment. However, there are also some limitations to this technique. The main limitation is that the cell is not in its normal physiological and original environment. Cell cultures are not in a normal physiological environment, e.g. there is no blood- or lymph circulation, there is no original tissue organization and structure is absent, and no other cell types are present. Additionally, cells are often not in full contact with other cells, as cultures never reach $100 \%$ confluency. This is a problem, as normal cells need cell-to-cell contract for optimal signal transduction and function. Other limitations include the finite doubling potential of most normal cells, the possibilities for unexpected infection with viruses or microorganisms, or even cross-contamination with other cells. Another drawback of some cultured cells is their tendency to change their morphology, functions, or the range of genes they express compared to cells in an in vivo setting.

Despite the number of limitations, the STC-1 cells provide a useful screening tool 
to study the release of several satiety hormones. This cell line was previously shown to secrete CCK and GLP-1, and we were the first to show that these cells also secrete PYY after exposure to different fatty acids (chapter 3 ). The observations in this study were in line with previously published data of human in vivo studies. In another study, we compared effects of proteins, protein hydrolysates, and specific peptides on their effects on satiety hormone release. Overall, it is believed that protein hydrolysates exert the strongest effects on the release of CCK and GLP-1. However, we demonstrated that intact proteins leads to the same levels of satiety hormones compared to several hydrolysates that were tested (chapter 4). The main disadvantage of using STC-1 cells is that the composition of most products tested does not represent the physiological circumstances. For example, intact proteins will not reach the small intestine, but will be partially digested in the stomach. Therefore, the interpretation of results obtained from in vitro assays must be handled with care.

\section{Ussing chambers}

The principle strength of the Ussing chamber technique is that it provides a short-term tissue culture method that enables precise measurements of electrical, transport, and secretion parameters of intact, polarized intestinal epithelium, both from animal and most importantly from human origin [11]. However, this technique also has some limitations. The main limitation of the technique lies in the interpretation of a relative small number of measurements to describe the complex physiological system of the intestinal mucosa [12]. The intestinal mucosa contains many cell types communicating through a variety of systems, e.g. cell-to-cell contact, immune system, neuroendocrine, and paracrine humoral agents, which may not be discerned or even considered during Ussing chamber measurements. The distribution of cells, such as enteroendocrine cells, is not consistent. To study cell secretions, it would be best to relate findings to the total amount of enteroendocrine cells present in the exposed tissue. However, quantification of enteroendocrine cells is hampered by the quality of tissue after being placed in the Ussing chambers, in combination with the small amounts of tissue used in Ussing chamber experiments applying human tissue. Another concern often raised with the Ussing chamber technology relates to the limited viability and optimal function of an ex vivo intestinal preparation. With a small tissue area exposed in the Ussing chamber, the influence of edge damage on electrophysiological measurements increases, which may result in false conclusions. $[13,14]$

Despite the number of limitations, this technique provides a valuable screening tool to study the effects of nutritional compounds on hormone release. The main advantage is that more compounds can be tested at the same time using intestinal tissue from one animal or human. This technique also makes it possible to measure hormone release directly from enteroendocrine cells, while this is not possible in 
vivo. The main disadvantage in studying only the release of satiety hormones using the Ussing chamber technique, one cannot tell whether the increase in satiety hormone release correlates with a decrease in food intake. By comparing the results from a human study (chapter 6 ) to results found in the Ussing chambers using the same subjects (chapter 7), we were able to validate the Ussing chamber technique to measure the release of satiety hormones from enteroendocrine cells. It was concluded that we can use the ex vivo Ussing chamber as an indicator for the in vivo studies on satiety. The increase in CCK and GLP-1 found in ex vivo experiments, correlates with results found in vivo. Even though the results are comparable with in vivo, most products that will be tested in the Ussing chambers are prescreened using in vitro assays. We demonstrated that results found using STC-1 cells are in part different from those that are found using the Ussing chambers. Addition of sucrose and sucralose to the STC-1 cells resulted in elevated levels of both CCK and GLP-1, whereas these compounds did not affect hormone release from human duodenal tissue (chapter 9). However, the combination of pea with sucrose or sucralose showed both in in vitro and ex vivo experiments the strongest results on hormone release. By using the Ussing chambers as an intermediate, false positive results from in vitro assays can be detected, and fewer in vivo tests will have to be performed.

\section{Human intervention studies}

Human intervention studies will always be necessary to evaluate the effects of dietary changes on food intake and weight management. The strength of this type of studies is the applicability to the real live situation. With in vitro and ex vivo assays, only the hormone levels can be investigated, whereas in a human short- and long term intervention study, changes in food intake can also be measured, which eventually will be the main focus in weight management and treatment of obesity. However, testing with human volunteers also has some drawbacks. The main limitation is that most studies that are performed are within laboratory settings, which is not always representative for daily life. In the intervention study described in this thesis (chapter 6), all subjects received a nasoduodenal tube to infuse the proteins directly into the small intestine. This is a relatively invasive procedure, which may have influenced the results from this study. Also, subjects will be more stressed the first test day, because they don't know what to expect in detail, despite extensive information. Randomized cross over studies are most commonly used, to correct of these effects. In our study, all subjects received the nasoduodenal catheter also on the test days that the protein or placebo was provided as an oral load, so the test burden would be the same during all experiments

Dietary intervention studies usually include the measurement of satiety hormone levels. The rise of systemic hormone levels is believed to correlate with a decrease in food intake. However, literature is not consistent. Some studies found a correlation 
between the increased levels of CCK and GLP-1 and decreased food intake [15, 16], whereas other studies did not find a correlation [17]. Also, there are indications that there are differences between lean and obese subjects in the release of satiety hormones [18]. We found that for obese subjects, CCK levels are significantly more increased after the protein load in the duodenum, when compared to lean subjects. However, there were no differences in food intake between both groups. This might indicate that obese subjects respond more strongly to ingested food, in order to get the same level of satiety signals. The question remains whether the satiety levels increased because obese subjects are more resistant to the satiety signals. More research is needed whether this development of resistance to hormonal activity is of importance. Also the choice of which hormones are measured is relevant. There are many different hormones that can be measured, but the time of sampling is very important. We were the first to demonstrate that the release of CCK occurs within 5 minutes after protein load, and that the levels are back to baseline within 30 minutes. Most dietary intervention studies draw their first blood sample approximately 30 minutes after food intake, which means that according to our findings, the peak levels of CCK are missed. This may explain why many studies did not show effects on CCK levels. Additionally, if GLP-1 is measured, it is very important that a protease inhibitor is added to the plasma; otherwise the active GLP-1 will be degraded.

It is also important to realize that the effects found in a short-term study, may not hold true for long-term intervention studies. The human intervention study described in this thesis showed that after protein infusion into the small intestine, subjects eat less during the next meal. However, we did not measure food intake after this meal. It could be possible that subjects compensated the decreased food intake during lunch by increasing the food intake after that day or even over the next days. Therefore it is always very important that not only short-term intervention studies are performed, but also long-term intervention studies. Hence, the findings shown in the present thesis will have to be confirmed in long-term intervention studies. Also, different options to deliver proteins to the small intestine should be explored further.

\section{Safety issues}

In the present project, intact pea protein was infused into the small intestine of human subjects. This infusion resulted in the strongest effects on satiety and food intake, which can be explained by the fact that under physiological circumstances this amount of intact pea protein will not reach the small intestine. From an evolutionary point of view it makes sense that by increasing the release of satiety hormones and thereby terminating food intake, the body protects itself from receiving too much intact proteins. The underlying reason for this would be that the appearance of large amounts of specific, but not all, intact proteins may provoke an immune or allergic response in the intestinal mucosa, which may cause damage to the gut and 
possibly may initiate a cascade of events leading to mucosal inflammation [19]. During the human intervention study described here, none of the subjects reported any feelings of discomfort or illness. Therefore we believe that even though it is not physiological to receive this amount of intact pea protein in the small intestine, it is also not harmful for humans. However further chronic safety tests should be done before use by the general population. To administer the intact protein into the small intestine, coatings are available that prevent protein degradation in the stomach [20-22].

We also investigated the effects of tastants on hormone release. Tastants are added to food products to increase the palatability. Recent literature describes that these tastants are also able to induce the release of satiety hormones [23]. In the present thesis, it was described that all tastants affect hormone release both dose- and time dependently (chapter 8). Bitter and sour tastants affected the secretion the most, which might be explained by the fact that bitter and sour taste is commonly associated with spoiled and toxic foods. Sweet tastants also had a strong effect on hormone release, and different sweeteners induce different effects. Sucralose and sucrose were the two most potent sweeteners with a satiety hormone release. Even though the results in vitro may seem promising, recent literature described that sucralose did not affect the release of GLP-1 in vivo [24]. We demonstrated that the combination of either sucrose or sucralose with intact pea protein had synergistic effects on the release of CCK and GLP-1, compared to the compounds alone (chapter 9). The addition of sucralose to the diet is preferred because it contains no calories. These findings open a whole new view on functional foods. Addition of specific compounds that not only give a good taste, but also stimulate hormone release via the taste receptors in the gut to a greater extent may provide a novel dietary tool to control appetite and food intake.

\section{GENERAL CONCLUSIONS AND FUTURE PERSPECTIVES}

There is a great need for screening methods to study the effects of dietary compounds on satiety and food intake. Here, we provide several tools how these compounds can be tested. As a high-throughput system, in vitro cell lines are very useful. Many compounds can be tested at the same time, and results are obtained very quickly. The ex vivo Ussing chamber technique provides a semi-high throughput system. Although the technique requires some hands-on experience, it provides a unique model to study dietary compounds on Gl tissue, outside of the body. Also, more products can be tested at the same time using tissue from the same subject. We demonstrated that the Ussing chamber technique gives similar results on hormone release when compared to the in vivo study, and can therefore 
be used to prescreen several nutritional compounds on their effects on hormone release from the intestine.

In the present thesis, many different compounds were tested on their effects of release of CCK and GLP-1. We demonstrated that intact proteins and some protein hydrolysates are the most potent, whereas specific amino acid sequences have no effect on hormone release. Of all tested compounds in vitro and ex vivo, intact pea protein appeared to be the most potent in stimulating CCK and GLP-1 release. In the in vivo study, we showed that intact pea protein infused in the small intestine not only affects CCK, GLP-1, and PYY release, but also decreases food intake in both lean and obese male subjects.

Other compounds that also were tested in the present thesis are tastants. Addition of tastants to STC-1 cells and human duodenal biopsies also resulted in elevated levels of CCK and GLP-1. Remarkably, combining sweet tastants with pea protein resulted in even higher levels of CCK and GLP-1.

\section{Future perspectives}

To our opinion future research should focus more on the combination of several dietary compounds such as specific proteins and tastants, and how these combinations contribute to the treatment of obesity. It is expected that in this way different pathways to elicit satiety hormones as well as probably activating the sympatic nerves system will more effectively lead to termination of food intake. The present thesis clearly demonstrates that intraduodenal administration of intact pea protein effectively reduces food intake in lean and obese male subjects.

Some gaps in clinical evidence or knowledge of mechanisms still remain. All studies described in the present thesis provide information on the short-term, while treatment of obesity must also be effective on the long-term in the real life situation. Many studies with a duration of up to 6 months have found that diets high in protein achieve greater weight loss than do high-carbohydrate diets [25-27]. More recent studies demonstrate that maintaining a high-protein diet up to 1 year after weight loss reduces weight gain compared to other diets $[28,29]$. The present thesis confirmed that proteins are able to induce the release of satiety hormones, and that intact pea protein is able to reduce ad libitum food intake. It is therefore plausible that addition of intact pea protein, in combination with sucralose, to the high-protein diets may have even more beneficial effects on weight loss and maintenance. However, more data is needed on long-term weight control effects, CNS activation, and the effects of a high protein diet, in which proteins will be delivered to the intestine in a intact form, applying enteric (micro) coatings. The amount of protein tested in the present thesis is very high, and not feasible for commercial applications due to the relatively high costs associated with products containing large amounts of proteins. Therefore, studies should be performed to investigate whether the protein shows the 
same effects at lower doses. It has previously been demonstrated that infusion of fatty acids into the ileum had strong effects on hormone release and food intake via the ileal brake $[30,31]$. It is possible that the intact or partially digested proteins may also stimulate the ileal brake, and that the intact proteins should be encapsulated in slow release capsules or coatings, which disintegrate in the lower small intestine instead of capsules or coatings that open in the duodenum.

The techniques used in this thesis mainly provide information on short-term hormone release. Perhaps cell cultures can provide more information on the long-term, by exposing them continuously to the test product before performing the experiment. In the case of hormonal responses to sweet tastants, exposing cells continuously to sucralose might give information on whether gastrointestinal cells decrease their sensitivity to sweet products. These cells can also be used to study the mechanism behind the release of satiety hormones. Why are CCK and GLP-1 levels more increased after addition of the combination sucralose and pea protein, compared to the products along or other combinations? Understanding how dietary compounds interact with each other may result in new combinations that are more effective. Ussing chambers also provide short-term information. However, using this technology in humans during a dietary intervention, it is possible to combine the advantages of the in vitro and in vivo studies.

Despite all types of new technologies becoming available to study the effects of dietary compounds on hormone release, human interventions studies will always be necessary to confirm these findings. 


\section{REFERENCES}

1. Strader, A.D. and S.C. Woods, Gastrointestinal hormones and food intake. Gastroenterology, 2005. 128(1): p. 175-91.

2. Moran, T.H. and K.P. Kinzig, Gastrointestinal satiety signals II. Cholecystokinin. Am J Physiol Gastrointest Liver Physiol, 2004. 286(2): p. G183-8.

3. Stanley, S., K. Wynne, and S. Bloom, Gastrointestinal satiety signals III. Glucagon-like peptide 1, oxyntomodulin, peptide YY, and pancreatic polypeptide. Am J Physiol Gastrointest Liver Physiol, 2004. 286(5): p. G693-7.

4. Druce, M. and S.R. Bloom, The regulation of appetite. Arch Dis Child, 2006. 91 (2): p. 183-7.

5. Wynne, K., S. Stanley, and S. Bloom, The gut and regulation of body weight. J Clin Endocrinol Metab, 2004. 89(6): p. 2576-82.

6. Karhunen, L.J., et al., Effect of protein, fat, carbohydrate and fibre on gastrointestinal peptide release in humans. Regul Pept, 2008. 149(1-3): p. 70-8.

7. Bezencon, C., J. le Coutre, and S. Damak, Taste-signaling proteins are coexpressed in solitary intestinal epithelial cells. Chem Senses, 2007. 32(1): p. 41-9.

8. Dyer, J., et al., Expression of sweet taste receptors of the TIR family in the intestinal tract and enteroendocrine cells. Biochem Soc Trans, 2005. 33(Pt 1): p. 302-5.

9. Engelstoft, M.S., et al., A gut feeling for obesity: 7TM sensors on enteroendocrine cells. Cell Metab, 2008. 8(6): p. 447-9.

10. Anderson, G.H. and S.E. Moore, Dietary proteins in the regulation of food intake and body weight in humans. J Nutr, 2004. 134(4): p. 974S-9S.

11. Li, H., D.N. Sheppard, and M.J. Hug, Transepithelial electrical measurements with the Ussing chamber. J Cyst Fibros, 2004. 3 Suppl 2: p. 123-6.

12. Hug, M.J., Transepithelial measurements using the Ussing chamber. 2002.

13. Wallon, C., et al., Endoscopic biopsies in Ussing chambers evaluated for studies of macromolecular permeability in the human colon. Scand J Gastroenterol, 2005. 40(5): p. 586-95.

14. Wallon, C., et al., Corticotropin-releasing hormone (CRH) regulates macromolecular permeability via mast cells in normal human colonic biopsies in vitro. Gut, 2008. 57(1): p. 50-8.

15. Astrup, A., et al., Effects of liraglutide in the treatment of obesity: a randomised, double-blind, placebo-controlled study. Lancet, 2009. 374(9701): p. 1606-16.

16. Gibbs, J., R.C. Young, and G.P. Smith, Cholecystokinin decreases food intake in rats. 1973. Obes Res, 1997. 5(3): p. 284-90.

17. Diepvens, K., D. Haberer, and M. Westerterp-Plantenga, Different proteins and biopeptides differently affect satiety and anorexigenic/orexigenic hormones in healthy humans. Int J Obes (Lond), 2008. 32(3): p. 510-8.

18. Sodowski, K., et al., Basal and postprandial gut peptides affecting food intake in lean and obese pregnant women. J Physiol Pharmacol, 2007. 58 Suppl 1: p. 37-52.

19. Cooke, S.K. and H.A. Sampson, Allergenic properties of ovomucoid in man. J Immunol, 1997. 159(4): p. 2026-32.

20. Malik, D.K., et al., Recent advances in protein and peptide drug delivery systems. Curr Drug Deliv, 2007. 4(2): p. 141-51.

21. Clear, N.J., et al., Evaluation of the Intelisite capsule to deliver theophylline and frusemide tablets to the small intestine and colon. Eur J Pharm Sci, 2001. 13(4): p. 375-84.

22. Mustata, G. and S.M. Dinh, Approaches to oral drug delivery for challenging molecules. Crit Rev Ther Drug Carrier Syst, 2006. 23(2): p. 111-35.

23. Kokrashvili, Z., B. Mosinger, and R.F. Margolskee, Taste signaling elements expressed in gut enteroendocrine cells regulate nutrient-responsive secretion of gut hormones. Am J Clin Nutr, 2009.

24. Ma, J., et al., Effect of the artificial sweetener, sucralose, on gastric emptying and incretin hormone release in healthy subjects. Am J Physiol Gastrointest Liver Physiol, 2009. 296(4): p. G735- 
9.

25. Baba, N.H., et al., High protein vs high carbohydrate hypoenergetic diet for the treatment of obese hyperinsulinemic subjects. Int J Obes Relat Metab Disord, 1999. 23(11): p. 1202-6.

26. Skov, A.R., et al., Randomized trial on protein vs carbohydrate in ad libitum fat reduced diet for the treatment of obesity. Int J Obes Relat Metab Disord, 1999. 23(5): p. 528-36.

27. Foster, G.D., et al., A randomized trial of a low-carbohydrate diet for obesity. N Engl J Med, 2003. 348(21): p. 2082-90.

28. Delbridge, E.A., et al., One-year weight maintenance after significant weight loss in healthy overweight and obese subjects: does diet composition matter? Am J Clin Nutr, 2009. 90(5): p. 1203-14.

29. Moore, C.S., et al., Dietary strategy to manipulate ad libitum macronutrient intake, and glycaemic index, across eight European countries in the Diogenes Study. Obes Rev, 2009.

30. Maljaars, J., et al., Effect of fat saturation on satiety, hormone release, and food intake. Am J Clin Nutr, 2009. 89(4): p. 1019-24.

31. Maljaars, J., et al., Effect of ileal fat perfusion on satiety and hormone release in healthy volunteers. Int J Obes, 2008. 32: p. 1633-1639. 


\section{SUMMARY}


Overweight and obesity have become a major health problem and strategies for prevention and treatment are needed. The most effective treatment is to decrease food intake, thereby modulating appetite sensations. The concept of appetite includes at least two separate components: satiation and satiety. Satiation refers to the processes that promote meal termination, thereby limiting meal size. Satiation results from signals that are produced in the gut in response to food-induced mechanical and chemical stimuli, such as the release of the satiety hormones cholecystokinin (CCK), glucagon-like peptide 1 (GLP-1), and peptide YY (PYY). These hormones are secreted upon food intake, since the gastrointestinal tract contains chemosensors that sense lumen contents and induce changes in gastrointestinal function and food intake though the release of these satiety hormones. Not only the macronutrient composition of the diet plays an important role in the release of these satiety hormones, but also the compounds, such as sweeteners, used to add flavour to the food affect hormone release. From the macronutrients, it seems that protein has the highest satiating effect when compared to other macronutrients in humans and animal studies. However, proteins differ in their amino acid composition and metabolism and thus may influence the satiating effects differently. There are also indications that tastants are able to affect hormone release from enteroendocrine cells, but whether this is true for all tastants, and whether there are differences between tastants is still unknown. In the present thesis several techniques are used to identify proteins and tastants that affected the gastrointestinal satiety hormone release the strongest.

The first technique that was used was the in vitro cell culture system. The STC1 cell line, derived from an intestinal tumor arising in double transgenic mice, is known to secrete CCK and GLP-1 after exposure to nutritional compounds. STC1 cells were incubated with several different proteins, hydrolysates, and synthetic peptides, and CCK and GLP-1 release was measured. We demonstrated that intact proteins such as casein, whey, and pea showed strongest effects on CCK release, whereas casein, codfish, egg, and wheat showed most pronounced effects on GLP-1 release. Egg-hydrolysate stimulated release of CCK and GLP-1, whereas all other tested hydrolysates and synthetic-peptides showed no significant effects on hormone release. As a second technique, the Ussing chambers were used. These chambers allow fresh human or animal tissue to stay alive for approximately 3-4 hours. The luminal side of both rat and human duodenal tissue was exposed to egg protein, codfish protein, pea protein, ovomucoid, or wheat protein for 2 hours. CCK and GLP-1 release was measured at the serosal side. Remarkably, no effects on CCK and GLP-1 release were found using rat duodenal tissue, whereas addition of pea and wheat protein did affect CCK and GLP-1 release from human duodenal tissue. 
Overall, intact pea protein seemed to be the most potent protein to stimulate hormone release from duodenal tissue; however, this had to be confirmed in a human intervention study. The study described in the present thesis compared the effects of intact pea protein on satiety hormone levels and food intake after either oral ingestion or duodenal administration in both lean and obese subjects. We showed that food intake was decreased after intraduodenal protein administration in both lean and obese subjects, in contrast to food intake after oral ingestion of the protein. Although there were no differences in appetite ratings between both groups, we observed elevated levels of CCK in obese subjects, and GLP-1 and PYY were elevated in both groups. These data suggest that the degradation of intact pea protein in the stomach must be prevented in order to decrease food intake. Additionally, the results from this in vivo intervention study were compared to results obtained from Ussing chamber experiments, using the same volunteers. It was demonstrated that the trend in hormone release measured in the Ussing chambers was comparable with the trend that was observed in the intervention study, indicating that the Ussing chamber technology provides a valid screening tool to study the effects of nutritional compounds on hormone release.

Not only the effects of proteins, but also the effects of several tastants were tested on their effects on hormone release from STC-1 cells. All tastants increased CCK levels both dose- and time-dependently. GLP-1 release dose-dependently increased after addition of all tastants, with the exception of citric acid. GLP-1 was released in a time-dependent manner after addition of all tastants, but bitter tastants stimulated GLP-1 release only during the first 15 minutes of exposure. All commercial sweeteners elevated CCK and GLP-1 levels, with Tagatesse® containing sucralose exerting the strongest effects.

Since sweeteners seemed to be the most potent tastants to stimulate hormone release, it might be possible that when combining sweeteners with intact pea protein, synergistic effects on hormone release may occur. Exposure to aspartame, sucralose, sucrose, pea, and pea with sucralose secreted elevated levels of CCK, whereas GLP-1 levels were increased after addition of all test-products. However, addition of sucrose and sucralose to human duodenal biopsies did not affect CCK and GLP-1 release; addition of pea did stimulate CCK and GLP-1 secretion. Combining pea protein with sucrose and sucralose induced even higher levels of CCK and GLP-1.

Overall, these studies show that infusing intact pea protein into the duodenum has the strongest effects on plasma hormone levels, and has the greatest effect on food intake. It has also been demonstrated that the combinations of dietary compounds may provide a novel dietary tool to adjust appetite and food intake. However, more studies will have to be performed to identify the lowest effective dose of the protein and sweetener, and whether (micro-) encapsulated proteins show the 
same effects on food intake. Also, long-term intervention studies will have to be performed to demonstrate the effects of intraduodenal pea protein administration on weight loss and weight maintenance. 
SAMENVATTING 
Overgewicht en obesitas zijn een van de grootste voeding gerelateerde gezondheidsproblemen geworden en strategieën voor de preventie en behandeling hiervan zijn nodig. De meest effectieve behandeling is het verminderen van voedselinname, waarbij ook de eetlust modulerende sensaties worden veranderd. Het concept van verzadiging omvat ten minste twee afzonderlijke processen. Het eerste proces speelt een rol bij de beëindiging van de maaltijd, waarbij de grootte van de maaltijd wordt beperkt. Het andere proces speelt een rol bij de duur tussen de maaltijden en het moment dat er weer gegeten gaat worden. Verzadiging ontstaat door signalen vanuit de darm in reactie op voedsel-geïnduceerde mechanische en chemische prikkels, zoals de afgifte door de enteroendocriene cellen in de darmwand van verzadigingshormonen zoals cholecystokinine (CCK), glucagon-like peptide 1 (GLP-1) en peptide YY (PYY). Het maag-darm kanaal bevat chemosensoren die de inhoud van de darm kunnen waarnemen en daardoor de opname van voedsel in de darm aanpassen en reguleren door de afgifte van deze verzadigingshormonen. Niet alleen de macronutriënten samenstelling van het voedsel speelt een belangrijke rol in de secretie van de verzadigingshormonen, maar ook andere bestands delen zoals zoetstoffen welke gebruikt worden om smaak toe te voegen aan het voedsel stimuleren de vrijlating van verzadigingshormonen. Van alle macronutriënten blijkt eiwit het meest verzadigende effect te hebben in vergelijking met andere macronutriënten in zowel humane als dierexperimentele onderzoeken. Echter, eiwitten verschillen in aminozuur samenstelling en metabolisme wat het effect op verzadiging kan beïnvloeden tussen de verschillende eiwitten. Ook zijn er aanwijzigingen dat smaakstoffen in staat zijn om de afgifte van verzadigingshormonen vit enteroendocriene cellen te stimuleren, maar of dit waar is voor alle smaakstoffen, en of er verschillen zijn tussen de smaakstoffen is nog onbekend. In dit proefschrift worden verschillende technieken gebruikt om specifieke eiwitten en smaakstoffen te identificeren welke de sterkste effecten hebben op de afgifte van verzadigingshormonen vanuit de darm.

De eerste techniek die werd gebruikt was het in vitro celkweek systeem. De STC-1 cellijn, afgeleid van een intestinale tumor ontstaan in dubbel transgene muizen, is in staat om CCK en GLP-1 vit te scheiden na blootstelling aan voedingsstoffen. STC-1 cellen werden geïncubeerd met verschillende eiwitten, hydrolysaten en synthetische peptiden, waarna de afgifte van CCK en GLP-1 gemeten werd. We hebben aangetoond dat intacte eiwitten zoals caseïne, whey en erwten eiwit het sterkste effect hadden op de CCK afgifte, terwijl caseïne, kabeljauw, ei en tarwe eiwit de meest vitgesproken effecten hadden of GLP-1 afgifte. Ei hydrolysaat stimuleerde ook de afgifte van CCK en GLP-1, terwijl alle andere geteste hydrolysaten en synthetische peptiden geen significante effecten hadden op de afgifte van de verzadigingshormonen. Als tweede techniek werden de Ussing kamers gebruikt. Deze kamers maken het mogelijk om menselijk of dierlijk weefsel in leven te houden 
gedurende 3-4 uur. De luminale zijde van zowel ratten- als humane dunne darm werd blootgesteld aan ei eiwit, kabeljauw eiwit, erwten eiwit, ovomucoïde, of tarwe eiwit gedurende 2 uur. CCK en GLP-1 afgifte werd gemeten aan de serosale zijde van het darmweefsel. Opmerkelijk was dat er geen veranderingen in CCK en GLP-1 afgifte gemeten werden bij de rattendarm, terwijl blootstelling aan erwten eiwit en tarwe eiwit een verhoogde CCK en GLP-1 afgifte tot gevolg hadden na blootstelling aan de menselijke darm.

Over het algemeen leek het intacte erwten eiwit het meest potente eiwit om afgifte van de verzadigingshormonen te stimuleren, maar dit moest worden bevestigd in een humane interventie studie. Het onderzoek beschreven in dit proefschrift vergeleek de effecten van intacte erwten eiwit op afgifte van verzadigingshormonen en voedsel inname na een orale inname of directe toediening in de dunne darm, in zowel slanke als obese mannelijke vrijwilligers. We lieten zien dat na toediening van het intacte eiwit rechtstreeks in de dunne darm voedsel inname was afgenomen in zowel slanke en obese mannen, in tegenstelling tot orale inname van het intacte eiwit wat geen effect had op de voedsel inname. Hoewel er geen verschillen waren in eetlust waarnemingen tussen beide groepen, zagen we een verhoogde afgifte van CCK in obese vrijwilligers. GLP-1 en PYY levels waren verhoogd in beide groepen. Deze gegevens suggereren dat als onverteerd eiwit in de dunne darm komt er een regulatie proces opgang komt dat er voor zorgt dat de passage van voedsel vertraagd wordt om alsnog het onverteerde eiwit zo snel mogelijk af te breken. Als consequentie zal de voedsel inname verlaagd worden. Daarnaast werden de resultaten van deze in vivo interventie studie vergeleken met de resultaten verkregen uit experimenten met de Ussing kamers, waarbij darmweefsel van dezelfde vrijwilligers werd gebruikt. Er werd aangetoond dat de trend in de afgifte van verzadigingshormonen gemeten in de Ussing kamers vergelijkbaar was met de trend die werd waargenomen in de humane interventie studie. Hieruit blijkt dat de Ussing kamer technologie een goed screenings instrument is om de effecten van voedings bestanddelen te bestuderen op de afgifte van verzadigingshormonen. Niet alleen de effecten van eiwitten, maar ook verschillende smaakstoffen werden getest op hun effect van de afgifte van hormonen door de STC-1 cellen. Alle smaakstoffen zorgden voor een verhoogde afgifte van CCK zowel dosis- en tijdsafhankelijk. De afgifte van GLP-1 nam dosis afhankelijk toe na toevoeging van alle smaakstoffen, met de vitzondering van citroenzuur. De afgifte van GLP-1 nam ook tijdsafhankelijk toe na toevoeginig van alle smaakstoffen, maar bittere smaakstoffen stimuleerde GLP-1 afgifte alleen gedurende de eerste 15 minuten na blootstelling. Alle commerciële zoetstoffen verhoogde CCK en GLP-1 afgifte, waarbij Tagatesse ${ }^{\circledR}$, dat sucralose bevat, het sterkste effect had.

Omdat zoetstoffen de meest potente smaakstoffen bleken te zijn om de afgifte van verzadigingshormonen te stimuleren, is het misschien ook mogelijk dat de 
combinatie van zoetstoffen met intact erwten eiwit een synergistisch effect kan hebben op de afgifte van verzadigingshormonen. Blootstelling van STC-1 cellen aan aspartaam, sucralose, suiker, erwten eiwit en erwten eiwit gecombineerd met sucralose resulteerde in verhoogde afgifte van CCK, terwijl de afgifte van GLP-1 werd verhoogd na toevoeging van alle testproducten. Echter, blootstelling van sucrose en sucralose aan human dunne darm weefsel had geen invloed op de afgifte van CCK en GLP-1; erwten eiwit verhoogde de afgifte van CCK en GLP-1 wel. De combinatie van erwten eiwit met sucrose en sucralose resulteerde in nog hogere niveaus van CCK en GLP-1 afgifte.

In conclusie, deze studies tonen aan dat de infusie van intacte erwten eiwitten in de dunne darm de sterkte effecten heeft op plasma verzadigingshormoon spiegels en het grootste effect heeft op de voedselinname. We hebben ook aangetoond dat de combinatie van verschillende voedingsingredienten nieuwe inzichten kan geven om de eetlust en voedsel inname aan te passen. Echter, meer studies zullen moeten worden vitgevoerd om de laagste effectieve dosis van eiwit en de zoetstoffen te bepalen, en of (micro) geïnkapsuleerde eiwitten dezelfde effecten geven op voedselinname. Ook zullen lange termijn studies moeten worden uitgevoerd om aan te tonen dat het inbrengen van intacte eiwitten in de dunne darm een langdurig effect heeft op gewichtsverlies en gewichts controle. 


\section{DANKWOORD}


Het eerste wat de meeste mensen doen als ze een proefschrift krijgen is het dankwoord lezen. Hoewel ikzelf ook al heel wat dankwoorden heb gelezen, blijkt het toch een stuk lastiger te zijn om er zelf een te schrijven, vooral omdat ik zoveel mensen wil bedanken.

Als eerste wil ik mijn promotor Wim Saris en co-promotor Freddy Troost bedanken. Wim, ik ben ontzettend blij dat je mij de mogelijkheid hebt gegeven om bij jou te mogen promoveren. Hoewel je fysiek niet veel aanwezig bent geweest al die jaren, was je wel altijd en overal bereikbaar via mail en telefoon, en hoefde ik nooit lang te wachten op een reactie of op correcties van de manuscripten. Ik heb heel erg veel van je geleerd en hoop dat we in de toekomst nog vaak mogen samenwerken. Freddy, bedankt voor de vrijheid die je me hebt gegeven om de afgelopen jaren mijn eigen weg te gaan.

De leden van de beoordelingscommissie: Prof. dr. M. Van Baak, Prof. dr. F.J. van Schooten, Prof. dr. R.F. Witkamp, Dr. H.P.F. Peters en Dr. J. Plat, wil ik graag bedanken voor het lezen van mijn proefschrift en hun bijdrage aan deze bijzondere dag.

Ook wil ik graag mijn paranimfen Boris en Marjet bedanken. Boris, het kwam als een verrassing voor je dat ik je vroeg of je mijn paranimf wilde zijn, maar wie anders dan jij kan mijn taal- en schrijffouten beter corrigeren ;-)? Jouw energie en humor (vooral de wiskundige vraagstukken) hebben me soms tot waanzin gedreven, maar het maakt je tot wie je bent, en ik heb ontzettend veel waardering voor je. Marjet, vanaf de eerste dag dat je bij HB bent komen werken klikte het, en ik ben blij dat we al die tijd kamergenoten zijn geweest! Niet alleen op het werk, maar ook tijdens congressen. Tevens is je appartement ondertussen ook mijn $2^{\text {de }}$ thuis geworden. Onze gesprekken over de meest viteenlopende dingen heb ik altijd ontzettend gewaardeerd! Ik ben heel blij dat jullie mij willen bijstaan tijdens mijn promotie!

Hoewel HB niet altijd goed in staat is om te integreren, ben ik blij dat ik veel van jullie heb leren kennen. Eefje, mijn eerste kamergenote, hoewel we niet lang bij elkaar op de kamer hebben gezeten wil ik je toch bedanken dat je me wegwijs hebt gemaakt op de uni! Guy P, ook wij hebben niet lang samen een kamer gedeeld, men vond het nodig dat jij een kamer voor jezelf had, maar in de korte periode hebben we elkaar goed leren kennen. Bedankt voor alle gezelligheid, concerten, en natuurlijk onderwijsuren! Ali en Joan, hoewel jullie vaker op het lab zaten dan achter de computer, ook jullie bedankt voor alle gezelligheid! Ook zijn er natuurlijk kamergenoten waar ik even aan moest wennen, of zij aan mij. Denis, hoewel je start ietwat moeizaam is gelopen, ik ben ondertussen aan je gewend geraakt en zal de treinritjes zeker gaan missen! Ralph, hoewel het de eerste tijd niet klikte, is het op de een of andere manier toch goed gekomen, en ben ik je heel erg gaan waarderen als goede vriend. Onze klaaguurtjes hebben me altijd geholpen om alles weer op 
een positieve manier te zien! (Hoewel een cursus positief denken zeker in het NUTRIM pakket moet worden opgenomen). Heren van kamer 2.318, Erik A, Maarten en ook Guy $\vee$, jullie zijn nog niet lang bij $H B$, maar jullie hebben het laatste jaar een stuk leuker gemaakt! Ik zal het gebonk tegen de muur van balletje balletje en de vele theemomenten per dag missen. Jos, wat moet HB zonder jou? Zonder jou geen Pub, geen borrel, en geen gegrom op het lab. Ik ben ontzettend blij dat ik je heb leren kennen, en hoop dat we nog vaak een biertje gaan drinken! Wendy, Antoine, Freek, Loek, Janneau, Sandy, Judith, Sanne O, Yvonne, en Hasibe, hartelijk bedankt voor de gezellige tijd tijdens de lunch. Desirée, Claudia, llona, Larissa, Kirsten, en Shelly, hartelijk bedankt dat jullie altijd klaar stonden om me te helpen met sleutels, faxapparaten, slingers, en natuurlijk voor de gezelligheid! Janneke, Anja, Esther P, Miranda, Silvie, en Anke, onze gesprekken over het AIO zijn hebben me altijd weer geholpen om toch door te gaan. Ook de mensen van de middenlob en de $3^{\text {de }}$ verdieping, en met name Florence, Eric van B, Marika, Ruth M, en Sanne V, bedankt voor alle steun en gezelligheid en een luisterend oor als er weer eens iets mis ging. Lauren and Heather, you haven't been in the Netherlands very long, but you both have been a great help. Thank you for all the great times, and Heather, I really want that recipe of the Long Island Icetea!!

Natuurlijk kan ik de mensen van Interne Geneeskunde niet overslaan. Steven, Henrike, en Andrea, het was altijd gezellig om bij jullie thee te leuten, te 'discusseren' over het werk, en te knutselen aan de Ussing chambers. Samefko, Daniel, Marielle, Esther, Karen, Jeroen, en Daisy, ook jullie bedankt voor alle hulp en gezelligheid.

Hoe zou ik mijn testen hebben kunnen vitvoeren zonder de hulp van de afdeling endoscopie. Ton, en natuurlijk alle andere verpleegsters en verplegers, hartelijk bedankt voor jullie hulp en geduld bij het afnemen van al die biopten bij de proefpersonen. Robert-Jan, bedankt voor de tijd en moeite om me te helpen met het testen van de beste manier om biopten te nemen die bleven leven in de Ussing chambers, en Rogier en Alexander, jullie bedankt voor alle hulp tijdens mijn testen! José en Joanna, bedankt voor de hulp bij het plaatsen van al die catheters. Ad, bedankt dat je me de mogelijkheid hebt gegeven om gebruik te mogen maken van jullie afdeling, en voor al je hulp bij het schrijven van de manuscripten. Ik hoop dat we in de toekomst nog vaak mogen samenwerken.

Ook veel dank aan Youri en Simon, voor al de technische ondersteuning bij het opzetten van de Ussing chambers. De heren van de spoelkeuken, bedankt dat jullie altijd alles op tijd weer schoon hadden zodat ik gewoon door kon gaan met mijn experimenten. En Eddy, jou vergeet ik natuurlijk ook niet! Het was altijd super gezellig met jou, en dat wokken komt zeker nog een keer!

I also would like to thank Johan Söderholm and Ylva Braaf for all their help and patience with teaching me the Ussing chamber technique. 
Alle proefpersonen die deelgenomen hebben aan mijn studies hartelijk bedank† hiervoor en sorry voor de vervelende slangen die ik jullie heb laten slikken. Zonder jullie was dit proefschrift er niet geweest.

Theo, hoewel we elkaar de laatste jaren niet meer vaak hebben gezien en gesproken, ben ik je ontzettend dankbaar. Zonder jou was ik waarschijnlijk niet eens gaan promoveren, en jouw steun en geloof in mij betekent ontzettend veel voor mij. Ik ben ook erg blij dat je tijd hebt weten vrij te maken om me te helpen met de layout van het proefschrift en met name de mooie kaft!

Promoveren kan je niet zonder eerst een studie gedaan te hebben. Mariel, Jeroen, Sietse, Kyra, Joe en Sharita, zonder jullie zouden de donderdagavonden en alle HLO feesten een stuk saaier zijn geweest. En ik ben jullie enorm dankbaar voor alle steun toen, en nog steeds, en ik hoop dat we nog vaak een reunie plannen.

Monique, ook wij hebben elkaar leren kennen via de studie, al was dat in het begin niet geheel positief. We weten in ieder geval wel dat we allebei erg vies kunnen kijken ;-), maar ook dat we in bijna alles hetzelfde denken en doen. Jij was er de afgelopen jaren altijd voor mij, voor de leuke dingen van het leven, maar ook in de tijden dat het allemaal wat minder liep. Bedankt voor wie je bent!

Mariëlle, nichie, hoewel jij alle reden hebt om te klagen, heb ik jou bijna nooit horen klagen, en stond je altijd voor mij klaar als ik weer eens wat te klagen had. Onze ritjes samen naar Maastricht waren altijd leuk (zolang je me maar niet meer laat schrikken zo vroeg in de ochtend), en de avonden thuis in de tuin en de wandelingen met de hondjes hebben mij ook altijd ontzettend geholpen om door een moeilijke periode heen te komen.

Marc, wij kennen elkaar al heel wat jaren, en ik ben ontzettend blij dat we de vriendschap weer hebben opgepikt!

Kelly en Marlou, ik ben er altijd trots op geweest dat ik jullie kleine zusje ben. Kelly, ik heb er ontzettend veel bewondering voor hoe je je drukke baan combineert met je gezin met Erik, Sophie en Froukje. Marlou, jij bent er altijd voor me geweest, en we hebben bijna altijd alle lief en leed gedeeld. Ik zou niet weten wat ik zonder je zou moeten doen.

Dan rest mij nu alleen nog maar twee mensen te bedanken, pappa en mamma. Pappa en mamma, bedankt voor alles dat jullie mij gegeven hebben: liefde, goede raad, genegenheid, begrip. Bedankt dat jullie altijd in mij zijn blijven geloven en dat jullie me altijd hebben gesteund in de keuzes die ik heb gemaakt. Jullie betekenen meer voor me dan woorden kunnen uitdrukken. 
CURRICULUM VITEA 


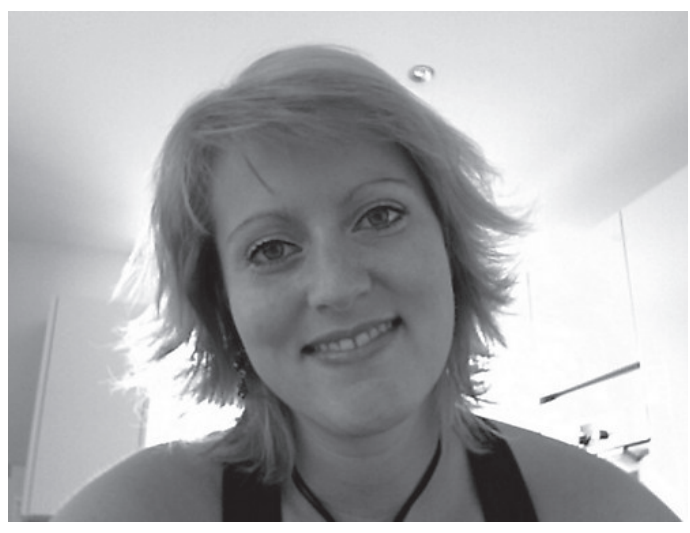

Maartje Geraedts was born on March $4^{\text {th }} 1982$ in Asselt, The Netherlands. She completed secondary school at the "Bischoppelijk College Broekhin" in 1998. In the same year, she started her study medical microbiology at the Gilde Opleidingen (Blerick, The Netherlands), where she graduated in 2001. She started her study Biochemistry at the Hogeschool Arnhem en Nijmegen (Nijmegen,

The Netherlands) in 2001, followed by the study Master of Molecular Life Science in 2004 at the same location, where she graduated in 2005. She did her master thesis entitled 'Glycosaminoglycans in the diaphragm of COPD patients' at the department of Pulmonary Diseases, Radboud Medical Center Nijmegen.

In February 2006, Maartje started her PhD at the University of Maastricht, at the department of Human Biology. She studied the effects of dietary proteins on release of satiety hormones from gastrointestinal cells, under supervision of Prof. Wim H.M. Saris and Dr. Freddy J. Troost. The research performed in this period is described in this thesis. In 2009, she was awarded a 3th place 'Foppe en Hoor' young investigator award by the Netherlands Organisation of Scientific Research (NWO) for her work on the effects of intraduodenally administered pea protein on food intake in lean and obese subjects.

Currently, Maartje is working as a post-doc at the department of Anatomy and Neurobiology, University of Maryland School of Medicine, USA. 


\section{LIST OF PUBLICATIONS}




\section{ARTICLES}

M.C.P. Geraedts, F.J. Troost, W.H.M. Saris. Addition of sucralose enhances the release of satiety hormones in combination with pea protein. Submitted.

M.C.P. Geraedts, F.J. Troost, W.H.M.Saris. Different tastants and low-caloric sweeteners induce differential effects on the release of satiety hormones. Submitted.

M.C.P. Geraedts, F.J. Troost, R.J.J. de Ridder, A.G.L. Bodelier, A.A.M. Masclee, W.H.M. Saris. Validation of Ussing chamber technology to study satiety hormone release from human duodenal specimens. Submitted.

M.C.P. Geraedts, F.J. Troost, M.J.M. Munsters, R.J.J. de Ridder, J.M. Conchillo, J.W. Kruimel, A.A.M. Masclee, W.H.M. Saris. Intraduodenal administration of intact pea protein effectively reduces food intake in both lean and obese male subjects. Submitted.

M.C.P. Geraedts, F.J. Troost, M.A.J.G. Fisher, L. Edens, W.H.M. Saris. Direct induction of CCK and GLP-1 release by intact proteins from murine endocrine cells. Molecular Nutrition and Food Science; In press.

M.C.P. Geraedts, F.J. Troost, W.H.M. Saris. Gastrointestinal targets to modulate satiety and food intake. Obesity Reviews; In press.

M.C.P. Geraedts, F.J. Troost, R. Tinnemans, J.D. Soderholm, RJ. Brummer, W.H.M. Saris. Release of Satiety Hormones in Response to Specific Dietary Proteins Is Different between Human and Murine Small Intestinal Mucosa. Annals of nutrition \& metabolism;56:308-13.

M.C.P. Geraedts, F.J. Troost, W.H.M. Saris. Peptide-YY is released by the intestinal cell line STC-1. J Food Sci. 2009 Mar;74(2):H79-82

C.A.C. Ottenheijm, G.J. Jenniskens, M.C.P. Geraedts, T. Hafmans, L.M.A. Heunks, T.H. Van Kuppevelt, and P.N.R. Dekhuijzen. Diaphragm dysfunction in chronic obstructive pulmonary disease: role for heparan sulfate? Eur Respir J, 2007;

J.H. Wijnhoven, L.M.A. Heunks, M.C.P. Geraedts, T. Hafmans, J.R. Viña, P.N.R. Dekhuijzen. Oxidative and nitrosative stress in the diaphragm of patients with chronic obstructive pulmonary disease. Int J COPD, 2006;2 
C.A.C Ottenheijm, L.M.A. Heunks, M.C.P. Geraedts, P.N.R. Dekhuijzen. Hypoxiainduced skeletal muscle fiber dysfunction: role for reactive nitrogen species. Am J Physiol Lung Cell Mol Physiol, 2006; 290: L127-L135

\section{ABSTRACTS}

M.C.P. Geraedts, F.J. Troost, M.J.M. Munsters, R.J. de Ridder, J.M. Conchillo, J.A. Kruimel, A.A. Masclee, W.H.M. Saris, 2010, Intraduodenal administration of intact pea protein effectively reduces food intake when compared to oral administration in healthy males. Obesity Reviews Vol 11 Isue s1, July 2010, page 225

M.J.M. Munsters, M.C.P. Geraedts, W.H.M. Saris, 2010, Effects of different protein and $\mathrm{Gl}$ diets on $24 \mathrm{~h}$ glucose, insulin and substrate partitioning. Obesity Reviews $\mathrm{Vol}$ 11 Isue s1, July 2010, page 108

S.A.L.W. Vanhoutvin, F.J. Troost, M.C.P. Geraedts, A.G.L. Bodelier, D.M.A.E. Jonkers, K. Venema, R-J.M. Brummer, A.A.M Masclee, 2010, Butyrate Attenuates DeoxycholateInduced Increase in Permeability of Human Colonic Tissue. Gastroenterology, Volume 138, Issue 5, Supp 1, may 2010, Pages S-274

M.C.P. Geraedts, F.J. Troost, W.H.M. Saris, 2007. Dietary proteins and serine proteases stimulate secretion of satiety hormones by the STC-1 cell line. Oral presentation at the Darmendag 2007, Wageningen, The Netherlands

M.C.P. Geraedts, F.J. Troost, W.H.M. Saris, 2007. The effects of dietary proteins on secretion of appitite associated peptide hormones by STC-1 cells. Poster presented at the $15^{\text {th }}$ UEGW, Paris, France. Gut supplement No III vol. 56, A289

M.C.P. Geraedts, F.J. Troost, W.H.M. Saris. 2006. Inhibition of serine proteases trypsin, chymotrypsin, and dipeptidyl peptidase IV by naturally occurring dietary proteins. Poster presented at the Darmendag 2006, Groningen, The Netherlands

M.C.P. Geraedts, T. Hafmans, C.A.C. Ottenheijm, G.J. Jenniskens, T.H. van Kuppevelt, P.N.R. Dekhuijzen. 2006. Glycosaminoglycans in diaphragm of COPD patients. Am.J. Respir.Crit Care Med. 


\section{PATENTS}

M.C.P. Geraedts, F.J. Troost, W.H.M. Saris. Proteins that stimulate the secretion of satiety hormones. WO 2009/053487 (A2)

M.C.P. Geraedts, F.J. Troost, W.H.M. Saris. Addition of sucralose enhances the release of satiety hormones in combination with pea protein. In preparation. 
